Check for updates

Cite this: Mater. Adv., 2021, 2, 6169

Received 19th June 2021

Accepted 7th September 2021

DOI: $10.1039 / \mathrm{d} 1 \mathrm{ma} 00535 \mathrm{a}$

rsc.li/materials-advances

\title{
Metal-organic framework thin films as versatile chemical sensing materials
}

\author{
James E. Ellis, $\dagger^{a}$ Scott E. Crawford (D) $\dagger^{a}$ and Ki-Joong Kim (D) *ab
}

\begin{abstract}
Metal-organic frameworks (MOFs) have been widely investigated as chemical sensing materials due to their periodic porosity, tunable chemical functionalities such as Lewis acid/base sites, potential conductivity and/or sensitive optical properties. However, most sensor devices require the integration of the sensing material as a thin film, which presents significant synthetic and stability challenges for MOF materials. In this review, we provide a background on why MOFs are excellent candidates for the chemical sensing of various analytes (i.e. gases, ions, $\mathrm{pH}$ ), as well as different techniques for MOF thin film growth and the challenges associated with each method. Examples of different MOF thin film chemical sensor devices will be discussed, as well as their various transduction mechanisms: electrical, optical, and acoustic. The review concludes with an outlook on potential future innovations for MOF thin film chemical sensors, and the remaining challenges associated with real-world implementation.
\end{abstract}

\section{Introduction}

\subsection{MOF thin films as sensing materials}

Metal-organic frameworks (MOFs), also known as porous coordination polymers, are crystalline nanoporous materials that

\footnotetext{
${ }^{a}$ National Energy Technology Laboratory, 626 Cochrans Mill Road, Pittsburgh, Pennsylvania, 15236, USA. E-mail: ki-joong.kim@netl.doe.gov; Tel: +1-412-386-4526

${ }^{b}$ NETL Support Contractor, 626 Cochrans Mill Road, Pittsburgh, Pennsylvania 15236, USA

$\dagger$ These authors contributed equally.
}

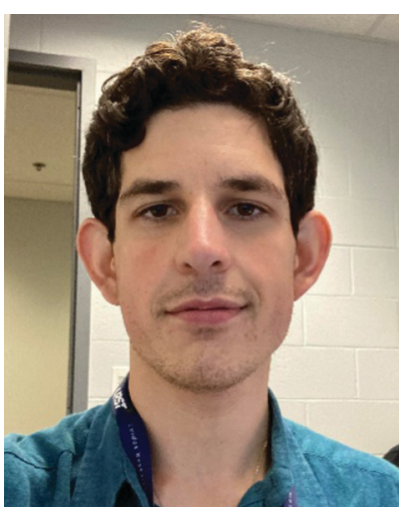

James E. Ellis
James E. Ellis is a research scientist for Leidos Inc. at National Energy Technology Laboratory, where he investigates electrochemical $\mathrm{CO}_{2}$ reduction catalysis. He obtained his PhD in Inorganic Chemistry from the University of Pittsburgh in 2018 under the supervision of Prof. Alexander Star, where he studied inorganic/ carbon nanomaterial composites and their application as chemical sensing materials. He was an Oak Ridge Institute for Science and Education (ORISE) postdoctoral researcher at NETL from 20192021 where he investigated porous nanomaterial, primarily metalorganic frameworks, thin films as sensing elements in optical fiberbased sensors. are built from metal ions or metal-containing clusters (i.e. secondary building units) connected by organic linkers to form a two-dimensional (2D) or three-dimensional (3D) extended network. Due to the diversity of available metal ions and organic linkers, and the variety of possible coordination linkages, there are theoretically unlimited types of potential MOF structures, and more than 70000 MOF species have been reported so far, according to Cambridge Structural Database (CSD) subset. ${ }^{1}$

In the early stages of MOF research, the synthesis of MOFs mainly focused on a systematic design and construction

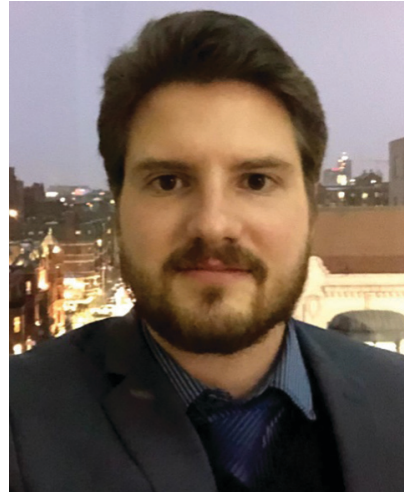

Scott E. Crawford
Scott E. Crawford is currently an Analytical Chemist at Leidos Inc.National Energy Technology Laboratory, where he develops optical sensors for high value metals. He obtained his PhD in Analytical Chemistry from the University of Pittsburgh in 2019 under the supervision of Prof. Jill Millstone, where he studied the impact of surface chemistry on the optical and charge transfer properties of luminescent coinage metal nanoparticles. Notable recognitions include the Mickey Leland Energy Fellowship, the Eastern Analytical Symposium Graduate Student Award, the University of Pittsburgh Andrew Mellon Predoctoral Fellowship, and the Society for Chemical Industry Scholar Award. 
through coordination chemistry. ${ }^{2-4}$ Later, research was dedicated to developing highly porous MOF materials with the ability for low temperature and pressure gas adsorption of energy-relevant gases such as $\mathrm{CO}_{2}, \mathrm{CH}_{4}, \mathrm{H}_{2}$, etc. At present, MOFs have exhibited potential for practical applications in many fields, such as catalysis, ${ }^{5}$ micro-electronic devices ${ }^{6,7}$ and sensors. ${ }^{8,9}$ Certainly, the most impressive traits of MOFs are their extremely high surface areas and tunable pore sizes, which present remarkable advantages over other porous materials (e.g. zeolites and activated carbons). Moreover, MOFs may have luminescent, magnetic, electrical conductivity, and catalytic properties, which make them of particular interest in various fields including chemical sensing. For sensor applications, the MOF should be able to be integrated on devices as a thin film, which is a prerequisite for their deployment in the field ${ }^{10}$ However, for initial MOF-based sensing studies, MOF films were usually prepared as pre-synthesized bulk powders, ${ }^{11}$ which made device processing with these insoluble materials difficult. As a result, integration of MOF materials was typically performed from suspensions of particles which may lead to brittleness, difficulty in spatial control, and overall poor processability. ${ }^{11}$ To address these challenges, there have been an increasing number of studies devoted to developing effective fabrication methods for high-quality MOF films targeted towards practical applications. ${ }^{8,9}$

In recent years, well-defined MOF thin films on various sensor platforms have been reported. ${ }^{12,13}$ While diverse MOF films and their applications have been demonstrated, this field is still at an emerging stage with several remaining issues. Indeed, the development of MOF-based sensing technologies

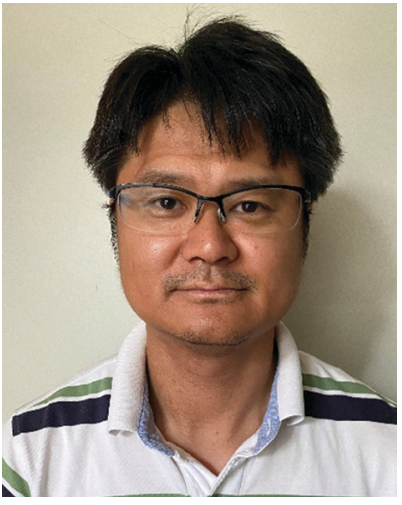

Ki-Joong Kim
Ki-Joong Kim is a research scientist with LRST working as an research support contractor at National Energy Technology Laboratory, US Department of Energy, where he focus on the nano-composite thin film synthesis for chemical sensor applications. He obtained his PhD degree in chemical engineering from Sunchon National University, South Korea, in 2009 under the supervision of Prof. Ho-Geun Ahn, where he studied catalytic reaction engineering on supported nanomaterials. He was a Postdoctoral scholar at Oregon State University, where he focused on solutionbased nanomaterials synthesis and use them for energy and environmental applications such as photocatalysts and photovoltaic cells. At NETL, he is involving in developing the sensing materials for carbon dioxide monitoring (including $\mathrm{pH}$ monitoring) in carbon storage applications and for methane leak detection in natural gas infrastructure, and detection of such species in wellbore integrity monitoring and drilling applications amongst others. necessitates further innovation in fabrication techniques to produce high-quality thin films. In this review, we focus on the recent progress in the development of MOF thin films and their application in various chemical sensor devices, including electrical, optical, and acoustic-based sensors.

\subsection{Fabrication of MOF thin films}

There has been significant research in the area of MOF thin film syntheses, and the multitude of techniques that have been developed has been the subject of several comprehensive reviews. ${ }^{9,14-16}$ A number of factors must be considered when selecting a fabrication technique: reaction time/temperature, the use of specialized equipment, scalability, film quality, and the sensing technique being used will all guide the choice of synthetic method.

Common synthetic methods used to prepare MOF thin films can be divided into four broad categories: (1) ex situ, (2) in situ, (3) templated in situ, and (4) seeding or secondary growth.

1.2.1 Ex situ. Ex situ methods include drop-casting (also known as solvent casting), ${ }^{17}$ dip-coating, ${ }^{18}$ spin-coating, ${ }^{19}$ Langmuir-Blodgett, $^{20}$ and various printing techniques. ${ }^{21}$ In these methods MOF (nano)crystals are first synthesized and dispersed into a solution, ideally as a colloid, and then coated onto the substrate through some mechanical means. Evaporation of the solvent creates a film of the remaining MOF crystals on the surface of the substrate. Ex situ methods are commonly used to create thin films of a variety of materials including metal nanoparticles, ${ }^{22}$ polymers, ${ }^{23}$ or supramolecular complexes. ${ }^{24}$ Besides the versatility of ex situ methods, they also allow the size of the particles to be controlled since the particle synthesis step is decoupled from the film deposition step. The simplest of these methods, drop-casting, is simply the evaporation of a droplet of the MOF solution on the surface of the substrate. Simplicity is the greatest advantage of this method; however, its disadvantages include high variability in surface coverage on the substrate (e.g. the coffee ring effect), high variability between substrates, and surface defects such as cracks and holes within the thin film. ${ }^{25}$ Certain parameters can be controlled to minimize these disadvantages, such as the choice of solvent, temperature, surface functionalization, and even the angle of the substrate. ${ }^{26-29}$ Dip-coating and spin-coating share the same disadvantages of drop-casting; however, they include more parameters that can be optimized to reduce these faults. For dip-coating, the speed of the substrate moving across the liquid-air interface can affect the film quality. ${ }^{30}$ Though dipcoating can be done manually, automated dip-coated machines reduce variability between substrates. ${ }^{18}$ For spin-coating, the spin speed and ramp rate highly affect the film thickness and quality.

1.2.2 In situ. Unlike ex situ methods, in situ methods couple the synthesis of MOF nanocrystals to the formation of the thin film to the substrate surface. Solvothermal MOF syntheses with the substrate present in the reaction solution will typically result in a weak and scattered association of MOF nanocrystals with the substrate surface, but the vast majority of MOF nucleation will occur in solution. ${ }^{10}$ In order to increase 
the coverage and attachment strength of the MOF thin film to the substrate surface, the substrate will often require a surface functionalization process prior to the solvothermal reaction. ${ }^{9}$ Functionalization of the substrate surface with molecules that increase the local concentration of reactants and intermediates close to the substrate surface via intermolecular interactions will promote MOF nucleation and subsequent film growth on the substrate surface. ${ }^{31}$ The main advantage of this method over ex situ methods is the adhesion strength of the MOF film to the substrate. Another in situ MOF thin film method is layerby-layer growth. This method alternately exposes the substrate surface area between the metal precursor solution and organic precursor solution with wash steps in between. ${ }^{32}$ Layer-by-layer (LbL) is usually used in conjunction with surface functionalization of the substrate. This method allows fine control over the thickness of the resulting MOF film since each iteration of the method will typically grow $<1 \mathrm{~nm}$ of MOF film. ${ }^{33}$ While fine thickness control may be an advantage, it can also be a disadvantage since the achievement of thick films may become time- and/or labor-intensive. However, innovations in layer-bylayer growth methods, such as automated spin-coating systems, dramatically reduce the time and labor previously required. ${ }^{34,35}$

1.2.3 In situ (template-assisted). Template-assisted in situ methods use the metal atoms incorporated within the substrate (metal or metal oxide) as a precursor for MOF thin film growth. These methods include electrochemical, ${ }^{36}$ microwave-assisted, ${ }^{37}$ and ceramic templating. ${ }^{38}$ Electrochemical MOF film growth is performed by placing a metal substrate in the organic ligand precursor solution and applying sufficient electrical potential to the substrate to coordinate organic ligands in solution to metal atoms on the substrate. ${ }^{14}$ Instead of electrical energy, microwaveassisted growth method utilizes high thermal energy on the metallic substrate formed via microwave radiation to drive coordination between organic ligands in solution and metal atoms on the substrate. ${ }^{39}$ In short, electrochemical and microwave-assisted growth methods produce high electrical or thermal energies, respectively, at the surface of the metallic substrate to initiate coordination and subsequent film growth. Ceramic template growth methods typically involve the solvothermal treatment of a metal oxide substrate in organic ligand precursor solution. ${ }^{40}$ At sufficiently high temperatures and pressures, the metal atoms in the metal oxide substrate will coordinate with organic ligands in solution and lead to MOF thin film formation on the substrate. The primary advantages of these template-assisted growth methods is the high adhesions strength of the resulting MOF thin films to the substrate, as well as the potential for patterning since MOF film will only grow where metal atoms are present. The main disadvantage of these methods is that they are energyintensive and require expensive equipment (e.g. potentiostat). However, it has been recently demonstrated that certain metal oxides can be converted to more reactive intermediates, namely hydroxy double salts (HDS), which can react with organic ligands to form MOF thin films even at ambient conditions. ${ }^{41}$

1.2.4 Seeding (secondary growth). Seeding or secondary growth methods involve a two-step process wherein MOF "seeds" are first synthesized and decorated onto the substrate surface. The seed-decorated substrate is then submerged in MOF growth solution to form a MOF film on the substrate surface. ${ }^{42}$ The primary advantage of this technique is the possibility of using physical features on the substrate's micro-surface, such as holes

Table 1 Summary of common MOF thin film fabrication techniques

\begin{tabular}{|c|c|c|}
\hline Technique & Advantages & Disadvantages \\
\hline Ex situ & Control of nanoparticle size, rapid ( $<1 \mathrm{~min})$ & Poor adhesion \\
\hline Drop-cast & Simple method & $\begin{array}{l}\text { Heterogeneity in film thickness, film defects }(e . g . \text { cracks and } \\
\text { pinholes), not appropriate for large substrates }\left(>25 \mathrm{~mm}^{2}\right), \\
\text { limited to planar substrates }\end{array}$ \\
\hline Spin-coat & Good control over film thickness & $\begin{array}{l}\text { Requires expensive equipment, limited to planar substrates smaller } \\
\text { than spin-coater }\end{array}$ \\
\hline Dip-coat & $\begin{array}{l}\text { Simple method, can be applied on range of substrate } \\
\text { sizes, can be combined with surface } \\
\text { functionalization }\end{array}$ & $\begin{array}{l}\text { Heterogeneity in film thickness, film defects (e.g. cracks and } \\
\text { pinholes) }\end{array}$ \\
\hline Contact printing & Patternable method & Low patterning resolution \\
\hline $\begin{array}{l}\text { Ink-jet printing and } \\
\text { spray coating }\end{array}$ & $\begin{array}{l}\text { Patternable method, can be applied on large size } \\
\text { range }\end{array}$ & Requires expensive equipment, low patterning resolution \\
\hline $\begin{array}{l}\text { Surface-assisted } \\
\text { (e.g. Langmuir- } \\
\text { Blodgett) }\end{array}$ & $\begin{array}{l}\text { Very fine control over film thickness, can be } \\
\text { combined with surface functionalization }\end{array}$ & May require expensive equipment, limited to planar substrates \\
\hline In situ & $\begin{array}{l}\text { Better substrate adhesion than ex situ, can be } \\
\text { combined with surface functionalization }(e . g . \text { SAM })\end{array}$ & Poor control over nanoparticle size, growth not limited to substrate \\
\hline Solvothermal & Simple method & $\begin{array}{l}\text { Film defects (e.g. cracks, pinholes, corrugation), requires high } \\
\text { temperature, time intensive }\end{array}$ \\
\hline $\mathrm{LbL}$ & $\begin{array}{l}\text { Fine control over film thickness, good control over } \\
\text { crystal orientation, compatible with automation }\end{array}$ & Potentially time intensive \\
\hline $\begin{array}{l}\text { In situ (template- } \\
\text { assisted) }\end{array}$ & Strong adhesion, patternable & Requires expensive equipment, poor control over nanoparticle size \\
\hline Electrochemical & - & Limited to metallic substrates \\
\hline Ceramic template & Can be combined with CVD & - \\
\hline Microwave-assisted & Rapid growth & - \\
\hline Seeding (secondary & Patternable & Growth not limited to substrate, poor adhesion \\
\hline
\end{tabular}




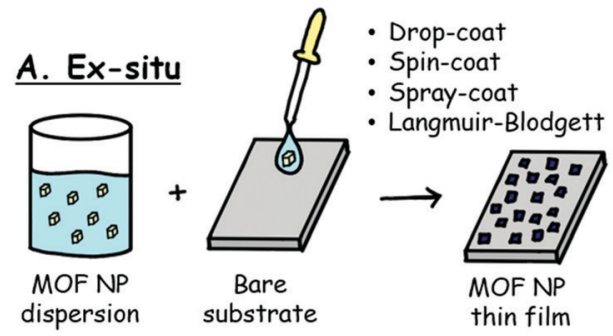

C. In-situ (Layer-by-layer)

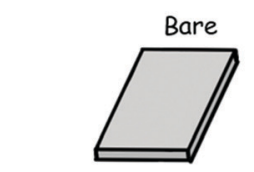

or

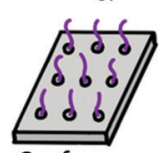

Surface functionalized

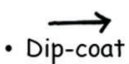

- Spin-coat

- Spray-coa

Metal

precursors

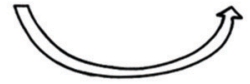

precursors

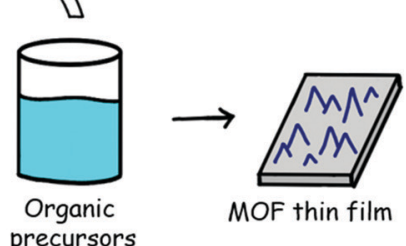

B. In-situ (Direct growth)

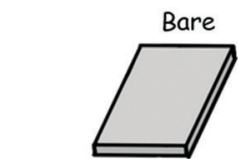

or

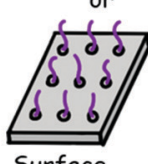

Surface

functionalized

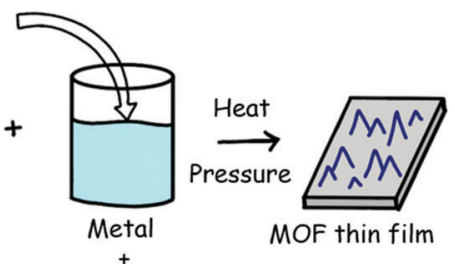

Organic

precursors

\section{In-situ (Template-assisted)}
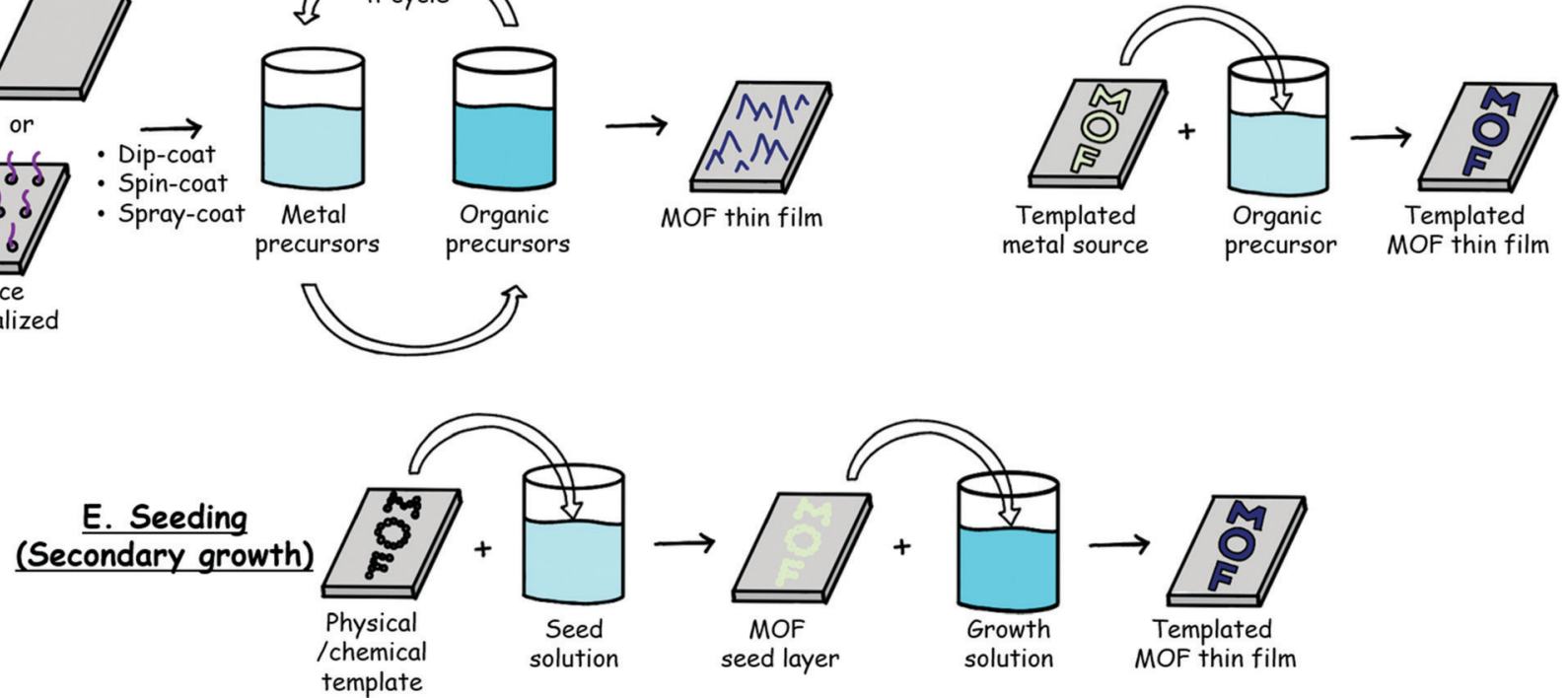

Fig. 1 Schematic depictions of the most common MOF thin film synthesis (or deposition) methods

and troughs, to pattern seed decoration and subsequent film growth. The disadvantages of seeding methods are potential detachment of seeds in the growth solution and poor adhesion of the film to the substrate surface.

Table 1 summarizes the general advantages and disadvantages of each technique, while Fig. 1 provides a schematic of the fabrication method. These techniques may be applied to deposit MOF films on a range of substrates depending upon the sensing technique. For example, optical fibers and/or quartz substrates are often employed for optical sensing techniques. Acoustic-based methods, on the other hand, require the MOFs to be deposited on planar substrates such as quartz crystal microbalances (QCM) and surface acoustic wave (SAW) devices. The film quality required is also somewhat dependent upon the sensing technique being deployed. As discussed in subsequent sections, high quality MOF films (e.g. uniformity, crystallinity, smooth surfaces, no bare patches, etc.) are required for absorbance-based and acoustic-based sensing techniques, whereas film quality is less important for luminescence-based sensors. Many of the fabrication techniques are desirable due to their inherent simplicity. For example, dip-coating, ${ }^{43}$ dropcasting, and the use of sacrificial templates typically do not require any specialized equipment and produce films relatively quickly. Yet there are drawbacks for each technique; dipcoating and drop-casting techniques, much like the layer-bylayer (LbL) method, often require multiple cycles to produce films of sufficient thickness in sensing applications. The use of a sacrificial template can be used to rapidly produce a MOF film in one step; ${ }^{41}$ however, only a select few MOF structures have been prepared using this synthetic method. Strategies requiring relatively expensive equipment include spin coating, electrochemical synthesis, microwave heating, and, when using a commercial apparatus, dip-coating, which can all be employed to produce films of relatively high quality and various thickness. Emerging fabrication methods (see Section 5.2) include solvent-free chemical vapor deposition (CVD) and other gas phase processes, ${ }^{44-46}$ which offer advantages in terms of scalability and morphological control, but require expensive and sophisticated equipment.

\section{Electrical MOF thin film sensors}

Electrical transduction of chemical interactions is a popular sensing approach because of (1) the extensive and well-known 
capabilities for electrical sensor fabrication and (2) the various electrical-based sensing mechanisms that provide theoretical pathways for enhanced sensitivity and selectivity. The working principle behind electrical chemical sensors is that chemical interactions between the target analyte and sensing material can cause changes in the electronic properties of the sensing material. Mechanisms for this working principle include intramolecular mechanisms (e.g. charge transfer, trap state formation), intermolecular mechanisms (e.g. swelling), or a combination that effects a change in the sensing material's charge concentration, charge mobility, or charge distribution. On the macroscale, these electronic events are reflected as changes in the material's resistance, permittivity (and consequently capacitance), and/or work function. Besides being a selective and sensitive sensing approach, electrical sensors have the additional benefit of potential miniaturization and integration with other electronic devices such as smartphones.

MOF thin films have been used as the sensing layer in various types of electrical sensors including chemiresistors, chemicapacitors, and field-effect transistors (FETs). ${ }^{12,47-49}$ MOF thin film electrical-based sensors are summarized in Table 2. The attraction of using MOFs as the sensing material for electrical sensors lies in their high porosity, chemical tailorability, and potential functionalization. While the majority of MOFs are nonconductive, the advent of conductive MOFs has paved the way for their integration into chemiresistors. ${ }^{50}$ The dual nature of MOFs creates a variety of potential active sites a target analyte may interact with. For example, reducing gases such as $\mathrm{NH}_{3}$ have strong interactions with open metal sites (OMS), ${ }^{51}$ while electrophilic analytes like $\mathrm{CO}_{2}$ are more likely to adsorb to a Lewis basic organic ligand. ${ }^{52}$

\subsection{Chemiresistive sensors}

In its simplest form, a chemiresistor sensing device is composed of two electrodes deposited on an insulating substrate with a conductive sensing material bridging the electrodes. The conductive sensing material serves as a variable resistor in the circuit whereby changes in the chemical environment modulate the resistance of the material. This modulation of resistance can be caused by charge transfer, introduction of electronic trap states or scattering sites that affect charge mobility or shifting of the Schottky barrier between the sensing material and electrode. Due to mismatched energy levels and poor orbital overlap between the metal centers and organic ligands, most 3D MOFs do not display conductivity under ambient conditions. However, the recent advent of conductive $2 \mathrm{D}$ MOFs that have in-plane charge delocalization and extended $\pi-\mathrm{d}$ conjugation has led to numerous examples of MOF-based chemiresistors. ${ }^{50} \mathrm{~A}$ mechanistic study of these conductive 2D MOFs found that their chemiresistive response towards a target analyte is related to its binding on the OMS of the MOF. ${ }^{51}$

The first example of a MOF-based chemiresistor was prepared from drop-cast films of $\mathrm{Cu}_{3}(\mathrm{HITP})_{2}(\mathrm{HITP}=2,3,6,7,10,11$ hexaiminotriphenylene), a conductive $2 \mathrm{D} \mathrm{MOF} .^{70}$ The electrical conductivity of this MOF can be attributed to the large aromatic core of HITP and favorable orbital overlap between the $\mathrm{Cu}^{2+}$ metal center and the imine base, which results in an extended $\pi-\mathrm{d}$ conjugation network along the $a b$ plane. This 2D MOF displayed a bulk conductivity of $0.2 \mathrm{~S} \mathrm{~cm}^{-1}$, which is more than enough conductivity to be applied in a chemiresistor device. In this work, bulk $\mathrm{Cu}_{3}(\mathrm{HITP})_{2}$ was synthesized, dispersed in solution, and drop-cast onto interdigitated electrodes (IDEs) to create a chemiresistor device that was sensitive to $\mathrm{NH}_{3}$ vapor. As a continuation of this work, three different conductive 2D MOFs were prepared to construct a cross-reactive sensor array that allowed for clear discrimination of volatile organic compounds (VOCs). ${ }^{69}$ The three conductive 2D MOFs prepared in this work were $\mathrm{Cu}_{3}(\text { HITP })_{2}, \mathrm{Ni}_{3}(\text { HITP })_{2}$, and $\mathrm{Cu}_{3}(\text { HHTP })_{2}($ HHTP $=$ 2,3,5,6,10,11-hexahydroxytriphenylene). This approach of using chemiresistor arrays in conjunction with principle component analysis (PCA) can provide discrimination between different target analytes and concentration ranges. A recent example of this approach utilized a series of isoreticular nickel metallophthalocyanine (NiPc) and metallonaphthalocyanine (NiNPc) frameworks. ${ }^{63}$ Frameworks were synthesized by "welding," NiPcs and NiNPcs together with $\mathrm{Cu}^{2+}$ and $\mathrm{Ni}^{2+}$ cations, producing a total of four unique frameworks: NiPc-Ni, Ni$\mathrm{NPc}-\mathrm{Ni}, \mathrm{NiPc}-\mathrm{Cu}$, and NiNPc-Cu. Compared to single molecule NiPc or NiNPc, welding these subunits into frameworks improved conductivity by 5-7 orders of magnitude. The excellent intrinsic conductivity (up to $10^{-2} \mathrm{~S} \mathrm{~cm}^{-1}$ ) of the frameworks allowed the sensor to be operated at low driving voltages (0.01-1.0 V). PCA applied toward the chemiresistor responses of these conductive MOFs provided discrimination of ppm levels of $\mathrm{NO}, \mathrm{NH}_{3}$, and $\mathrm{H}_{2} \mathrm{~S}$, even in the presence of $18 \%$ relative humidity. These NiPc and NiNPc framework chemiresistor sensors displayed excellent sensitivity toward $\mathrm{NH}_{3}$ (limits of detection (LOD): 0.31-0.33 ppm), $\mathrm{H}_{2} \mathrm{~S}$ (LOD: 19-32 ppb), and NO (LOD: 1.0-1.1 ppb).

There have been several examples of in situ growth of conductive 2D MOFs on chemiresistive devices. Mirica and co-workers developed an in situ synthetic method to grow two different conductive 2D MOFs, $\mathrm{Cu}_{3}(\mathrm{HHTP})_{2}$ and $\mathrm{Ni}_{3}(\mathrm{HHTP})_{2}$, on a shrinkable polymer substrate with graphite electrodes. ${ }^{68}$ Thick films $(5-10 \mu \mathrm{m})$ of these 2D MOF were grown on a polymer substrate by submerging the substrate in the MOF growth solution for a set time period (Fig. 2A-D). An array of these chemiresistors were able to distinguish between $\mathrm{NH}_{3}$, $\mathrm{H}_{2} \mathrm{~S}$, and NO (Fig. 2E and F) as well as different concentration ranges (Fig. 2G and $\mathrm{H}$ ). An advantage of this synthetic method is its adaptability to different substrates. This in situ synthetic method was utilized to grow conductive 2D MOFs on textile fibers, allowing chemiresistor devices to be prepared on fabric. ${ }^{67}$ The combination of the textile's mesoporosity with the MOF's microporosity makes a device of enhanced porosity that translates into excellent gas sensing ability. At the time of publication, this work showed the best performance of any smart fabric sensor or MOF-based chemiresistor toward $\mathrm{NO}$ and $\mathrm{H}_{2} \mathrm{~S}$ detection, displaying LODs for $\mathrm{NO}$ and $\mathrm{H}_{2} \mathrm{~S}$ of $0.16 \mathrm{ppm}$ and $0.23 \mathrm{ppm}$, respectively. Unlike $\mathrm{H}_{2} \mathrm{~S}, \mathrm{NO}$, or $\mathrm{NH}_{3}$, $\mathrm{CO}_{2}$ is not a strong electron donating or accepting molecule, 
Table 2 MOF thin film electrical-based sensors

\begin{tabular}{|c|c|c|c|c|c|c|c|}
\hline Material & Film growth method & Device type & Target analyte & $\begin{array}{l}\text { Sensing } \\
\text { range } \\
(\mathrm{ppm})\end{array}$ & $\begin{array}{l}\text { Film } \\
\text { thickness } \\
(\mu \mathrm{m})\end{array}$ & LOD (ppb) & Ref. \\
\hline Mg-MOF-74 & Solvothermal & Chemicapacitor & Benzene, $\mathrm{CO}_{2}$ & $\begin{array}{l}5-100 \\
200-5000\end{array}$ & 7.00 & - & 53 \\
\hline Ni-MOF-74 & Metal oxide template & Chemicapacitor & Benzene & $25-100$ & 0.09 & - & 54 \\
\hline MFM-300 & Solvothermal & Chemicapacitor & $\mathrm{SO}_{2}$ & $0.075-1$ & - & 5 & 55 \\
\hline fum-fcu-MOF & Solvothermal & Chemicapacitor & $\mathrm{H}_{2} \mathrm{~S}$ & $0.1-100$ & - & 5 & 56 \\
\hline NbOFFIVE-1-Ni/AlFFIVE-1-Ni & Spin-coat & Chemicapacitor & $\mathrm{CO}_{2}$ & $400-5000$ & 2.00 & - & 57 \\
\hline CuBTC & Drop-cast & Chemicapacitor & $\begin{array}{l}\text { Methanol, ethanol, } \\
\text { isopropanol, acetone }\end{array}$ & $250-1500$ & 8.00 & $\begin{array}{l}61990,71050 \\
77800,100180\end{array}$ & 58 \\
\hline $\mathrm{Cu}(\mathrm{bdc}) \cdot x \mathrm{H}_{2} \mathrm{O}$ & $\mathrm{LbL}$ & Chemicapacitor & Humidity, VOCs & - & 1.50 & - & 59 \\
\hline CuBTC & Electrochemical & Chemicapacitor & Methanol, ethanol & $200-2000$ & 5.00 & 39100,130000 & 29 \\
\hline NDC-Y-fcu-MOF & Solvothermal & Chemicapacitor & $\mathrm{NH}_{3}$ & $1-100$ & - & 92 & 60 \\
\hline $\mathrm{Cu}_{3}(\mathrm{HITP})_{2-x}(\mathrm{HHTP})_{x}$ & Spray LbL & Chemiresistor & Benzene & $1-100$ & $0.02-0.07$ & $24-96$ & 61 \\
\hline $\mathrm{Cu}_{3}(\mathrm{HHTP})(\mathrm{THQ})$ & Drop-cast & Chemiresistor & $\mathrm{NH}_{3}$ & $1-100$ & - & $20-350$ & 62 \\
\hline $\begin{array}{l}\mathrm{M}(\mathrm{Cu}, \mathrm{Ni}) \text { phthalocyanines, } \\
\mathrm{M}(\mathrm{Cu}, \mathrm{Ni}) \text { naphthalocyanines }\end{array}$ & Drop-cast & $\begin{array}{l}\text { Chemiresistor } \\
\text { array }\end{array}$ & $\mathrm{NO}, \mathrm{H}_{2} \mathrm{~S}, \mathrm{NH}_{3}$ & $\begin{array}{l}0.02-1, \\
0.2-80,2- \\
80\end{array}$ & $1-6$ & $\begin{array}{l}1,19-32,310- \\
330\end{array}$ & 63 \\
\hline $\mathrm{Cu}_{3}(\mathrm{HHTP})_{2} / \mathrm{M}(\mathrm{Pt}, \mathrm{Pd}) \mathrm{NPs}$ & Drop-cast & Chemiresistor & $\mathrm{NO}_{2}$ & $1-5$ & - & - & 64 \\
\hline $\mathrm{Cu}_{3}(\mathrm{HHTP})_{2} / \mathrm{Cu}_{3}(\mathrm{TCPP})_{2}$ & $\begin{array}{l}\text { Spray LbL and } \\
\text { interface-assisted } \\
\text { dip-cast }\end{array}$ & Chemiresistor & $\mathrm{NH}_{3}$, benzene & $1-100$ & 0.075 & 120 (benzene) & 65 \\
\hline $\mathrm{Cu}_{3}(\mathrm{HIB})_{2}$ & Drop-cast & Chemiresistor & $\mathrm{CO}_{2}$ & $400-2500$ & - & - & 52 \\
\hline $\mathrm{Cu}_{3}(\mathrm{HHTP})_{2}$ & Spray LbL & Chemiresistor & $\mathrm{NH}_{3}$ & $1-100$ & 0.02 & 600 & 66 \\
\hline $\mathrm{Ni}_{3}(\mathrm{HHTP})_{2}, \mathrm{Ni}_{3}(\mathrm{HITP})_{2}$ & Solvothermal & Chemiresistor & $\mathrm{NO}, \mathrm{H}_{2} \mathrm{~S}$ & $\begin{array}{l}0.1-80,1- \\
80\end{array}$ & - & 160,230 & 67 \\
\hline $\mathrm{Cu}_{3}(\mathrm{HHTP})_{2}, \mathrm{Ni}_{3}(\mathrm{HHTP})_{2}$ & Solvothermal & $\begin{array}{l}\text { Chemiresistor } \\
\text { array }\end{array}$ & $\mathrm{NH}_{3}, \mathrm{H}_{2} \mathrm{~S}, \mathrm{NO}$ & $2.5-80$ & $5-10$ & - & 68 \\
\hline $\begin{array}{l}\mathrm{Cu}_{3}(\mathrm{HHTP})_{2}, \mathrm{Cu}_{3}(\mathrm{HITP})_{2}, \\
\mathrm{Ni}_{3}(\mathrm{HITP})_{2}\end{array}$ & Drop-cast & $\begin{array}{l}\text { Chemiresistor } \\
\text { array }\end{array}$ & VOCs & $200-2500$ & - & - & 69 \\
\hline $\mathrm{Cu}_{3}(\mathrm{HITP})_{2}$ & Drop-cast & Chemiresistor & $\mathrm{NH}_{3}$ & $0.5-10$ & - & $<1000$ & 70 \\
\hline
\end{tabular}

thus it is a difficult target for chemiresistor sensor detection. To address this challenge, chemiresistor devices prepared from $\mathrm{Cu}_{3}$ (hexaiminobenzene $)_{2}\left(\mathrm{Cu}_{3} \mathrm{HIB}_{2}\right)$ thin films were shown to sense practically relevant concentrations of $\mathrm{CO}_{2}$ (4002500 ppm) with a sensitivity nearly independent of the relative humidity level. ${ }^{52}$ The high density of $\mathrm{NH}$ moieties on hexaiminobenzene promotes the formation of acid-base adducts or bicarbonate salts between $\mathrm{CO}_{2}$ and $\mathrm{Cu}_{3} \mathrm{HIB}_{2}$. The formation of these adsorbed $\mathrm{CO}_{2}$ species caused $\mathrm{e}^{-}$withdrawal from the MOF, resulting in charge traps that affected charge mobility and consequently resistance.

$\mathrm{Xu}$ and co-workers were the first to demonstrate thin films $(<100 \mathrm{~nm})$ of conductive 2D MOFs integrated into chemiresistor devices (Fig. 3). ${ }^{66}$ They developed a spray LBL method whereby solutions of the metal precursor and organic ligand of $\mathrm{Cu}_{3}$ (HTTP $)_{2}$, as well as a rinsing solvent, were sequentially sprayed directly onto a chemiresistor device. They found that -OH functionalization on the substrate acted in the same way as a SAM for adhering and orienting MOF thin films. Each spray cycle of this method grew approximately $2 \mathrm{~nm}$ of $\mathrm{Cu}_{3}$ (HTTP $)_{2}$ on the device surface. When exposed to $\mathrm{NH}_{3}$ vapor, the $\mathrm{Cu}_{3}(\mathrm{HTTP})_{2}$ chemiresistor displayed an increase in resistance. Ultraviolet photoelectron spectroscopy found that the Fermi level of the $\mathrm{Cu}_{3}(\mathrm{HTTP})_{2}$ film increased by $1.13 \mathrm{eV}$ after exposure to $\mathrm{NH}_{3}$, indicating that $\mathrm{NH}_{3}$ binding was n-type doping in $\mathrm{Cu}_{3}(\mathrm{HTTP})_{2}$, a p-type semiconductor. This spraycoating technique was adapted to grow van der Waals stacked dual MOF thin films directly on chemiresistor devices (Fig. 4). ${ }^{65}$
In this work, a conductive 2D MOF thin film, Cu-HHTP, was first grown onto the chemiresistor device through spraycoating, followed by the growth of a molecular sieving MOF, $\mathrm{Cu}$-TCPP (tetrakis(4-carboxyphenyl)porphyrin), thin film on top. The sensitivity of only the Cu-HHTP thin film toward $\mathrm{NH}_{3}$ and benzene was tested, and it was found to have a much higher sensitivity to $\mathrm{NH}_{3}$ than benzene because of the electrondonating character of $\mathrm{NH}_{3}$. However, the growth of the molecular sieving $\mathrm{Cu}$-TCPP above $\mathrm{Cu}-\mathrm{HHTP}$ caused lower sensitivity toward $\mathrm{NH}_{3}$ than benzene, thus reversing the selectivity. This modulation in gas selectivity was caused by the chemisorption of $\mathrm{NH}_{3}$ molecules within the Cu-TCPP layer, which prevents $\mathrm{NH}_{3}$, but not benzene, from reaching the underlying Cu-HHTP thin film.

Recent examples of conductive MOFs prepared from a mixture of two ligands have been shown to modulate the sensing properties of these materials as compared to their single-ligand counterparts. Kitagawa, Otake, and co-workers synthesized dual-ligand conductive $\mathrm{MOF}, \mathrm{Cu}_{3}(\mathrm{HHTP})(\mathrm{THQ})$ (THQ = tetrahydroxy-1,4-quinone), which showed intermediate conductivity and surface area $\left(\sim 10^{-5} \mathrm{~S} \mathrm{~cm}^{-1} ; \sim 440 \mathrm{~m}^{2} \mathrm{~g}^{-1}\right)$ between $\mathrm{Cu}_{3} \mathrm{HTTP}_{2}\left(\sim 10^{-3} \mathrm{~S} \quad \mathrm{~cm}^{-1} ; \sim 540 \mathrm{~m}^{2} \mathrm{~g}^{-1}\right)$ and $\mathrm{Cu}_{3} \mathrm{THQ}_{2}\left(\sim 10^{-8} \mathrm{~S} \mathrm{~cm}^{-1} ; \sim 140 \mathrm{~m}^{2} \mathrm{~g}^{-1}\right) .{ }^{62}$ A thick film of this dual-ligand MOF was deposited on a chemiresistor device through drop-casting. Surprisingly, the lower conductivity baseline of $\mathrm{Cu}_{3}(\mathrm{HHTP})(\mathrm{THQ})$ as compared to $\mathrm{Cu}_{3} \mathrm{HHTP}_{2}$ made the dual-ligand MOF more sensitive to small charge transfers, resulting in good discrimination of $\mathrm{NH}_{3}$ at low concentrations 

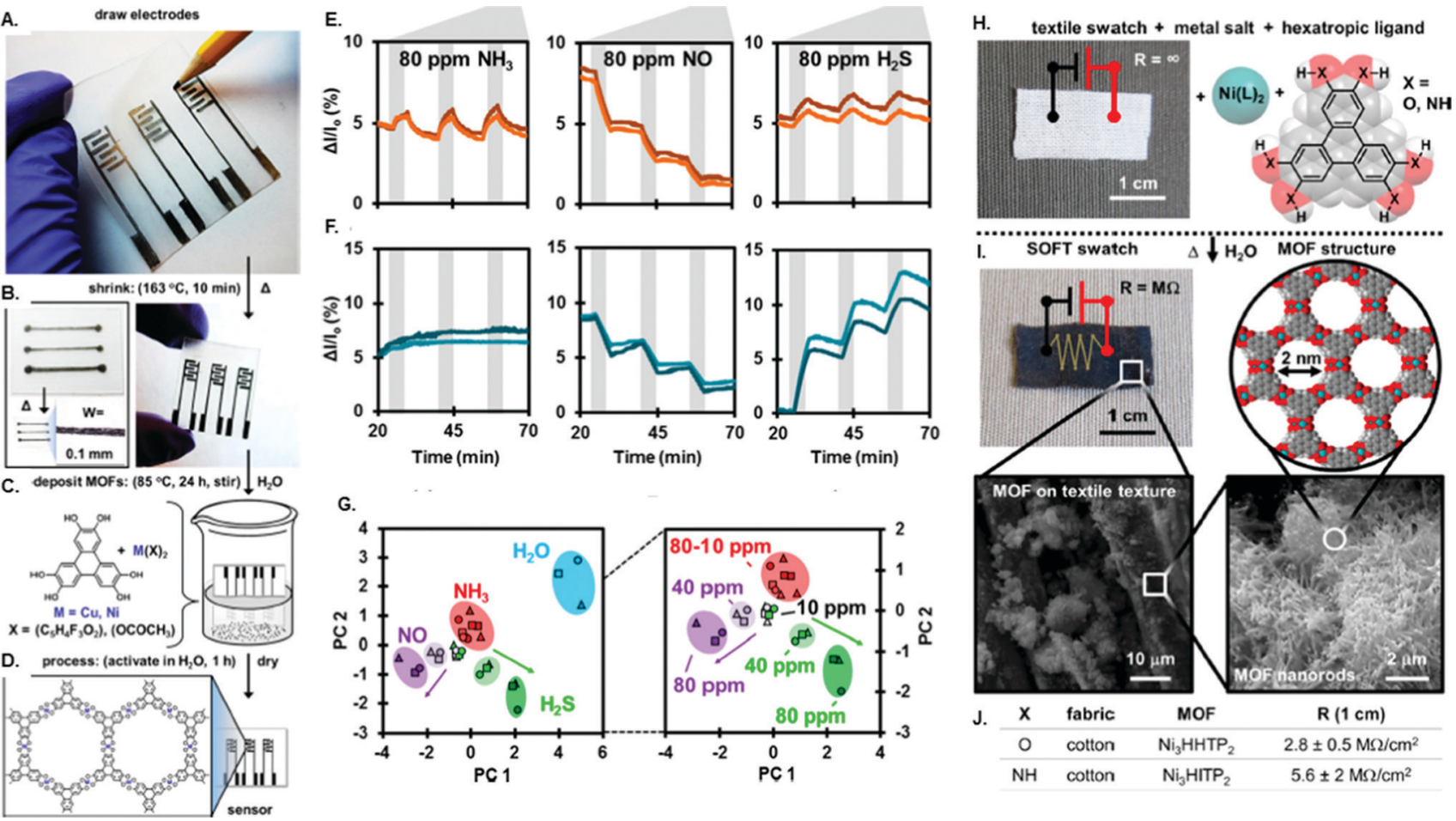

Fig. 2 Solution-based growth of 2D conductive MOFs on various substrates. (A) Photograph showing the process of drawing electrodes on a shrinkable polymeric film with a commercial HB (hard black) pencil. (B) Shrinking of the film $\left(10 \mathrm{~min}, 163^{\circ} \mathrm{C}\right)$ miniaturizes lateral features of the electrodes $(\mathrm{W}=$ wire width). (C) Solution-based growth of MOFs onto the device. (D) Schematic illustration of the resulting MOF-based chemiresistive sensors on the surface of a shrinkable polymeric film. Representative sensing traces for (E) $\mathrm{Cu}_{3} \mathrm{HHTP}_{2}$ and (F) $\mathrm{Ni}_{3} \mathrm{HTTP}_{2}$ exposed to 80 ppm of various gases three times. (G) PCA discrimination of different gases and concentrations. (H) Starting materials for SOFT-sensors: a cotton swatch (no conductivity), the organic triphenylene-based ligand (HHTP or HATP), and metallic node ( $\mathrm{Ni}-(\mathrm{OAc})_{2}$ or $\left.\mathrm{NiCl}_{2}\right)$. A photograph of the cotton swatch is shown. (I) Solvothermal condensation of these reagents in water produces conductive smart fabric sensors: textiles coated with nanoporous MOF. Macroscopic through molecular level detail is shown, from a photograph of cotton SOFT sensor postreaction (top left), to scanning electron micrographs detailing MOF coating on fibers (bottom left), and characteristic MOF nanorod texture (bottom right), to space-filling model of MOF (top right). (J) Sheet resistance measurements for smart fabric sensors prepared in this work. (A)-(G) was adapted with permission from J. Am. Chem. Soc., 2016, 28(15), 5264-5268. Copyright 2016 American Chemical Society. (H)-(J) was with permission from J. Am. Chem. Soc. 2017, 139(46), 16759-16767. Copyright 2017 American Chemical Society.

(1-100 ppm) and a LOD down to 0.02-0.35 ppm. In another work, $\mathrm{Xu}$ and co-workers adapted their spray LBL method to assemble a dual-ligand conductive MOF thin film directly onto a chemiresistive device. ${ }^{61}$ A mixed ligand solution was used during the spray LBL assembly to produce thin films of $\mathrm{Cu}_{3}(\text { HHTP })_{2-x}$ (HITP $)_{x}$. They observed that HITP doping below $1.0 \mathrm{~mol} \%$ resulted in a conductivity increase of the MOF thin film; however, doping above $1.0 \%$ resulted in decreased conductivity due to diminished crystallinity. Besides conductivity, the selectivity of $\mathrm{Cu}_{3}(\mathrm{HHTP})_{2-x}(\mathrm{HITP})_{x}$ toward different gas analytes was modulated by tuning the doping concentration. Selectivity for benzene $v$ s. $\mathrm{NH}_{3}$ was improved $220 \%$ for $10 \mathrm{~mol} \%$ HITP doping as compared to undoped $\mathrm{Cu}_{3}$ (HHTP).

\subsection{Chemicapacitive sensors}

Unlike chemiresistors, which require sensing materials with high conductivities, chemicapacitors can utilize non-conducting materials as the dielectric sensing material. Many examples of non-conductive MOFs integrated as dielectric films in chemicapacitors have been shown well before the first MOF chemiresistor was demonstrated. ${ }^{48}$ The working principle behind chemicapacitor sensors is the relationship between analyte adsorption in the dielectric material and the subsequent modulation of the material's permittivity constant caused by changes in charge distribution. Both parallel plate design, ${ }^{58}$ as well as complementary metal oxide semiconductor-compatible IDE design ${ }^{53-57,59,60}$ have been used to make MOF film-based chemicapacitors. While parallel plate capacitor devices may have higher nominal capacitance and sensitivity, IDE chemicapacitors have the same benefits of IDE chemiresistors, including ease of process, miniaturization, low power consumption, and inexpensive manufacturing cost. ${ }^{71}$ A challenge of capacitor sensing devices is the requirement for AC, which adds AC frequency as another parameter for optimization. Overall, chemicapacitors are promising devices for the incorporation of MOF thin films because of their simplified IDE design and the requirement for non-conductive sensing materials, of which the majority of MOFs are non-conductive.

Achmann and co-workers first demonstrated the integration of non-conductive MOF films on IDE devices by screen-printing MOF pastes on an IDE and heating to evaporate the solvent. ${ }^{72}$ These devices were coupled to an impedance analyzer to 

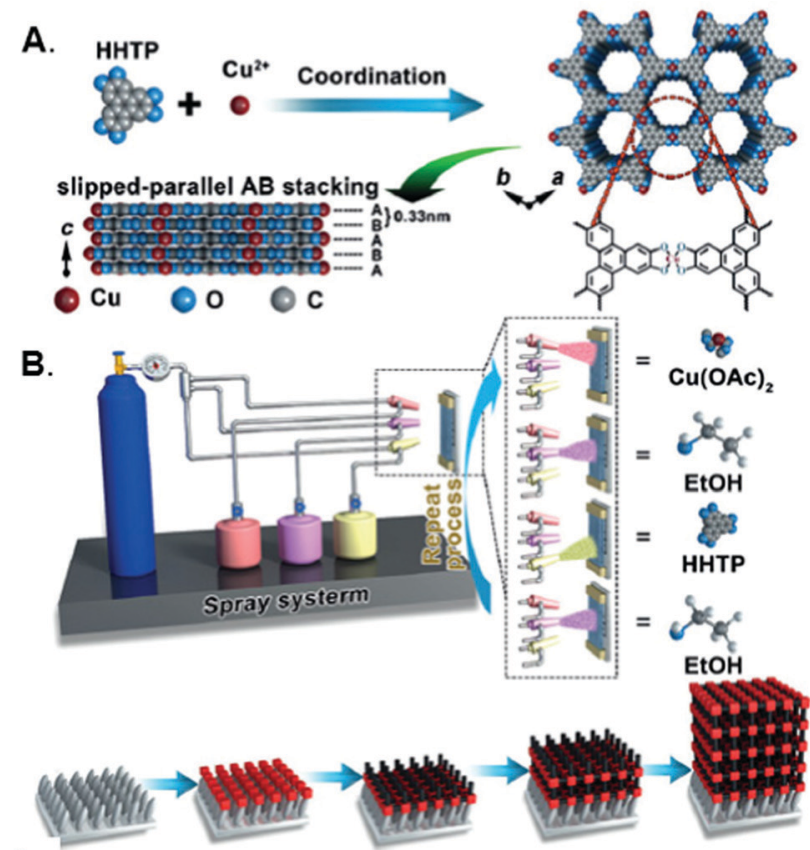

C.
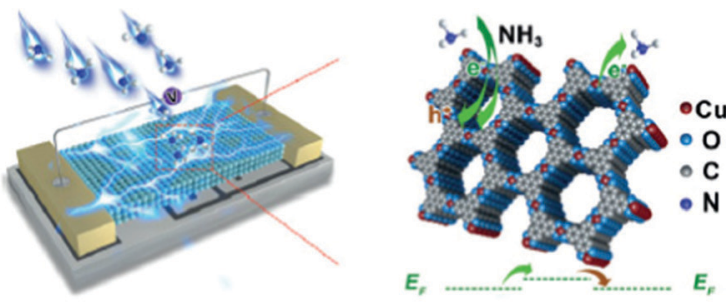

Fig. 3 Spray-coating of a 2D conductive MOF thin film on a chemiresistor device. Illustration of (A) the crystal structure of $\mathrm{Cu}_{3}(\mathrm{HHTP})_{2}$ and $(\mathrm{B})$ the preparation of $\mathrm{Cu}_{3}(\mathrm{HHTP})_{2}$ thin-film gas sensors through successive spray-coating of metal linker solution, organic linker solution, and wash solvent. (C) Schematic of the chemiresistor gas sensor and possible gassensing mechanism for $\mathrm{NH}_{3}$. This figure was adapted with permission from Angew. Chem., Int. Ed., 2017, 56(52), 16510-16514. Copyright 2017, John C. Wiley and Sons, Inc.

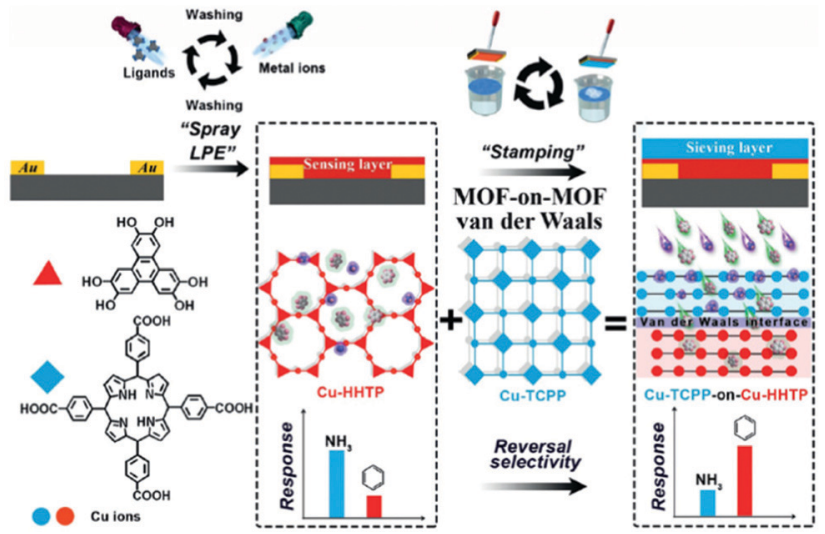

Fig. 4 Illustration of the preparation of MOF-on-MOF thin films by van der Waals integration and application of the films as highly selective benzene-sensing materials. This figure was adapted from Angew. Chem., Int. Ed., 2019, 58(42), 14915-14919. Copyright 2019, John C. Wiley and Sons, Inc. monitor impedance between $1 \mathrm{~Hz}$ and $1 \mathrm{MHz}$ in the presence of humidity and VOCs. The first MOF thin film chemicapacitor was demonstrated by Omran and co-workers, wherein crystalline and highly oriented $\mathrm{Cu}(\mathrm{bdc})$ thin films were grown on IDE devices functionalized with OH-terminated SAMs through an LBL procedure ${ }^{59}$ for humidity and VOC sensing. Humidity is a common sensing target for chemicapacitors because of its large molecular dipole $(1.85 \mathrm{D})$ and the high permittivity constant of liquid water (78.3). The choice of MOF used in a sensor must take chemical stability into account for corrosive targets such as $\mathrm{H}_{2} \mathrm{~S}$ and $\mathrm{NH}_{3}$. Salama, Eddouadi, and co-workers developed rare earth (RE) MOFs with face-centered cubic (fcu) topology that are stable even in the presence of corrosive gases. These RE-fcu-MOFs were integrated into IDE capacitor devices via surface functionalization and solvothermal reaction in order to sense $\mathrm{H}_{2} \mathrm{~S}$ or $\mathrm{NH}_{3}$, depending on the organic linker. ${ }^{56,60} \mathrm{RE}$-fcu-MOF showed stability toward $\mathrm{H}_{2} \mathrm{~S}$ for weeks, in contrast to other more common MOFs like $\mathrm{Cu}(\mathrm{bdc}) \cdot x \mathrm{H}_{2} \mathrm{O}$ or $\mathrm{ZIF}-8$, which decomposed due to metal sulfide formation in a short period of time.

Zhao and co-workers demonstrated how the selectivity of MOF chemicapacitors can be modulated with post-synthetic modifications to the MOF sensing layer. ${ }^{53}$ Mg-MOF-74 films were grown on IDE devices via a solvothermal process and showed sensitivity toward both benzene vapor and $\mathrm{CO}_{2}$. However, after functionalizing the Mg-MOF-74 thin film with ethylenediamine, the chemicapacitor showed an approximately $60 \%$ decrease in benzene sensitivity and an approximately $25 \%$ increase in $\mathrm{CO}_{2}$ sensitivity. This effect was attributed to ethylenediamine binding to the OMS of Mg-MOF-74, which weakens $\pi$-complexation of the benzene molecules to the OMS, and the increased adsorption of $\mathrm{CO}_{2}$ due to amine- $\mathrm{CO}_{2}$ interactions.

Solvothermal syntheses of MOF thin films on surface functionalized devices is the most prevalent synthetic approach for chemicapacitors because of its wide applicability, potential for patterning, and ease-of-use. However, other methods such as electrochemical deposition and the use of metal oxide precursors have also shown success in chemicapacitor preparation. ${ }^{29,54}$ Yuan et al. compared two synthetic methods for growing Ni-NDC (NDC = 2,6-naphthalenedicarboxylic acid) MOF thin films grown on an IDE device: (1) in situ solvothermal synthesis and (2) $\mathrm{Ni}(\mathrm{OH})_{2}$ precursor conversion (Fig. 5). ${ }^{54}$ The Ni-NDC MOF thin film grown through the solvothermal method showed poorly adhered, corrugated thin films on the surface of the IDE device. In contrast, MOF growth via a $\mathrm{Ni}(\mathrm{OH})_{2}$ precursor showed compact, homogeneous thin films that displayed no delamination from the substrate. This Ni-NDC thin film IDE device was used to sense benzene down to $25 \mathrm{ppm}$.

\subsection{Field effect transistor sensors}

Field-effect transistor (FET) sensors are composed of conducting channels (typically the sensing material) that are modulated by electric fields generated by gate electrodes. The gate electrode may be separated from the conductive channel by a solid dielectric layer or a liquid electrolyte solution, depending on the application. The type of gate electrode set-up used in an FET depends on the application. For example, an FET sensor of 
A.

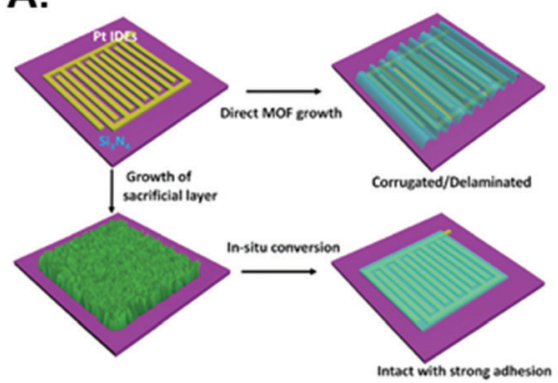

B.

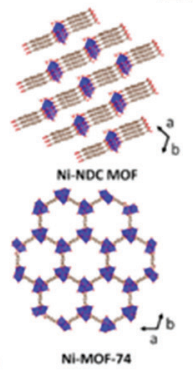

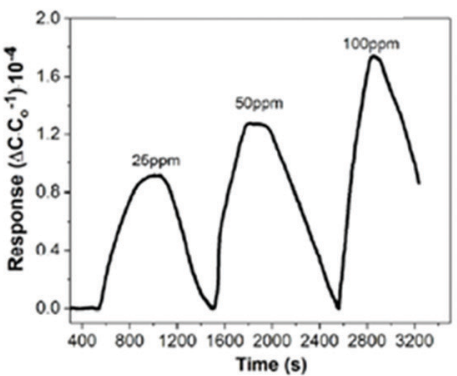

C.

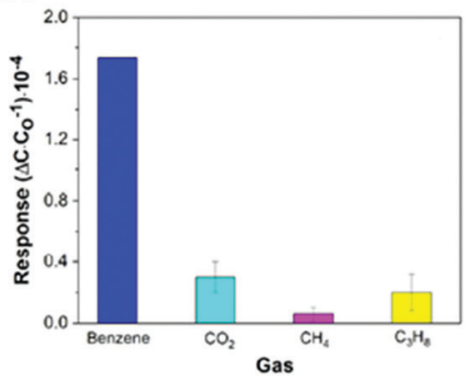

Fig. 5 On-chip template-directed conversion of metal hydroxides to MOF thin films as chemicapacitor-based gas sensors. (A) Scheme of direct solvothermal growth on IDE device versus template-directed growth on an IDE device via a sacrificial metal hydroxide layer. (B) Dynamic response of the $\mathrm{Ni}-\mathrm{NDC}$ MOF-coated capacitive sensor upon exposure to various concentrations of benzene vapor at room temperature. (C) Selectivity of the Ni-NDC MOF-coated sensor toward different analytes. The concentration of benzene is $100 \mathrm{ppm}$, whereas the concentration of the other gases is 1000 ppm. This figure was adapted with permission from ACS Appl. Mater. Interfaces, 2020, 12(32), 36715-36722. Copyright 2020, American Chemical Society.

gases used the solid back-gate architecture, while an FET sensor of aqueous biomolecules would use a liquid gate architecture. There have been few examples of MOF thin films integrated into FET devices. ${ }^{73,74}$ Duan and co-workers have demonstrated for the first time the application of conductive 2D MOFs, in this case Ni-HTTP, as the conducting channel of an FET sensor. ${ }^{75}$ In this work, Ni-HTTP thin films were prepared on the surface of an FET device through an interface-assisted/solvothermal synthesis. Briefly, ozone-treated FET devices are contacted with the liquidair interface of the Ni-HTTP precursor solution and then heated in a water bath at $65{ }^{\circ} \mathrm{C}$ for a set time period. The optimal Ni-HTTP FET device showed excellent FET properties with a charge mobility of $45.4 \mathrm{~cm}^{2} \mathrm{~V}^{-1} \mathrm{~s}^{-1}$ and an on/off current ratio of $2.29 \times 10^{3}$. A liquid gate composed of phosphate buffer solution and a silver reference electrode was placed above the Ni-HTTP FET device in order to sense different concentrations of gluconic acid in solution. As the gluconic acid concentration increased, the FET's conductance decreased and threshold voltage shifted towards more negative gate voltages, thus demonstrating the potential for a MOF-based FET sensor device.

\subsection{Device integration considerations for electrical sensors}

Defects in MOF film quality such as cracks, inhomogeneity, and poor substrate adhesion can lead to device-to-device variation in electrical properties (e.g. resistance, capacitance), limited device lifetime, and leakage current in the case of alternating current (AC) chemicapacitors. ${ }^{54,58}$ Moreover, as device miniaturization continues apace, fine area control becomes important for the integration of MOF thin films into devices, especially when incorporating electrically conductive MOF thin films. ${ }^{8}$ Thus, more sensitive and controllable synthetic methods such as SAM-directed $\mathrm{LbL}^{76}$ and metal oxide templating are crucial for the realization of MOF-based electrical sensors.

\section{Optical MOF thin film sensors}

Optical sensors utilizing MOF thin films offer many advantages, from low equipment costs, rapid response times, and recyclability.
Consequentially, it is anticipated that this sensor class will continue to receive significant attention, particularly for the detection of various gases. MOF-based optical sensors rely on changes to the MOF's photofunctional properties (e.g. reflectance, ${ }^{77}$ refractive index (RI) ${ }^{78}$ absorbance, ${ }^{79}$ photoluminescence, ${ }^{13,80-83}$ etc.) in response to interaction with variables of interest, such as ions, gases, and temperature. ${ }^{84,85}$ Photofunctionality can be introduced into MOF thin films through a variety of ways: ${ }^{86}$ the use of chromophoric organic linkers within the MOF structures ${ }^{87}$ optically-active metal centers (particularly emissive lanthanides) ${ }^{88}$ or via host-guest interactions, in which photoactive ions, ${ }^{89,90}$ metal complexes, ${ }^{91,92}$ molecules ${ }^{93-96}$ nanoparticles, ${ }^{97-100}$ and/or other species are encapsulated by the MOF. MOF-based optical sensors are intriguing because they typically exhibit rapid response times (often on the order of seconds), ${ }^{101-104}$ high sensitivity (ppb or lower LOD), ${ }^{103,105,106}$ recyclability (via removal of analyte from the MOF after each sensing cycle), ${ }^{103,104,107-109}$ and usually can be integrated with inexpensive, portable equipment, ${ }^{90}$ such as fiber optic-based platforms. ${ }^{104,110,111}$ Indeed, many optical sensors allow for naked-eye detection of analytes and require only simple laser pointers, light-emitting diodes, UV lamps, or other portable excitation sources for operation. ${ }^{103,112,113}$ Thus, provided MOF films can be tailored to be sufficiently selective for analytes of interest for "real-world" deployment, ${ }^{114}$ optical sensors represent a powerful platform for detecting a wide range of analytes. In this section, we describe optical sensing mechanisms, materials, strategies, and techniques using MOF thin films. Table 3 is included here to summarize important parameters from a range of thin-film based-optical sensing studies, with additional details and examples provided in subsequent sections.

\subsection{Luminescence-based sensors}

3.1.1 Luminescent sensor readouts. MOF materials may emit energy in the form of light upon excitation from a range of sources: incident light (photoluminescence) ${ }^{115}$ heat (thermoluminescence), ${ }^{116}$ electric current (electroluminescence), ${ }^{117}$ chemical reactions (chemiluminescence),${ }^{118}$ mechanical stress 
Table 3 Summary of analytes detected using MOF thin films and optical techniques

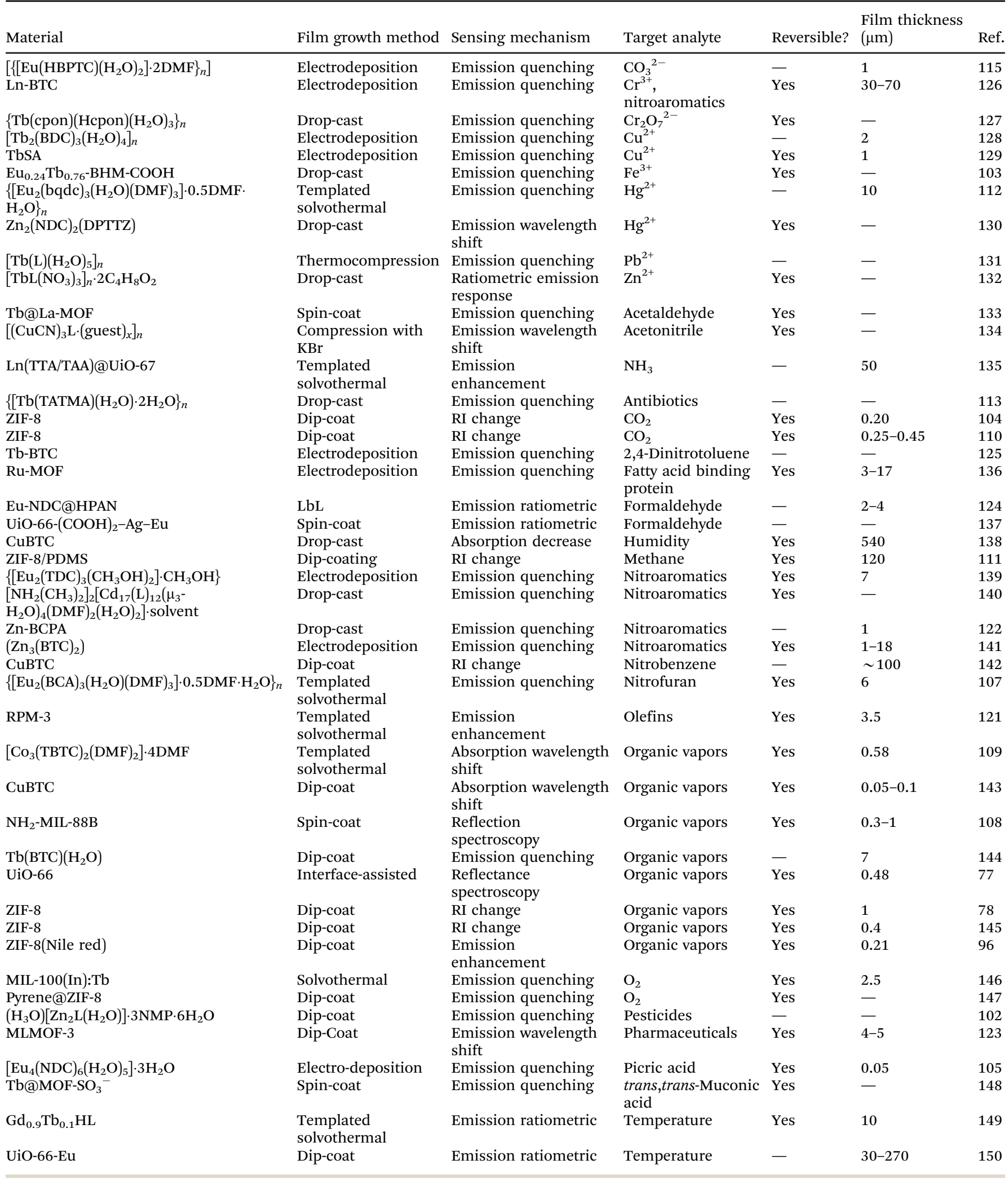

(mechanoluminescence), ${ }^{119}$ and ionizing radiation (radioluminescence $)^{120}$ are all examples of stimuli capable of producing a luminescent response. The luminescent signal may change in a variety of ways in the presence of target analytes: the emission intensity may be enhanced, ${ }^{96,121}$ reduced (quenched), ${ }^{122}$ or the emission energy may shift. ${ }^{123}$ In some cases, two separate 


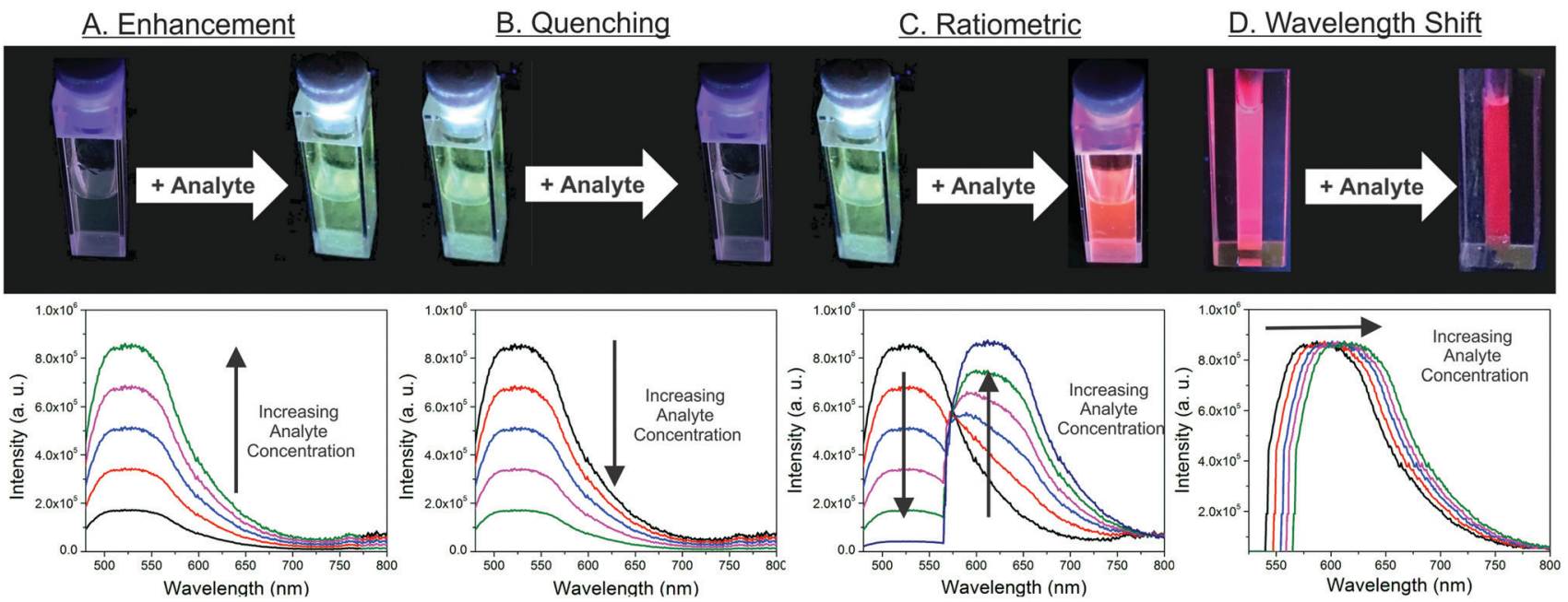

Fig. 6 Summary of steady-state luminescence-based sensing mechanisms. (A) Analyte enhances the sensor emission intensity. (B) Analyte reduces, or quenches, the sensor emission intensity. (C) Analyte enhances the intensity of one emission peak and reduces the intensity of a second peak, producing a change in the intensity ratios between the two peaks. (D) The analyte changes the emission energy of the sensor.

emission peaks may respond to an analyte, and the ratio of the peak areas or intensities may be used for chemical sensing. ${ }^{124}$ Examples of these steady-state sensing mechanisms are summarized in Fig. 6. Additionally, it is also possible to use time-resolved luminescence techniques, in which the emission lifetime changes as a function of analyte concentration. ${ }^{125}$

3.1.2 Design of luminescent MOFs. There are a multitude of strategies that may be employed to impart luminescence to the MOF (Fig. 7). MOFs are often comprised of rigid, aromatic organic linkers that are inherently luminescent. ${ }^{151}$ Highly emissive linkers may be designed by functionalizing chromophores such as pyrene, ${ }^{152}$ naphthalene,${ }^{124,130}$ and anthracene, ${ }^{122}$ among others with groups capable of binding to metal centers (e.g. carboxylates, amines, etc.). ${ }^{86}$ Conversely, MOFs may employ emissive metal centers, often using lanthanide elements, ${ }^{115,128}$ to produce a luminescent response. Terbium and/or europium are

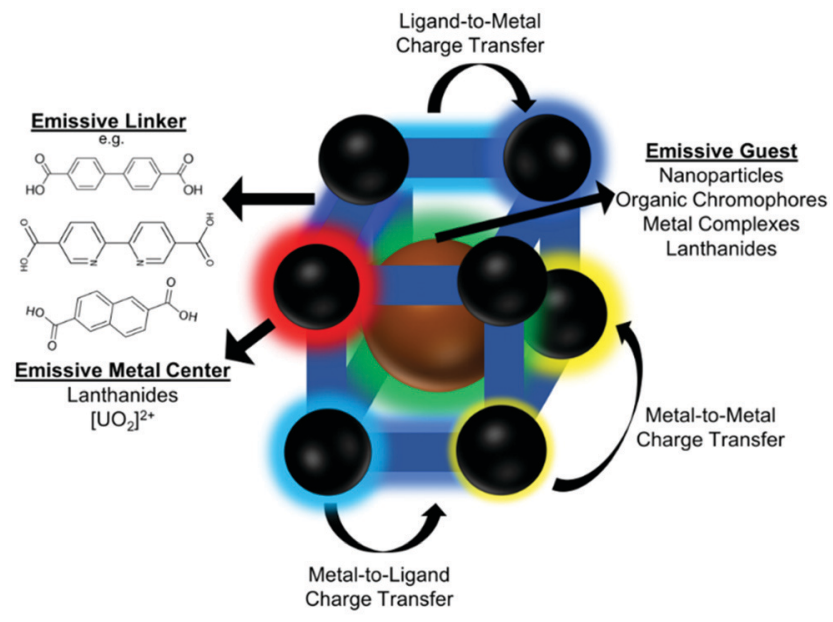

Fig. 7 Summary of methods and processes for the design of luminescent MOFs. most often used due to their intrinsically high quantum yield in the visible emission range (relative to the other lanthanides), ${ }^{153,154}$ while near-infrared (NIR)-emitting MOFs usually incorporate ytterbium, neodymium, and/or erbium. ${ }^{155}$ NIR-emitting MOFs are less commonly used in part due to higher equipment costs for NIR detection; however, emission in this range is optimal for optical fiber and biological applications. ${ }^{155}$ Importantly, while lanthanides produce intense, narrow emission bands that are desirable for sensing applications, the absorption transitions that give rise to this emission are parity forbidden; therefore, sensitizer molecules (such as the linkers used in MOFs) are typically required to first transfer energy to the lanthanide metal centers. ${ }^{90}$ In rare cases, MOFs may also be designed with emissive uranyl $\left[\mathrm{UO}_{2}\right]^{2+}$ centers. ${ }^{156,157}$ It is important to note that the emission observed from MOFs often is not solely from the ligand or the metal, but may often be influenced by charge transfer processes between the ligands and/or metal centers. ${ }^{158}$

In addition to linkers and metal-centers, luminophores may be taken into the MOF pores (e.g. host-guest interactions) to promote luminescence. The luminophore may be added during synthesis for encapsulation ${ }^{136,159,160}$ or using post-synthetic techniques. Post-synthetic uptake of luminophores may be driven by van der Waals forces, ${ }^{161}$ electrostatic interactions (i.e. anionic MOFs encapsulating cations), ${ }^{162,163}$ and/or coordination with unbound functional groups on the linker, ${ }^{164}$ to name a few examples. Common luminescent guests include lanthanides, ${ }^{101,162}$ emissive nanoparticles, ${ }^{159}$ metal complexes, ${ }^{136}$ and organic molecules. ${ }^{147}$

3.1.3 Device integration considerations for luminescent sensing. In general, luminescence-based sensing does not require the MOF to be in thin film form. Indeed, MOFs are most commonly dispersed in solution or used as a dry powder for luminescent sensing. ${ }^{83,84,165,166}$ However, MOFs in thin film form can offer benefits including enhanced emission intensity (due to a reduction in self-quenching) and faster analyte uptake. ${ }^{129}$ 
Furthermore, the use of MOFs in thin film form can offer advantages in terms of portability and recyclability. In many designs, MOF "test strip" films have been developed with sufficiently strong emission that inexpensive, handheld light sources such as laser pointers may be used as the excitation source with detection made by the naked eye. ${ }^{112}$ Several examples of portable luminescent sensing films are displayed in Fig. 8. These films are typically fabricated by deposition on substrates such as glass, ${ }^{128,129,144}$ metal oxides, ${ }^{102}$ and paper, ${ }^{148,167}$ or by dispersing the MOF in glues ${ }^{113}$ and transparent polymers ${ }^{131}$ such as poly(methyl methacrylate). ${ }^{127}$ Additionally, it is often straightforward to reuse immobilized MOF thin films across multiple sensing cycles, whereas MOFs dispersed in solution are typically more difficult to recover and regenerate (Table 4). For example, MOF thin film ion sensors are often regenerated by exposing the film to a chelating agent (e.g. ethylenediaminetetraacetic acid) or fresh solvent. ${ }^{130}$ Portability and recyclability are crucial, practical considerations for minimizing costs and potential commercialization..$^{90}$

3.1.4 Examples of luminescence-based MOF thin film sensors. As shown in Table 3, luminescence-based MOF thin film sensors have been designed to detect a range of analytes,

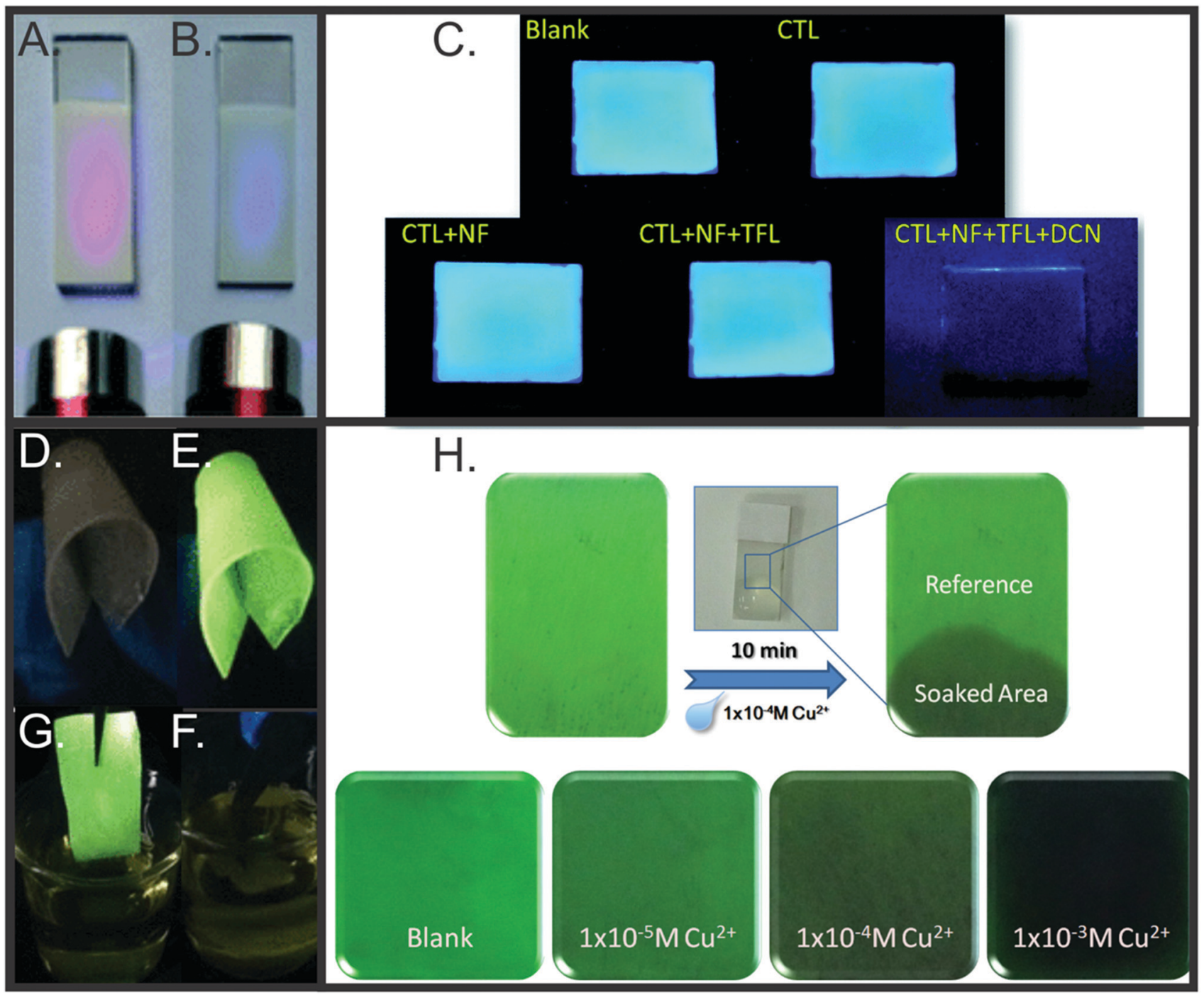

Fig. 8 Examples of portable luminescent sensing MOF films. A mercury $(\|)$ sensor based on a $\left\{\left[\mathrm{Eu}_{2}(\mathrm{bqdc})_{3}\left(\mathrm{H}_{2} \mathrm{O}\right)(\mathrm{DMF})_{3}\right] \cdot 0.5 \mathrm{DMF} \cdot \mathrm{H}_{2} \mathrm{O}\right\}_{n}(\mathrm{BQDC}=2,2-$ biquinoline-4,4-dicarboxylate). Under illumination from a handheld UV light, the MOF film exhibits red Eu-centered emission (A), which is selectivity quenched by mercury ions (B). Reproduced with permission from J. Mater. Chem. A, 2013, 1, 11312-11319. Copyright 2013, Royal Society of Chemistry. (C) A blue-emitting thin film $\left(\mathrm{H}_{3} \mathrm{O}\right)\left[\mathrm{Zn}_{2} \mathrm{~L}\left(\mathrm{H}_{2} \mathrm{O}\right)\right] \cdot 3 \mathrm{NMP} \cdot 6 \mathrm{H}_{2} \mathrm{O}$ under UV light is exposed to various pesticides (100 $\mu \mathrm{L}$ of $0.01 \mathrm{M}$ solutions): chlorothalonil (CTL), nitrofen (NF), trifluralin (TF), and 2,6-dichloro-4-nitroaniline (DCN). Noticeable quenching is observed in the presence of DCN. Reproduced with permission from RSC Adv., 2019, 9, 38469-38476. Copyright 2019, Royal Society of Chemistry. A flexible film of $\left\{\left[T b(T A T M A)\left(\mathrm{H}_{2} \mathrm{O}\right) \cdot 2 \mathrm{H}_{2} \mathrm{O}\right\}_{n}\right.$ dispersed in a gelatinous glue under ambient (D) and UV (E) light. Emission is quenched upon exposure to $0.5 \mathrm{mM}$ of the antibiotic nitrofurantoin (F), with emission restored upon film removal (G). Reproduced with permission from Inorg. Chem., 2019, 58, 7746-7753. Copyright 2019, American Chemical Society. (H) A film of a terbium-succinate MOF under UV light. The MOF emission is gradually quenched with increasing $\mathrm{Cu}^{2+}$ exposure. Reproduced with permission from Sens. Actuators, B, 2015, 220, 779-787. Copyright 2015, Elsevier, Inc. 
Table 4 Strategies for regenerating MOF thin films for optical sensing

Sensing

target Recycling technique

Ions/ Exposure to fresh solvent, ${ }^{103,127,130}$ chelating agent

molecules (e.g. ethylenediaminetetraacetic acid $)^{129}$

Solvents Desolvation (heat/vacuum) ${ }^{134,140}$ drying, ${ }^{133}$ rinsing with fresh solvent ${ }^{105,107,139}$

Gases/vapors Gas purge, ${ }^{104,111,146}$ vacuum $^{147}$

Temperature Temperature change ${ }^{149}$

included gases, ${ }^{146}$ organic vapors, ${ }^{96}$ ions, ${ }^{112}$ explosives, ${ }^{122}$ pharmaceuticals, ${ }^{123}$ and even temperature. ${ }^{149}$

Ion sensors. The rapid, sensitive, and selective detection of ions has utility in a wide range of areas, including prospecting for high-value elements, ${ }^{90}$ identifying heavy metal contaminants in water sources, ${ }^{127,131}$ and medical diagnostics, ${ }^{103,132}$ for example. MOFs may interact with ions through binding sites within the MOF pores, ${ }^{103,131}$ or through electrostatic interactions $^{101}$ (e.g. the use of a cationic MOF to sense anions and anionic MOFs to sense cations). Selective ion detection is often enabled via the inhibition (for "turn off" sensors) or promotion (for "turn on" sensors) of energy transfer states within the MOF upon ion binding. ${ }^{82}$ For example, Yang and co-workers demonstrated that $\mathrm{Cu}^{2+}$ selectively undergoes partial ion exchange with terbium in a terbium-succinate MOF, which disrupts the sensitization of terbium and reduces emission (Fig. 8H). ${ }^{129}$ For "turn off" sensors, insights into the emission quenching mechanism may be gained through a Stern-Volmer analysis of the quenching ${ }^{106,168}$ and through time-resolved studies. ${ }^{169}$

A key challenge is the development of sensors that exhibit a selective emission response only in the presence of a target ion, hence it is crucial for the sensor to be tested on a multitude of potential interferants that may be encountered in "realworld" systems, such as environmental waters and biological matrices. ${ }^{114}$ Therefore, cross-sensitivity studies analyzing the impact of competing ions are crucial to evaluating the sensor efficacy. Examples of such studies for ion sensors are shown in Fig. 9.

Molecule sensors. In addition to detecting ions in solution, MOF thin films may also be used for the luminescence-based detection of a wide range of molecules, such as solvents, ${ }^{124,133}$ biomolecules, ${ }^{136,148}$ and pharmaceuticals. ${ }^{113,123}$ As such, the thin films have potential utility in medical diagnostics, ${ }^{136}$ pollution monitoring, ${ }^{105,124,133}$ and explosives detection, ${ }^{139}$ among others. The sensing considerations for molecules are similar to those described above for ion detection, in that experimentation in environmentally relevant condition and
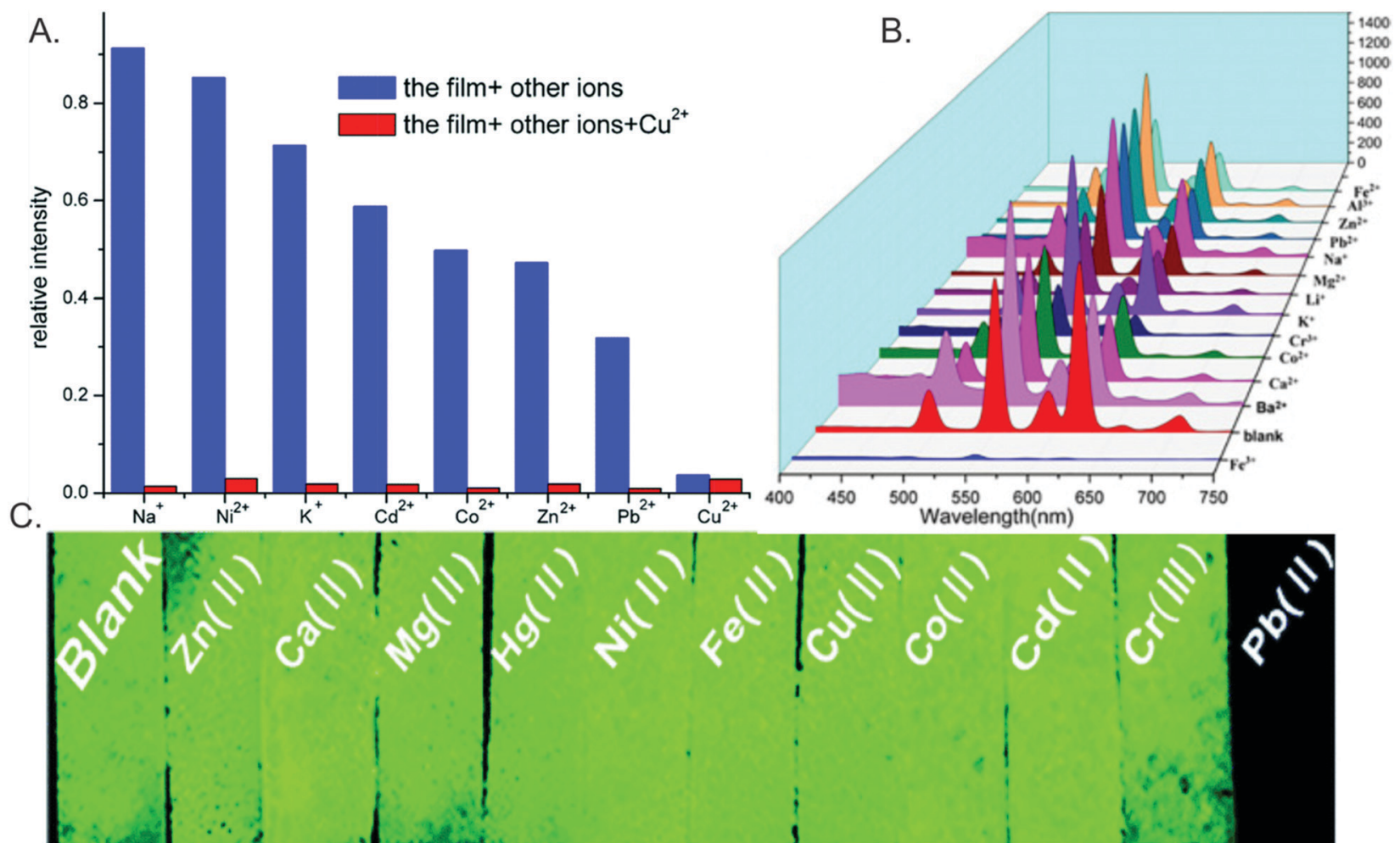

Fig. 9 Examples of interferant studies conducted with luminescent $M O F$ thin film ion sensors. (A) Relative emission intensity from $\left[\mathrm{Tb}_{2}(\mathrm{BDC})_{3}\left(\mathrm{H}_{2} \mathrm{O}\right)_{4}\right]_{n}$ in the presence of $1 \mathrm{mM}$ cation solutions with (red) and without (blue) $\mathrm{Cu}(I)$ added. Reproduced with permission from RSC Adv., $2014,4,58178-58183$. Copyright 2014, Royal Society of Chemistry. (B) Emission spectra of $\mathrm{Eu}_{0.24} \mathrm{~Tb}_{0.76}-\mathrm{BHM}-\mathrm{COOH}$ in the presence of $0.01 \mathrm{M}$ of various cations. Reproduced with permission from Spectrochim. Acta, Part A, 2020, 230, 118084. Copyright 2020, Elsevier, Inc. (C) Image of $\left[T b(L)\left(\mathrm{H}_{2} \mathrm{O}\right)_{5}\right]_{n}$ under UV light in the presence of $1 \mathrm{mM}$ cation solutions. In each example, quenching is most pronounced selectively for the ion of interest. Reproduced with permission from J. Mater. Chem. A, 2017, 5, 10200-10205. Copyright 2017, Royal Society of Chemistry. 
selectivity studies are both critical. A diversity of sensing mechanisms can be observed for molecular targets. For example, an Eu MOF linked by 2,6-naphthalenedicarboxylate (NDC) grown as a thin film on hydrolyzed polyacetonitrile was selectively degraded by formaldehyde (as evidenced by XRD), leading to a ratiometric response in which emission signal from freed NDC was enhanced while Eu emission was quenched. ${ }^{124}$ Conversely, a lanthanum MOF with encapsulated Tb ions (Tb@La-MOF) exhibits selective quenching from acetaldehyde exposure without undergoing any structural change. Rather, quenching is observed because an acetaldehyde absorption band overlaps with the Tb@La-MOF excitation band, ${ }^{133}$ and this competitive absorption mechanism has been exploited for other MOF thin-film sensors as well (Fig. 10). ${ }^{105,139,148}$

In addition to quantitatively detecting individual compounds, MOF thin film sensors have also been designed to distinguish analytes of interest by monitoring responses to multiple
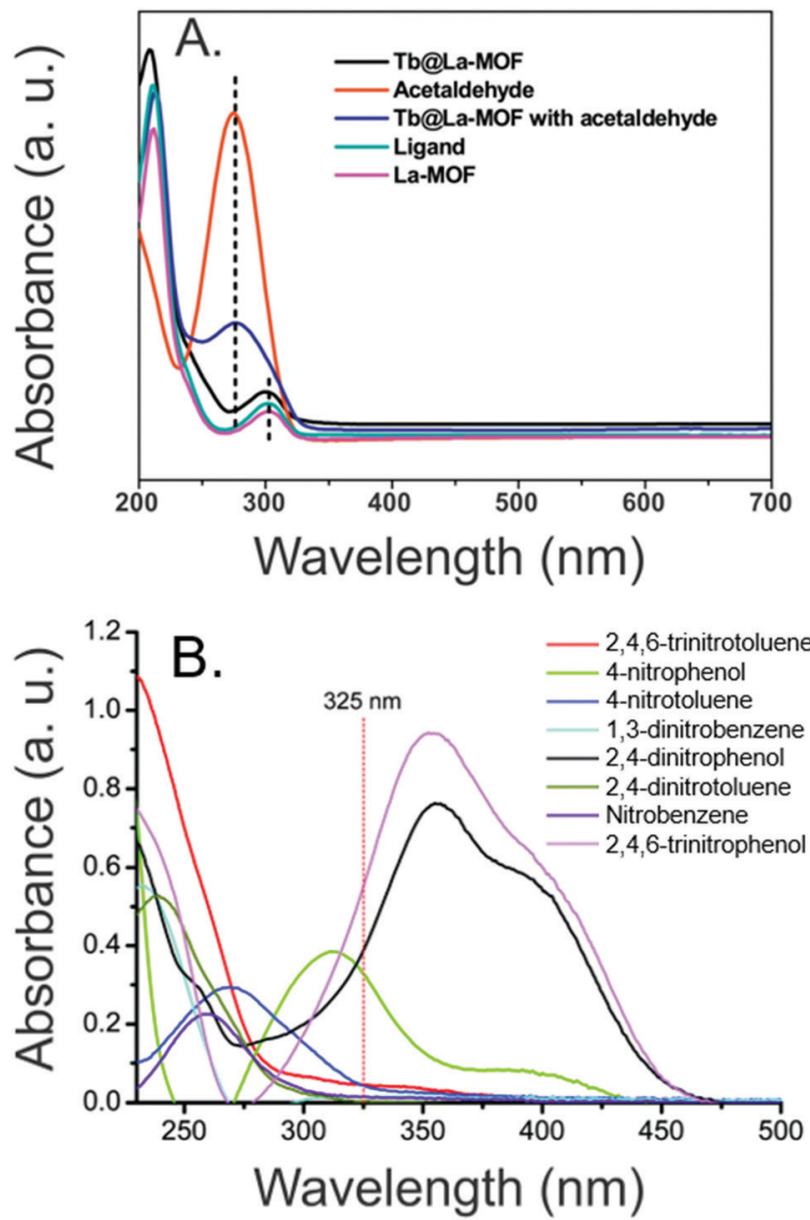

Fig. 10 Examples of competitive absorption quenching mechanisms for "turn-off" sensors of molecules. (A) Absorption bands of acetaldehyde overlaps strongly with the excitation band of TbaLa-MOF, causing a selective reduction in emission. Reproduced with permission from Sens. Actuators, B., 2019, 300, 126985. Copyright 2019, Elsevier, Inc. (B) An Eu-TDC MOF selectively detects nitrophenols over other nitroaromatic compounds due to competitive absorption at $325 \mathrm{~nm}$. Reproduced with permission from Analyst, 2016, 141, 4502-4510. Copyright 2016, Royal Society of Chemistry. emission peaks. For example, a MOF thin film containing both $\mathrm{Tb}$ and Eu was developed for distinguishing different pharmaceutical molecules by comparing changes in the intensity ratios of the $\mathrm{Tb}$ and Eu peaks following exposure to each molecule (Fig. 11A). ${ }^{123}$ Similarly, alterations in observed emission color can be used as a visual indicator of the concentration of a single analyte. For example, a thin film of Tb encapsulated by a zinc, 2-sulfonylterephthalate, and 4,4-bipyridine based MOF (MOF$\mathrm{SO}_{3}{ }^{-}$) on test paper exhibits distinct color changes in the presence of the benzene biomarker trans,trans-muconic acid. This effect is due to quenching of both the Tb and MOF emission peaks, thus providing a pathway towards rapid diagnostics (Fig. 11B). ${ }^{148}$

Gas/vapor sensors. MOF thin films may also be employed as luminescent sensors in the gas phase. Often, guest ions/molecules within the MOF pore are used to ensure a selective response upon interaction with target gasses, producing a range of innovative sensing mechanisms. Sensitive sensors for oxygen have been developed based upon the quenching of emission from terbium ${ }^{146}$ and pyrene ${ }^{147}$ within MOF hosts. An Eu-functionalized UiO-67 MOF exhibited selective emission enhancement in the presence of ammonia vapors. This enhancement was attributed to hydrogen bonding between the $\mathrm{NH}_{3}$ gas and the MOF linker, which increased the linker triplet state energy and facilitated energy transfer to the Eu (Fig. 12A). ${ }^{135}$ Similarly, a dual-emissive UiO MOF (zirconium linked with 1,2,4,5-benzenetetracarboxylate) was functionalized with $\mathrm{Ag}$ and $\mathrm{Eu}$ ions for formaldehyde sensing. When Eu alone

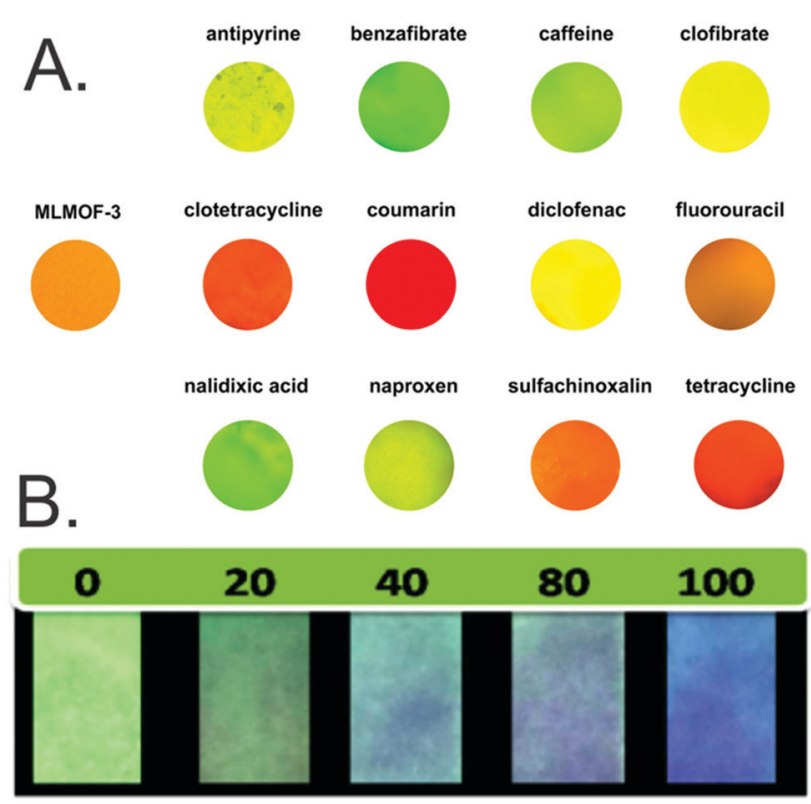

Fig. 11 (A) A Tb/Eu mixed lanthanide MOF thin film that provides a visual method for distinguishing various antibiotic molecules. Reproduced with permission from Sens. Actuators, B, 2018, 257, 931-935. Copyright 2018, Elsevier, Inc. (B) A test paper with a thin film of $\mathrm{Tb}\left(\mathrm{MOF}-\mathrm{SO}_{3}{ }^{-}\right.$that provides a visual method for rapidly quantifying between $0-100 \mathrm{ppm}$ of trans, trans-muconic acid. Reproduced with permission from Inorg. Chem., 2018, 57, 7815-7824. Copyright 2018, American Chemical Society. 

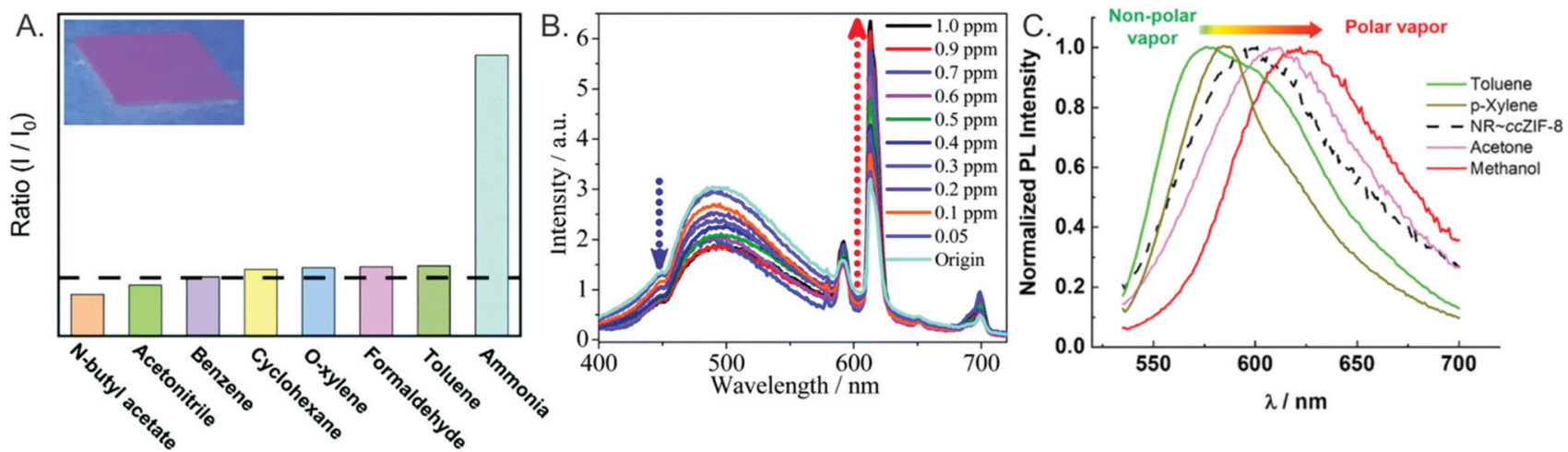

Fig. 12 Examples of luminescent MOF thin film vapor sensors. (A) Interaction between ammonia and the linker of an Eu-functionalized UiO-67 MOF leads to enhanced Eu emission (inset: Eu@UiO-67 under $310 \mathrm{~nm}$ light). Reproduced with permission from Dalton Trans., $2020,49,15663-15671$. Copyright 2020, Royal Society of Chemistry. (B) Incorporation of Eu and Ag ions into the pores of a UiO MOF produces a ratiometric response upon formaldehyde interaction with Ag. Reproduced with permission from Nanoscale, 2016, 8, 12047-12053. Copyright 2016, Royal Society of Chemistry. (C) A thin film of Nile Red dye@ZIF-8 exhibits vapor-chromic luminescence upon vapor absorption. Reproduced with permission from Adv. Opt. Mater., 2020, 8, 2000961. Copyright 2020, John C. Wiley \& Sons, Inc.

is in the MOF, only Eu emission is observed. The presence of $\mathrm{Ag}^{+}$decreases the energy transfer between the MOF and the $\mathrm{Eu}$, enabling emission peaks from both $\mathrm{Eu}$ and the MOF to be observed. Upon formaldehyde interaction with $\mathrm{Ag}$, a ratiometric response occurs in which the Eu peak is enhanced and the MOF peak is quenched (Fig. 12B). ${ }^{137}$ Nile red dye embedded in a ZIF-8 thin film exhibits a vapor-chromic luminescence response in which non-polar vapors induce a blueshift in the emission wavelength and more polar vapors induce a red-shift. Importantly, the use of a MOF matrix (relative to Nile Red embedded on a thin film of polystyrene beads) enhanced the sensor sensitivity due to greater interfacial area for vapor interactions (Fig. 12C). ${ }^{96}$

\subsection{Absorbance-based sensors}

3.2.1 Absorbance sensor readout. A range of MOF thin films have been developed that exhibit selective changes to its absorbance spectrum upon analyte interaction. Readouts may include changes in the absorption, ${ }^{138}$ transmission, ${ }^{104}$ or reflectance spectrum. ${ }^{108}$ The readout mechanisms shown in Fig. 6 are also applicable here: peaks may gain or lose intensity as a function of analyte interaction, or may shift in energy. The underlying mechanism for these changes in the optical spectrum are often driven by RI changes ${ }^{77,78,104,108,111,145}$ and/or changes in the coordination environment of MOF metal centers. ${ }^{109,138}$ As with luminescent-based sensors, absorbance sensors exhibit desirable characteristics such as the ability to use relatively low-cost, portable equipment, ${ }^{104}$ recyclability, ${ }^{78,104,110}$ and rapid response times. ${ }^{111,143}$ Examples of sensor readouts are shown in Fig. 13.

3.2.2 Design of absorbance-based MOF thin film sensors. The design rules for absorbance-based MOF thin films are generally simpler than those in the development of luminescent MOFs. The encapsulation of optically-active guest molecules is less common for absorbance sensors. Instead, absorption peaks arising from aromatic ligands or d-band transitions in transition metal centers typically provide the needed optical response. ${ }^{104,109,138}$ For sensors relying upon RI changes, designing MOFs with the
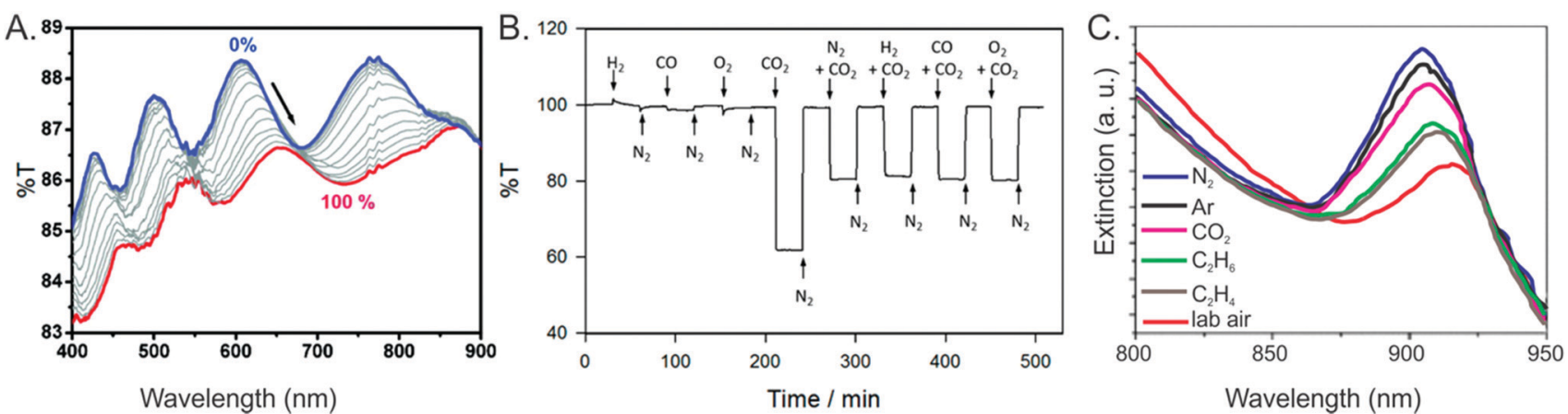

Fig. 13 Examples of typical readouts used in absorbance-based MOF thin film sensors. (A) A Fabry-Pérot device uses ZIF- 8 thin films to detect propane vapor (0\% to $100 \%$ ), detected by tracking shifts in the reflectance interference peaks due to RI changes. Reproduced with permission from J. Am. Chem. Soc., 2010, 132, 7832-7833. Copyright 2010, American Chemical Society. (B) ZIF- 8 film on an optical fiber detects $\mathrm{CO}_{2}$ gas by monitoring changes in the transmission spectra, which are altered due to a change in RI. Reproduced with permission from ACS Sens., 2018, 3, 386-394. Copyright 2018, American Chemical Society. (C) A thin film of CuBTC on silica beads exhibits gas-dependent shifts in its near-infrared extinction, which is dependent upon the amount of gas absorbed as well as the RI. Reproduced with permission from Adv. Mater., 2011, 23, 4449-4452. Copyright 2011, John C. Wiley \& Sons, Inc. 
ability to "breath" (e.g. expand or contract upon gas sorption) enhances sensitivity (vide infra). ${ }^{108,109}$

3.2.3 Device integration considerations for absorbance sensors. Unlike luminescence-based MOF sensors that can often be used in either powder or film form, it is often essential for absorbance-based MOF sensors to be in thin film form. Continued synthetic innovations to improve MOF thin film quality will therefore enable more absorbance-based sensors to be developed, with a corresponding increase in performance. For example, reflection interference peaks (Fabry-Pérot fringes) are often used as a sensor readout, and the number and energies of these peaks are directly influenced by MOF thin film thickness (Fig. 14). ${ }^{77}$ Further, sensor performance is often highly sensitive to film thickness and film quality, as defects lead to increased scattering and poorer performance. ${ }^{104}$ Film thicknesses for this sensor class are typically on the hundreds of nanometer scale, on par with the wavelength of visible light. ${ }^{108}$ MOF thin films for absorbance-based sensing have been grown on a range of substrates, including optical fibers, ${ }^{104,111}$ silicon, ${ }^{77,78,108}$ gratings, ${ }^{145}$ glass, ${ }^{145}$ alumina, ${ }^{109}$ and others.

3.2.4 Examples of absorbance-based sensors. Absorbancebased MOF thin film sensors are generally used to quantitatively detect gases of interest, or to differentiate between gases, a process governed by the RI of each gas as well as the selectivity and capacity of the MOF for each gas. ${ }^{77,108}$ For example, Kim et al. developed a selective, sensitive sensor for $\mathrm{CO}_{2}$ (Fig. 13B) over other gases with similar refractive indices (e.g. $\mathrm{N}_{2}, \mathrm{H}_{2}$, $\mathrm{CO}$ and $\mathrm{O}_{2}$ ) using a $200 \mathrm{~nm}$ ZIF-8 thin film grown directly on an optical fiber core (Fig. 15A-C). Because ZIF-8 exhibits an adsorption capacity for $\mathrm{CO}_{2}$ that is over 10 times higher than $\mathrm{N}_{2}$ and similar gases, $\mathrm{CO}_{2}$ adsorption by ZIF-8 leads to a RI change in the sensing layer, monitored by a decrease in transmission. ${ }^{104}$ Doping ZIF-8 with cobalt provided additional optical features (from $\mathrm{d}-\mathrm{d}$ transitions) in the visible spectra, and the optical fiber platform was found to be significantly more sensitive than measurements conducted on a planar substrate. ${ }^{170}$ Similarly, a fiber optic platform with ZIF-8 dispersed in polydimethylsiloxane polymer was capable of detecting $1 \%$ methane in $\mathrm{N}_{2}{ }^{111}$ while ZIF-8 growth on an optical fiber long period grating has been used to differentiate organic vapors such as ethanol and methanol. ${ }^{145}$ CuBTC, which has an optical transition near $\sim 700 \mathrm{~nm}$ from $\mathrm{d}-\mathrm{d}$ transitions, has also been integrated onto an optical fiber platform for humidity detection (Fig. 15D). Coordination of water with $\mathrm{Cu}$ leads to a blue-shift in this transmission peak, enabling sensitive water detection of 40 ppb by volume. ${ }^{138}$ Similarly, a nitrobenzene sensor was developed based upon RI changes by gluing a single crystal of CuBTC onto an optical fiber tip. ${ }^{142}$

Other sensing platforms involve growth of the MOF thin film onto planar substrates, with measurements made either visually or using a spectrometer (e.g. Fig. 14). Rather than being used to detect a single analyte, the sensors typically exhibit different responses to different gases. For example, a composite film of CuBTC and silica beads displays gas-dependent extinction shifts in the NIR, where different pure gases produce different wavelengths of maximum intensity (Fig. 13C). ${ }^{143}$ Similarly, a film of $\mathrm{NH}_{2}$-MIL-88B (Fe(III) and 2-aminoterephthalic acid) undergoes gas-dependent changes in its reflectance spectrum, enabling visual differentiation of several different pure gases. ${ }^{108} \mathrm{~A}$ film of UiO-66 demonstrated a similar response to various organic vapors, including ethanol; a selfassembly growth mechanism producing a mesoporous UiO-66 film significantly outperformed a sensor using a dense UiO-66 layer grown solvothermally, highlighting the important role of the MOF growth technique in sensor development. ${ }^{77}$

\section{Acoustic MOF thin film sensors}

Acoustic-based sensors such as QCM and SAW devices have been functionalized with MOF films to great effect. The working principle behind acoustic-based sensors is the relationship between the mass of a piezoelectric crystal and its resonant frequency induced by an alternating electric field. In the case of QCM, small gravimetric changes caused by adsorption on a quartz piezoelectric crystal surface modulate the resonant shear wave frequency across the crystal. This relationship between change in mass $(\Delta m)$ and frequency $(\Delta f)$ is described by the Sauerbrey equation (eqn (1)):

$$
\Delta f=\frac{2 f_{\mathrm{o}}^{2}}{A \sqrt{p_{\mathrm{q}} \mu_{\mathrm{q}}}} \Delta m
$$

in which $f_{\mathrm{o}}$ is the resonant frequency of the quartz piezoelectric crystal, $A$ is the piezoelectrically active crystal area, $p_{\mathrm{q}}$ is the
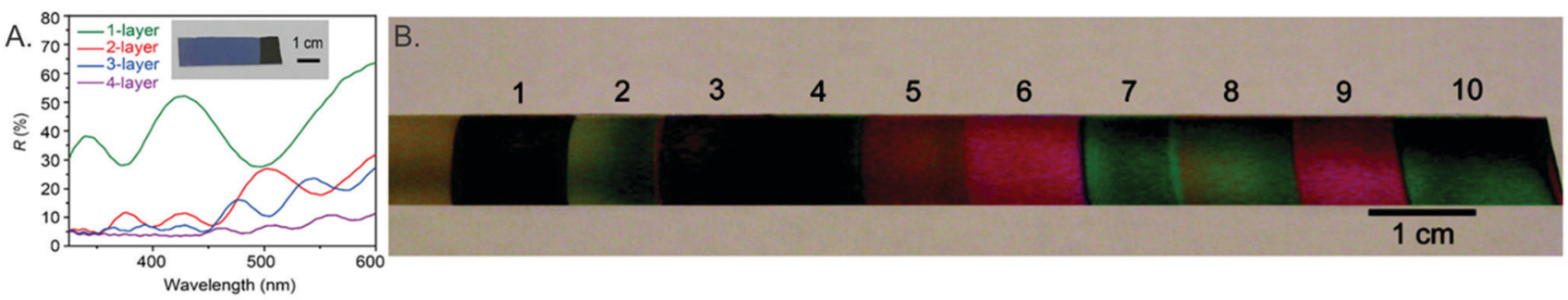

Fig. 14 (A) Evolution of the reflectance spectra of UiO-66 monolayers grown on a silicon substrate (inset: photograph of a single monolayer). Both the number and energies of interference peaks change as a function of the MOF layer thickness. Reproduced with permission from ACS Appl. Mater. Interfaces, 2019, 11, 21010-21017. Copyright 2019, American Chemical Society. (B) Photograph of 1 to 10 layers ( 100 to $1000 \mathrm{~nm}$ ) of ZIF-8 on a silicon substrate. Color changes due to alterations in reflectance are observable to the naked eye. Reproduced with permission from J. Am. Chem. Soc., 2010, 132, 7832-7833. Copyright 2010, American Chemical Society. 
A
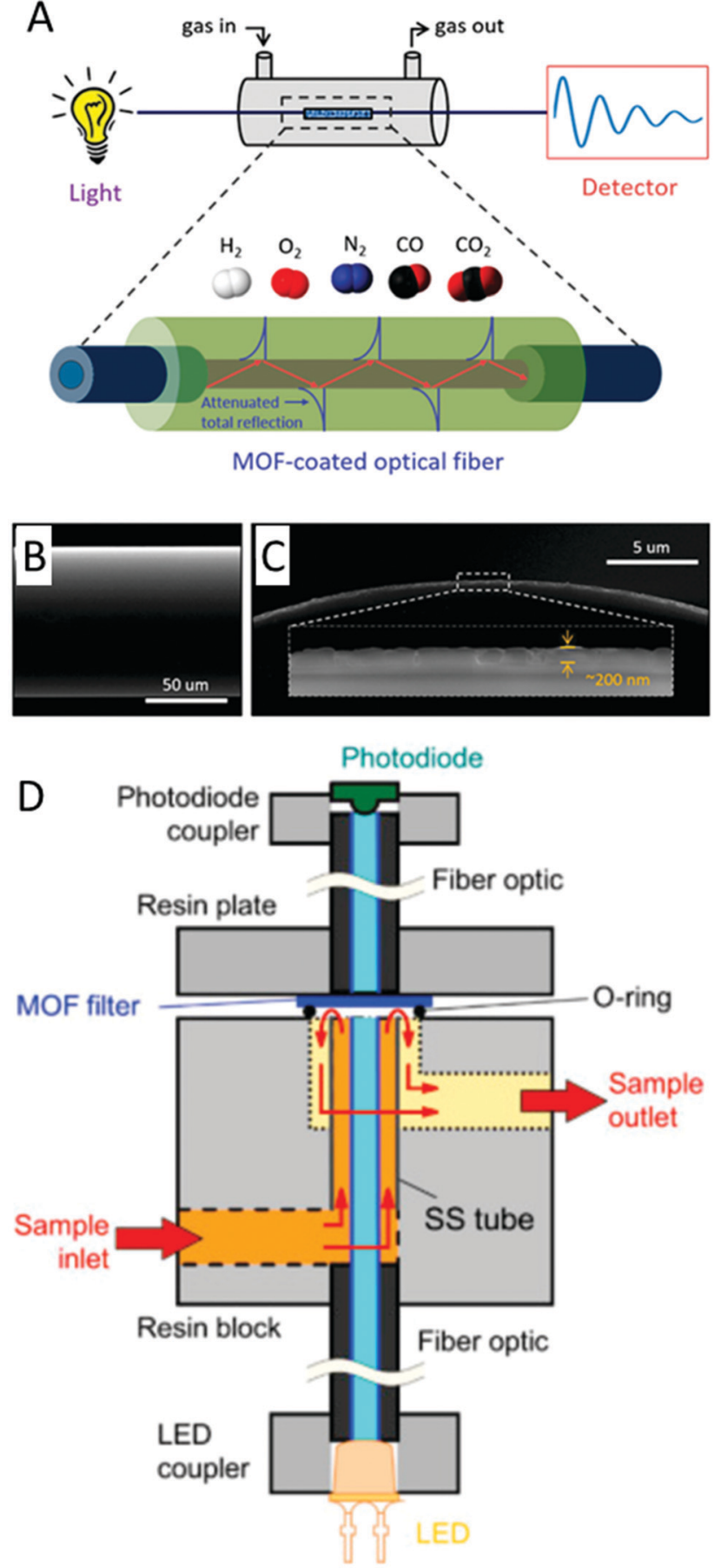

Fig. 15 Examples of fiber optic MOF thin film sensor platforms. (A) A thin coating of ZIF-8 onto an etched optical fiber is used to detect $\mathrm{CO}_{2}$ selectively over competing gases. (B) Side view and (C) cross-section of the optical fiber functionalized by $200 \mathrm{~nm}$ ZIF-8. Reproduced with permission from ACS Sens., 2018, 3, 386-394. Copyright 2018, American Chemical Society. (D) Schematic of a fiber optic humidity sensor using CuBTC as the sensing layer. Reproduced with permission from Anal. Chim. Acta, 2015, 886, 188-193. Copyright 2015, Elsevier, Inc.

density of quartz, and $\mu_{\mathrm{q}}$ is the shear modulus of quartz. In the case of SAW devices, gravimetric changes modulate the surface acoustic wave frequency propagated along the surface of a piezoelectric substrate. Functionalization of these devices with nanoporous materials, including MOF films, has been shown to significantly increase sensitivity and selectivity toward various gases and vapors. One advantage of the excellent correlation between frequency and mass in acoustic-based devices is that it allows gas adsorption isotherm experiments to be performed with thousandfold ( $\mu \mathrm{g} v s$. mg) less MOF material. A conventional $9 \mathrm{MHz}$ QCM sensor can ideally sense mass changes down to the nanogram level, thus modification with a MOF film that concentrates gas molecules on the device surface is a promising avenue for gas detection. MOF thin film acousticbased sensors are summarized in Table 5 .

\subsection{QCM sensors}

Dual layer MOF films wherein a "shell" MOF layer chosen for its molecular sieving effect is grown above a "core" MOF layer chosen for its high gas uptake has been successfully demonstrated on QCM-based sensors. A "Janus" film composed of two different MOFs was shown to significantly improve selectivity toward methanol without diminishing sensitivity. ${ }^{171}$ In this work three films were prepared via LbL growth on a pyridylterminated SAM QCM: $\left[\mathrm{Cu}_{2}(\text { ndc })_{2}(\text { dabco })\right]_{n}$ above $\left[\mathrm{Cu}_{2}(\mathrm{HOOC}\right.$ $\left.\left(\mathrm{CH}_{2}\right)_{2} \mathrm{OCNH}-\mathrm{bdc}\right)\left(\mathrm{NH}_{2} \text {-bdc) }(\text { dabco })\right]_{n}$ (A@C), $\left[\mathrm{Cu}_{2}\left(\mathrm{HOOC}\left(\mathrm{CH}_{2}\right)_{2}{ }^{-}\right.\right.$ OCNH-bdc) $\left(\mathrm{NH}_{2}\right.$-bdc $)($ dabco $\left.)\right]_{n}$ grown above $\left[\mathrm{Cu}_{2}(\mathrm{ndc})_{2}\right.$ $($ dabco $)]_{n}$ (C@A), and a randomly mixed film of $\left[\mathrm{Cu}_{2}(\mathrm{ndc})_{2}\right.$ (dabco $)]_{n}$ and $\left[\mathrm{Cu}_{2}\left(\mathrm{HOOC}\left(\mathrm{CH}_{2}\right)_{2} \mathrm{OCNH} \text {-bdc) }\left(\mathrm{NH}_{2} \text {-bdc }\right)(\text { dabco })\right]_{n}\right.$ (AC). Of the three films, only C@A showed excellent selectivity for methanol and nearly complete exclusion of $n$-hexane from the QCM surface. This selectivity for methanol over hexane is attributed the small polar pores of $\left[\mathrm{Cu}_{2}\left(\mathrm{HOOC}\left(\mathrm{CH}_{2}\right)_{2} \mathrm{OCNH}-\right.\right.$ bdc) $\left(\mathrm{NH}_{2}\right.$-bdc)(dabco $\left.)\right]_{n}$, which prevent the large non-polar hexane molecules from reaching the underlying $\left[\mathrm{Cu}_{2}(\mathrm{ndc})_{2}\right.$ $($ dabco $)]_{n}$ layer. The underlying $\left[\mathrm{Cu}_{2}(\mathrm{ndc})_{2}(\text { dabco })\right]_{n}$ layer has the highest adsorption capacity of the two MOFs, thus sensitivity toward methanol was not diminished. Similar to this work, hierarchical structured core-shell MOF architectures on QCM devices were prepared to achieve highly selective VOC sensors based on size selectivity. ${ }^{172}$ In this work, small pore "shell" MOF films on large pore "core" MOF films, both based on $\left[\mathrm{Zn}_{4} \mathrm{O}(3,5 \text {-dialkylcarboxypyrazolate })_{3}\right]_{n}$ structures, were grown via liquid phase epitaxy (LPE) on QCM devices (Fig. 17). These hierarchical core/shell films were able to selectively adsorb VOC molecules purely based on size while still maintaining high adsorption capacity because of the underlying large pore MOF film. This size exclusion effect was demonstrated with two polar VOCs: methanol and isopropanol. The isotherm of a hierarchical film composed of a small pore shell-layer of $\left[\mathrm{Zn}_{4} \mathrm{O}(3,5-\right.$ dialkylcarboxypyrazolate $\left.)_{3}\right]_{n}$ and a large pore core-layer of $\left.\left[\mathrm{Zn}_{4} \mathrm{O} \text { (3,5-dimethyl-4-carboxypyrazolate }\right)_{3}\right]_{n}$ showed a nearly constant adsorbed amount when the methanol partial pressure was constant and the isopropanol partial pressure was increased. This experiment shows the effectiveness of dual layer MOF films for achieving both molecular sieving and high gas adsorption capacity.

The array approach has been applied to QCM devices in order to discriminate between various gases. The straightforward 
Table 5 MOF thin film acoustic-based sensors

\begin{tabular}{|c|c|c|c|c|c|c|c|}
\hline Material & $\begin{array}{l}\text { Film growth } \\
\text { method }\end{array}$ & Device type & Target analyte & $\begin{array}{l}\text { Sensing range } \\
(\mathrm{ppm} \text { or } \%)\end{array}$ & $\begin{array}{l}\text { Film thick- } \\
\text { ness }(\mu \mathrm{m})\end{array}$ & LOD (ppb) & Ref. \\
\hline CuBTC, MIL-53, CuBPDC & Spray LbL & QCM & VOCs & $1.0-40$ & - & - & 175 \\
\hline Chiral and achiral MOF array & $\mathrm{LbL}$ & QCM & $\begin{array}{l}\text { Chiral/achiral } \\
\text { VOCs }\end{array}$ & $10-100$ & - & - & 176 \\
\hline CuBTC & LbL and LPE & Microcantilever & $\begin{array}{l}\mathrm{H}_{2} \mathrm{O}, \mathrm{MeOH} \\
\text { EtOH, } \mathrm{CO}_{2}\end{array}$ & $\mathrm{~N} / \mathrm{A}$ & 0.1 & - & 187 \\
\hline $\begin{array}{l}{\left[\mathrm{Cu}_{2}(\mathrm{ndc})_{2}(\mathrm{dabco})\right] \mathrm{n} @} \\
{\left[\mathrm{Cu}_{2}\left(\mathrm{NH}_{2}-\mathrm{bdc}\right)_{2}(\mathrm{dabco})\right]_{n}}\end{array}$ & $\mathrm{LbL}$ & QCM & MeOH, hexane & $5-100 \%$ & 0.05 & - & 171 \\
\hline CuBTC, MOF-5 & LbL & QCM & VOCs & $100-1000$ & 0.5 & $\begin{array}{l}1000 \\
\text { (toluene) }\end{array}$ & 189 \\
\hline $\begin{array}{l}{\left[\mathrm{Zn}_{4} \mathrm{O}(3,5-\right.} \\
\left.\text { dialkylcarboxypyrazolate })_{3}\right]_{n} \text {-based } \\
\text { core-shell }\end{array}$ & $\mathrm{LbL}$ & QCM & VOCs & $1-100 \%$ & - & - & 172 \\
\hline MIL-53 & Solvothermal & QCM & Hexane & $3-40 \%$ & 3 & - & 190 \\
\hline MIL-101 & $\begin{array}{l}\text { Langmuir- } \\
\text { Blodgett }\end{array}$ & QCM & $\mathrm{CO}_{2}$ & $20-100 \%$ & 0.05 & - & 20 \\
\hline MIL-96(Al) & $\begin{array}{l}\text { Langmuir-Blod- } \\
\text { gett/Schaefer }\end{array}$ & QCM & $\mathrm{CO}_{2}$ & $20-100 \%$ & 0.2 & - & 186 \\
\hline$[\mathrm{Al}(\mathrm{OH})(1,4-\mathrm{NDC})]$ & Drop-cast & QCM & Pyridine vapor & $0.3-25$ & - & 40 & 183 \\
\hline KAUST-7, KAUST-8 & Spin-coat & QCM & $\mathrm{SO}_{2}$ & $5-150$ & 2 & 5000 & 184 \\
\hline MIL-101 & Drop-cast & QCM & VOCs & $5-700$ & 3 & $\begin{array}{l}1603 \\
\text { (pyridine) }\end{array}$ & 185 \\
\hline MOF-14 & Drop-cast & QCM & Benzene & $0.5-10$ & - & 150 & 191 \\
\hline $\begin{array}{l}{\left[\mathrm{Cu}_{3}(4-(2 \text {-carboxyphenoxy)- }\right.} \\
\text { isophthalic acid })]\end{array}$ & & QCM & Humidity & $20-96.7 \% \mathrm{RH}$ & - & - & 192 \\
\hline CAU-1 & N/A & QCM & Methanol & $32-128$ & - & - & 193 \\
\hline MIL-101 & Drop-cast & QCM & Formaldehyde & $2-700$ & 3 & 1790 & 194 \\
\hline PIZA-1 & Spray LbL & QCM & Benzene & N/A & $0.340-0.732$ & - & 195 \\
\hline ZIF-8 & LPE & QCM/SAW & $\mathrm{CO}_{2}, \mathrm{CH}_{4}$ & $\begin{array}{l}1-100 \%, 20- \\
100 \%\end{array}$ & 0.3 & - & 180 \\
\hline $\mathrm{Cu}_{2}(\mathrm{ndc})_{2}(\mathrm{dabco})$ & $\begin{array}{l}\text { Metal oxide } \\
\text { template }\end{array}$ & QCM & $\mathrm{CO}_{2}$ & $5-100 \%$ & 0.6 & - & 196 \\
\hline MFU-4, MFU-4l & Solvothermal & SAW & $\mathrm{CO}_{2}$ & $1 \mathrm{ppm}-100 \%$ & 0.2 & 1000 & 179 \\
\hline ZIF-8/ZIF-67 & Spin-coat & SAW & $\begin{array}{l}\text { Acetone, etha- } \\
\text { nol, } \mathrm{NH}_{3}\end{array}$ & $5-25$ & - & $\begin{array}{l}1100,500, \\
1600\end{array}$ & 181 \\
\hline CuBTC & $\mathrm{LbL}$ & SAW & Humidity & $3-14800$ & 0.2 & 280 & 197 \\
\hline $\mathrm{UiO}-66-\mathrm{NH}_{2}$ & Spray-coat & $\begin{array}{l}\text { Magnetoelastic } \\
\text { resonator }\end{array}$ & Toluene & $3728-8869$ & 15 & - & 246 \\
\hline
\end{tabular}

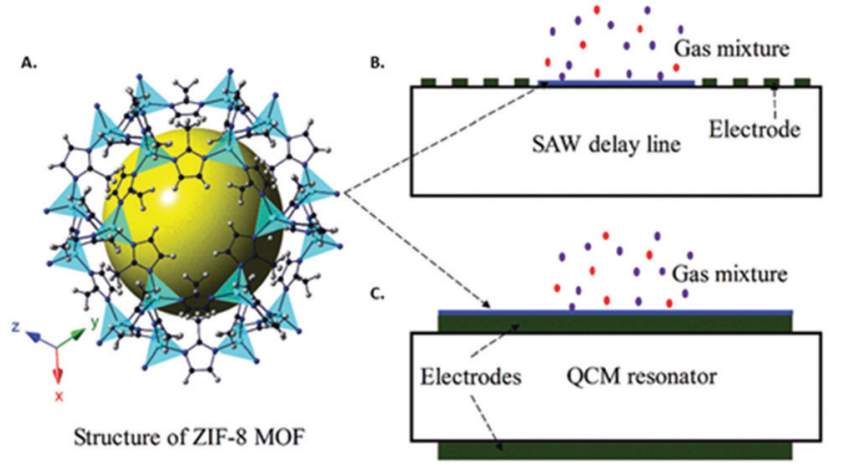

Fig. 16 Schematic of (A) a ZIF-8 crystal and its films applied to (B) SAW and (C) QCM transducers. This figure was adapted with permission from Nanoscale, 2018, 10, 8075-8087. Copyright 2018, Royal Society of Chemistry.

transduction pathway for QCM, whereby the gas uptake for the partial pressure of a particular gas is directly related to the change in acoustic frequency via the Sauerbrey equation, has allowed for various mathematical investigations into theoretical MOF QCM arrays. ${ }^{173,174}$ In one of these mathematical studies, a priori data of the gas adsorption properties for individual MOFs, as determined by molecular modelling and simulation, are used to curate the ideal MOF selection for sensor arrays. ${ }^{173}$ One experimental example of a QCM array composed of three different surfacemounted MOF (SURMOF) thin films (CuBTC, Cu-benzene dicarboxylate, and Cu-biphenyl dicarboxylate) was applied toward the discrimination of different volatile plant oil odors. ${ }^{175}$ This 3 SURMOF QCM array, in combination with k-nearest neighbour analysis algorithms, was able to discriminate between six VPOs and their binary mixtures with nearly 100\% accuracy. Another work constructed a QCM array of 3 chiral MOF and 3 achiral MOFs in order to discriminate between enantiomers of various odor molecules (Fig. 18). ${ }^{176}$ Interestingly, the chiral MOFs could discriminate between isomer pairs, whereas the achiral MOF devices showed identical responses to isomer pairs. Combination of the chiral and achiral MOF devices into a six-device array led discrimination of five enantiomeric molecule pairs with $96 \%$ average accuracy.

\subsection{SAW sensors}

MOF thin films have been grown on SAW-based sensors as a sensitizing material for various gas sensing applications. In the case of QCM devices, a shear acoustic wave is propagated through the piezoelectric quartz crystal such that only 
A.

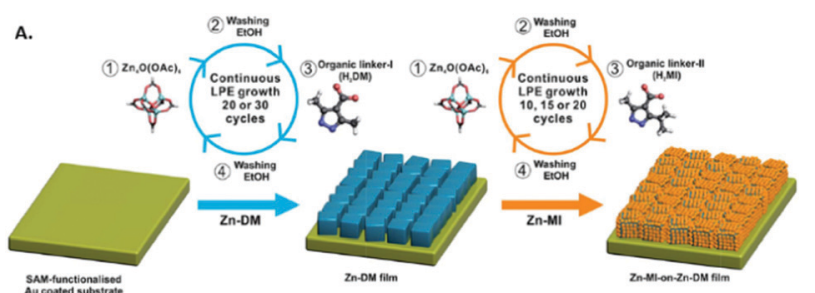
SAM-tunctionalisoc
Au costed substrate
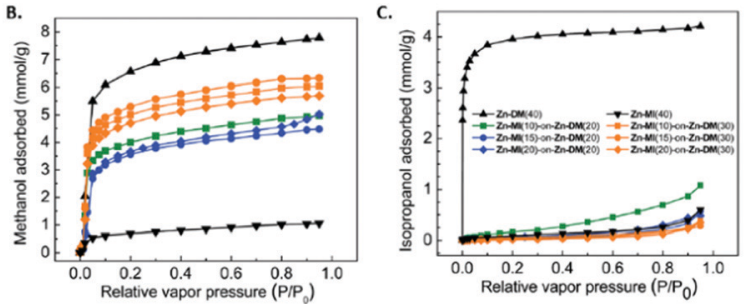

Fig. 17 Hierarchical structuring of MOF thin films on QCM substrates for selective adsorption. (A) Schematic illustration of the continuous stepwise $\mathrm{LPE}$ fabrication of heterostructured $\left.\left[\mathrm{Zn}_{4} \mathrm{O} \text { (carboxypyrazolate) }\right]_{n}\right]_{n}$ thin films, wherein the core-layer MOF is composed of $\mathrm{Zn}$-DM and the shell-layer MOF is composed of $\mathrm{Zn}-\mathrm{MI}$. Single-component (b) methanol and (c) isopropanol adsorption isotherms at $25{ }^{\circ} \mathrm{C}$ for $\mathrm{Zn}-\mathrm{MI}, \mathrm{Zn}-\mathrm{DM}$ and various $\mathrm{Zn}-\mathrm{MI}(x)$-on-Zn-DM(y) heterostructured films using an environmentalcontrolled QCM. Note that $x$ and $y$ represent the number of deposition cycles for $\mathrm{Zn}-\mathrm{Ml}$ and $\mathrm{Zn}-\mathrm{DM}$, respectively. This figure was adapted with permission from J. Mater. Chem. A, 2015, 3, 23385-23394. Copyright 2015, Royal Society of Chemistry.

gravimetric changes on the sensing material affect changes in acoustic frequency. In contrast, the acoustic wave in SAW devices runs along the surface of the device and is thus affected by different properties of the sensing material besides gravimetric changes, such as roughness and conductivity. While this adds a complicating factor to SAW in comparison to QCM, SAW devices have the advantage of operating at frequencies 2 to 3 orders of magnitude greater than QCM devices. This higher operating frequency of SAW devices results in increased sensitivity towards gravimetric changes. For example, a ZIF-8 thin film-coated SAW device that operated at a resonant frequency of $860 \mathrm{MHz}$ displayed four times greater sensitivity toward $\mathrm{CO}_{2}$ than a similar ZIF-8 thin film-coated SAW device that operated at a resonant frequency of $430 \mathrm{MHz} .^{177}$

For the reasons mentioned above, thin and uniform sensitizing films are required for SAW-based gas sensors. Therefore, any incorporation of a MOF sensitizing layer must utilize synthetic methods that produce well-controlled thin films on areas typically smaller than $1 \mathrm{~cm}^{2}$. For example, a LbL method was shown to grow dense "nbo" topology MOF thin films (100-200 nm) on the surface of SAW devices with good mechanical coupling. ${ }^{178}$ These MOF thin film SAW devices were applied toward organic vapor sensing. In another work, a solvothermal method, in conjunction with a small PDMS reaction chamber deposited on the SAW device, was used to grow a thin film of $200 \mathrm{~nm}$ MFU-4 NPs. ${ }^{179}$ The high sensitivity and fast response time of SAW devices made it feasible to perform gas uptake kinetic experiments at different temperatures and to determine the activation energies for a series of different gas uptakes. Liquidphase epitaxy has been used to directly grow a ZIF-8 thin film on

A.
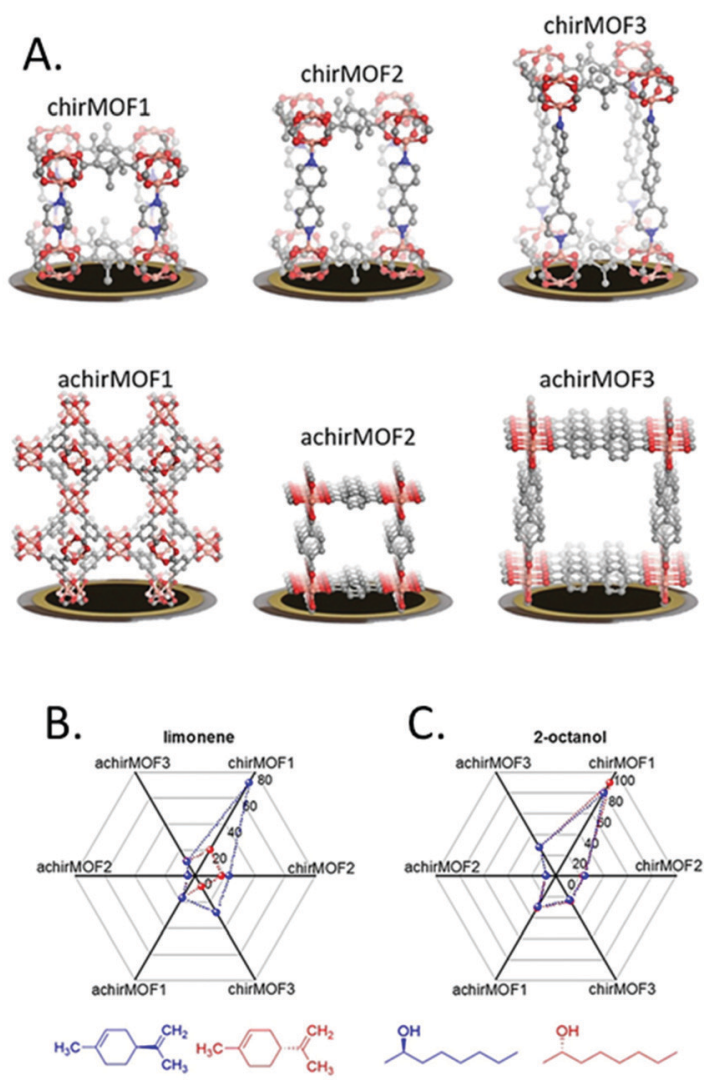

$\mathrm{OH}$
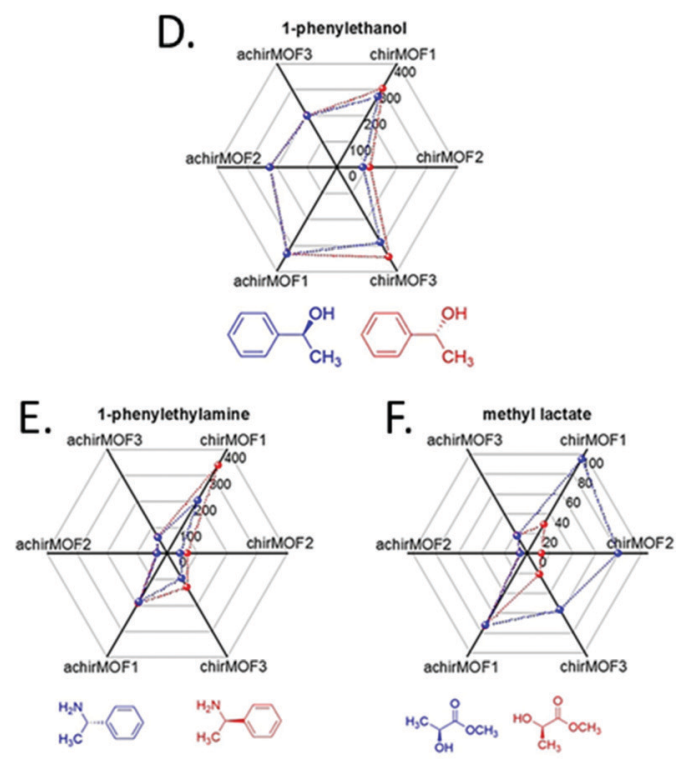

Fig. 18 Enantioselective e-nose array prepared with chiral and achiral MOFs. (A) Chiral (top) and achiral (bottom) MOF structures coating the QCM sensors of the e-nose. The term chirMOF1 denotes $\mathrm{Cu}_{2}(\mathrm{DCam})_{2}$-(dabco), chirMOF2 is $\mathrm{Cu}_{2}(\mathrm{DCam})_{2}(\mathrm{BiPy})$, chirMOF3 is $\mathrm{Cu}_{2}(\mathrm{DCam})_{2}-(\mathrm{BiPyB})$, achirMOF1 is CuBTC, achir-MOF2 is $\mathrm{Cu}(\mathrm{BDC})$, and achir-MOF3 is $\mathrm{Cu}(\mathrm{BPDC})$. Radar plots of the sensor response to the exposure of $(B)(R)$ - and $(S)$-limonene, $(C)(R)$ - and $(S)$-2octanol, (D) (R)- and (S)-1-phenylethanol, (E) (R)- and (S)-1-phenylethylamine, and $(F)$ methyl $(R)$ - and $(S)$-lactate. The $R$-enantiomers are plotted in red, $S$-enantiomers are plotted in blue. The concentration is $50 \mathrm{ppm}$. The axes of the radar plots are the negative values of the recorded frequency shifts in $\mathrm{Hz}$ at the end of each uptake period, averaged over 40 points. These values correspond to the averaged maximum signals. This figure was adapted with permission from Angew. Chem., Int. Ed., 2021, 60(7), 3566-3571. Copyright 2021, John C. Wiley and Sons, Inc. 
the surface of a $\mathrm{Y}-\mathrm{Z} \mathrm{LiNbO}_{3} \mathrm{SAW}$ device for the detection of $\mathrm{CO}_{2}$ and $\mathrm{CH}_{4} \cdot{ }^{180}$ Interestingly, the same difference in $\mathrm{CO}_{2}$ and $\mathrm{CH}_{4}$ adsorption isotherms for bulk ZIF-8 was reflected in the sensitivity difference of ZIF-8 thin film-coated SAW devices towards these gases. A type of SAW device called Love-wave devices are less affected by roughness or defectiveness of the sensing layer because a low propagation velocity guiding layer $\left(\right.$ e.g. $\left.\mathrm{SiO}_{2}\right)$ is deposited above the piezoelectric material (e.g. quartz), thus limiting direct interaction between the acoustic wave and the sensing material. Therefore, the use of more rapid but less precise methods such as spin-coating can be used to deposit MOF films. In one example, an array of Love-wave devices spin-coated with ZIF type MOF NPs were used to discriminate between various breath biomarkers such as $\mathrm{NH}_{3}$, acetone, and ethanol. ${ }^{181}$

\subsection{Device integration considerations for acoustic sensors}

For QCM, the thickness of the MOF film is proportional to the sensitivity enhancement; however, past a certain thickness the correlation between mass change and frequency change (see Sauerbrey equation) no longer applies. MOF thin films are required for SAW devices since surface acoustic waves decay exponentially perpendicular to the surface.

MOF thin films have been grown or deposited on acoustic sensing devices using a variety of methods previously discussed. Similar to electrical sensing devices, methods such as drop-casting and spin-coating have been used to deposit thick films of MOF particles and nanoparticles on acoustic devices. ${ }^{181-185}$ However, like electrical devices, thick film deposition methods can lead to nanoparticle agglomeration, which causes a loss in surface area and a consequent loss in sensitivity. The large planar dimensions of QCM devices make them well-suited for depositing thin films through the LangmuirBlodgett (LB) or Langmuir-Schaefer (LS) method, wherein monolayers of MOF NPs at the solution-air interface are deposited on the quartz substrate. ${ }^{20,186}$ The substrate orientation for LB is perpendicular to the solution surface, whereas the substrate orientation for LS is parallel to the solution surface. The gold electrodes on QCM devices provide a surface for SAM growth, which has been used to grow MOF thin films through LbL methods. ${ }^{171,187-189}$ Unlike QCM devices, which can function with thick sensing films, the superficial nature of SAWs requires the
MOF sensing film on SAW devices to be thin (i.e. hundreds of nanometers). ${ }^{177,179,180}$ Fig. 16 shows schematics of a ZIF-8 film on a QCM and SAW device.

\section{Outlook and future directions}

\subsection{Composite MOF materials}

An exciting aspect of MOFs is that they can easily be integrated with a variety of other materials. Indeed, as discussed in Section 3, optical sensors have been developed by exploiting host-guest interactions within the MOF, where lanthanide ions or dyes are used as the sensing material within a MOF scaffold. Beyond dyes or ions, sensors can be designed by combining MOFs with other materials that exhibit unique optical ${ }^{198,199}$ or physical $^{200}$ properties, $^{201,202}$ in which MOF pore functionalities tune selectivity while the second material provides a sensing response. Indeed, a range of MOF thin film composite materials have been developed for sensing applications, ${ }^{203,204}$ where MOFs have been combined with functional materials such as graphene, ${ }^{205,206}$ carbon dots, ${ }^{100,207}$ perovskites, ${ }^{208}$ polymers, ${ }^{209,210}$ biomolecules, ${ }^{210}$ quantum dots, ${ }^{201}$ and various metal nanoparticles ${ }^{201,210,211}$ (Fig. 19). In particular, metal NPs encapsulated within conductive MOFs create Schottky junctions at their interface, which act as active sites for analyte adsorption and charge transfer. ${ }^{64}$ Similarly, metal nanoclusters composed of coinage metals $(\mathrm{Cu}, \mathrm{Ag}$, and $\mathrm{Au}$ ) exhibit surface chemistry-dependent photoluminescence ${ }^{212,213}$ and can be linked together by rigid organic molecules to form MOFs with unique optical properties. ${ }^{214,215}$ Emission from powders of these materials has been used for gas sensing applications, ${ }^{216,217}$ indicating that these MOFs will likely have utility as thin film sensors. In addition to improving sensor performance, integrating MOFs with other materials may improve material stability, an important consideration for sensor deployment. ${ }^{218,219}$ Another emerging technique is the preparation of thin films comprised of layers of different MOF structures (Fig. 20). The presence of multiple layers of different MOFs can enhance selectivity for analytes of interest by selectively absorbing analytes of interest and blocking potential interferants. ${ }^{20-222}$

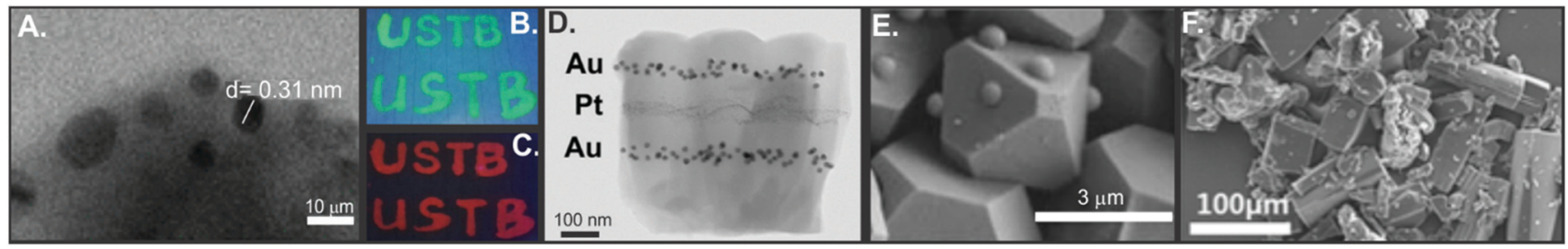

Fig. 19 Examples of MOF composite materials. (A) TEM image of an Eu-BTC MOF encapsulates a $\mathrm{CH}_{3} \mathrm{NH}_{3} \mathrm{PBr}_{3}$ perovskite, producing a dual-emitting film that emits green light under $365 \mathrm{~nm}$ excitation (B) and red light under $254 \mathrm{~nm}$ excitation (C), reproduced with permission from ACS Appl. Mater. Interfaces, 2018, 10, 27875-27884. Copyright 2018, American Chemical Society. (D) A ZIF-8 film produced with excellent spatial control of gold and platinum nanoparticles is shown in a TEM image, reproduced with permission from Chem. Commun., 2014, 50, 4296-4298. Copyright 2014, Royal Society of Chemistry. (E) An SEM image of polystyrene beads $(620 \mathrm{~nm})$ encapsulated by CuBTC MOF, reproduced with permission from Nat. Commun., 2014, 5, 1-9. Copyright 2014, Springer Nature. (F) SEM image of a zinc stilbene MOF encapsulating graphene oxide, reproduced with permission from Nanoscale, 2013, 5, 8533-8540. Copyright 2013, Royal Society of Chemistry. 


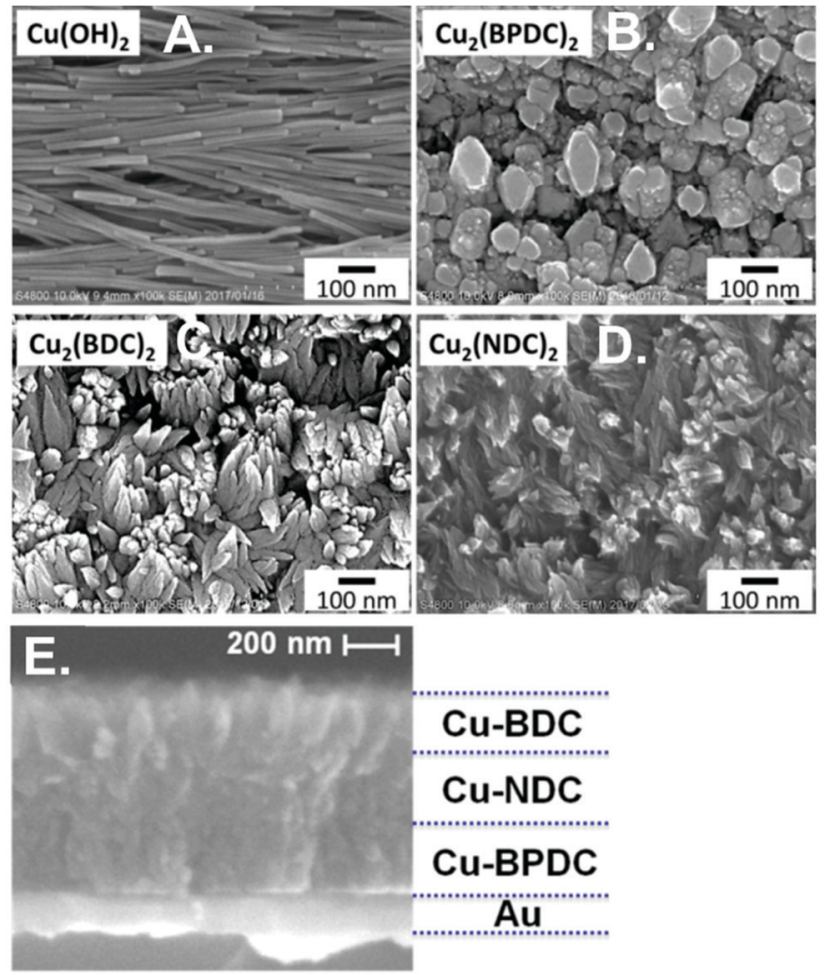

Fig. 20 Example of a 4 layer film of (A) $\mathrm{Cu}(\mathrm{OH})_{2}$, (B) $\mathrm{Cu}_{2}(\mathrm{BPDC})_{2}$ (C) $\mathrm{Cu}_{2}(\mathrm{BDC})_{2}$ and (D) $\mathrm{Cu}_{2}(\mathrm{NDC})_{2}$ MOFs, shown in a top-down view by SEM. Reproduced with permission from Angew. Chem., 2019, 131, 69606964. Copyright 2019, John C. Wiley and Sons, Inc. (E) SEM of a crosssection of three MOF layers grown on a gold substrate. Reproduced with permission from Nano Lett., 2014, 14, 1526-1529. Copyright 2014 American Chemical Society.

\subsection{Synthetic innovations}

New synthetic innovations are needed to improve the scalability, quality, and generality (e.g. a method capable of accommodating a range of different MOF structures) of MOF thin film syntheses. One unique emerging method is to synthesize MOFs directly within the system of interest. For example, recently a terbium terephthalate MOF was synthesized within a living plant via immersion of the roots in MOF precursor, enabling luminescent detection of pollutants within the plant over time. ${ }^{223}$ On-surface vapor-assisted crystallization (or conversion) synthesis ${ }^{224,225}$ has been introduced as an efficient method in the synthesis of high quality MOF thin films. This method provides a more environmentally friendly process compared to conventional techniques by mitigating chemical waste and eliminating undesired side reactions. Other emerging synthetic processes gaining traction include supersaturation-driven crystallization and continuous flow-fluidic techniques (for liquid phase reactions) and gas phase processes (such as CVD, molecular vapor deposition, and atomic layer deposition), which offer excellent control over MOF film morphology and potential for scalability. ${ }^{226,227}$ Such innovations are essential for translating MOF thin film technologies from the research lab into industrial-scale, commercial production. $^{228}$

\subsection{Emerging sensing techniques}

In addition to innovations in materials science, the development of new sensing techniques and platforms will further advance the field. Recently, several MOFs have been designed using qubit arrays and/or the encapsulation of quantum materials, ${ }^{229-233}$ which may facilitate their use in quantum sensing techniques, an emerging field with the potential to offer unprecedented levels of sensitivity. ${ }^{234,235}$ Nanocomposite films (Section 5.1) comprised of MOFs and plasmonic structures can be utilized for plasmonic sensing, another important sensing technique in which changes in the plasmon peak intensity or wavelength can track analytes of interest. ${ }^{236}$ For example, changes in the plasmonic peak of silver nanoparticles (AgNPs) have been used to detect $\mathrm{CO}_{2}$; growing CuBTC over the AgNPs improved the signal 14-fold by concentrating the $\mathrm{CO}_{2}$ near the AgNPs. ${ }^{237}$ The near-infrared response of indium tin oxide (ITO) nanoparticles to $\mathrm{CO}_{2}$ has similarly been enhanced by CuBTC (Fig. 21A-D). ${ }^{238}$ A fiber optic sensor comprised of a plasmonic gold film with a MOF coating was shown to sensitively detect alcohol vapors down to a 2.5 ppm level. ${ }^{239}$ Additionally, plasmonic-MOF nanocomposites have promise in surface enhanced Raman spectroscopy-based sensor applications. $^{240-245}$

A magnetoelastic sensor technique was recently demonstrated, in which UiO-66- $\mathrm{NH}_{2}$ was spray-coated onto a rhombic-shaped strip of a ferromagnetic alloy, which could be used as a wireless sensor for toluene. Similar to SAW devices, a magnetoelastic sensor operates based upon the impact of mass change on the magnetoelastic resonance frequency. ${ }^{246}$ The relatively simple fabrication process and high sensitivity indicate that MOF-based magnetoelastic sensors are worthy of additional study and optimization (Fig. 21E).

\subsection{Challenges}

The ubiquity of water presents a challenge for most sensor applications, especially when utilizing a new material class like MOFs. The sensing of ions or other chemical species in water, as well as any sensing application done in humid environments, necessitates the use of materials that are (1) stable in aqueous solution or water vapor and (2) selective to the target analyte even in the presence of water. While water stability for the most studied MOF materials (e.g. CuBTC, ZIF-8) have been thoroughly investigated, the water stability of the majority of synthesized MOF materials have yet to be investigated. Though a thorough investigation must be done if a particular MOF thin film will be utilized as a sensing material, a few rules of thumb can be used to predict the relative stability and selectivity against water: (1) the absence of OMS, (2) hydrophobic organic ligands, and (3) strong metal-organic bonds (e.g. M(III)-carboxylate bonds). Post-functionalization of MOF thin films and compositing MOFs with hydrophobic polymer are two methods that have been applied to mitigate the negative effects of water. ${ }^{247-249}$

Beyond proof-of-principle and developmental testing in laboratory settings, consideration for the processability of 

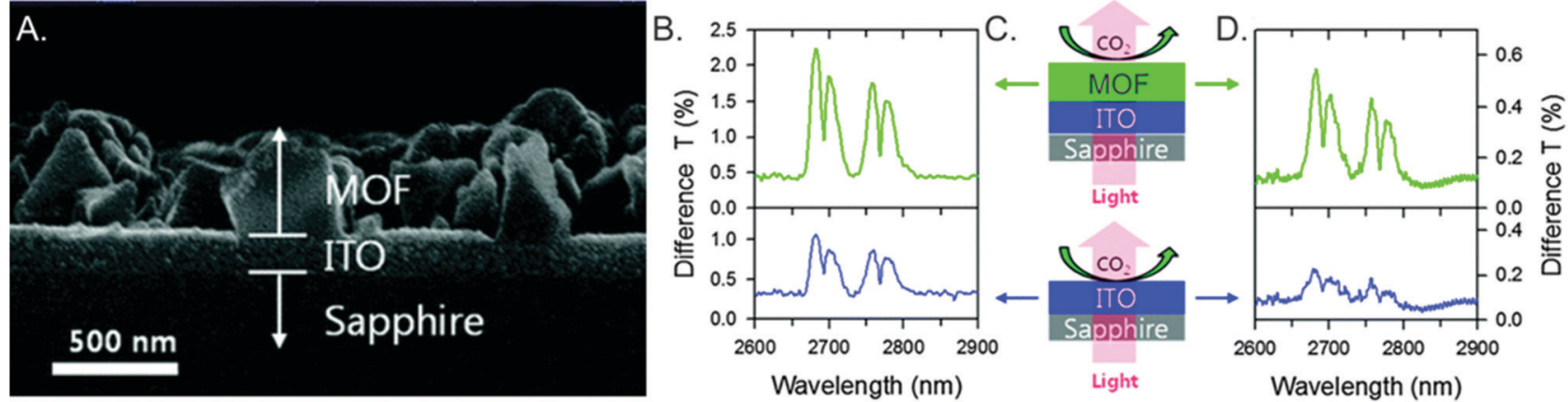

E.

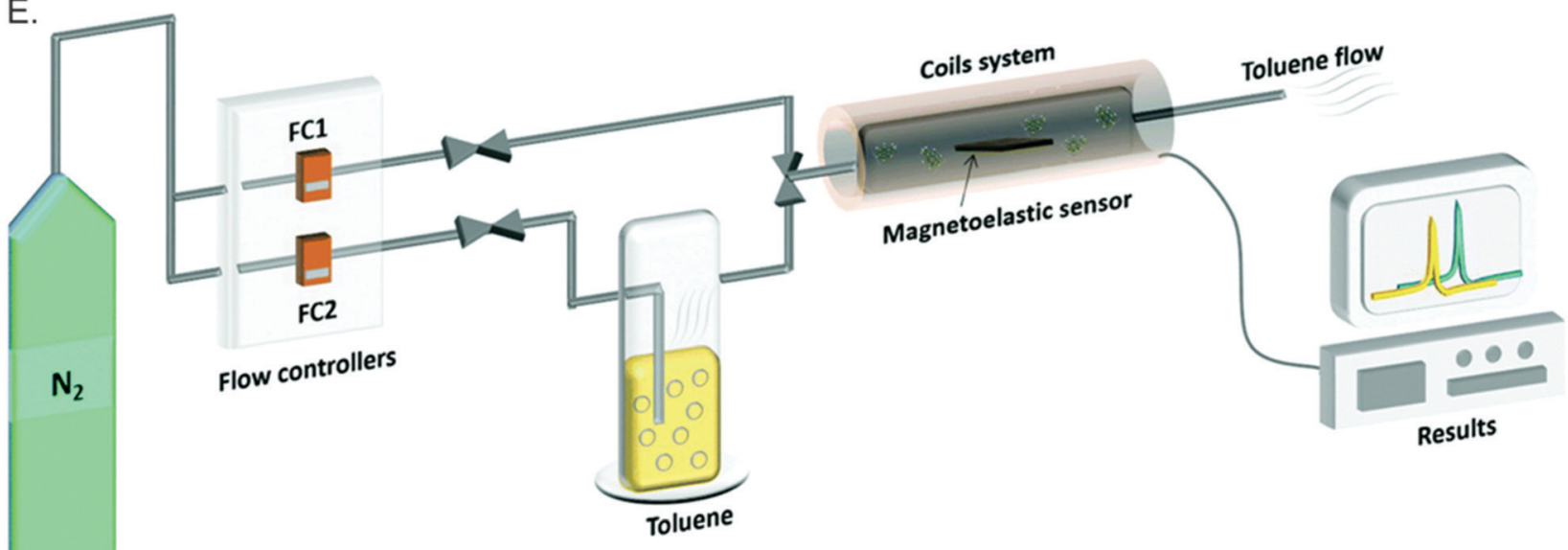

Fig. 21 Examples of emerging sensor techniques using MOF thin films. (A) SEM image of a plasmonic sensor consisting of a CuBTC thin film grown on a plasmonic indium tin oxide (ITO) substrate. The sensing response of the ITO plasmon peak from the MOF/ITO composite (top plots) is compared to that of bare ITO (bottom plots) under (B) high (100\%) and (D) low (0.1\%) $\mathrm{CO}_{2}$ conditions, with schematics of each set-up shown in (C). The presence of the MOF layer significantly enhances the sensor response to $\mathrm{CO}_{2}$. Reproduced with permission from J. Mater. Chem. C, 2015, 3, 2763-2767. Copyright 2015, Royal Society of Chemistry. (E) Schematic of a MOF-coated magnetoelastic sensing apparatus, which was used to detect toluene vapor. Reproduced with permission from J. Mater. Chem. C, 2020, 8, 13743-13753. Copyright 2020, Royal Society of Chemistry.

MOF thin films within a sensor device architecture is required for any large-scale fabrication. Processability of a material includes factors such as device-to-device variability, patterning resolution, and processing time. Research into the integration of MOF thin films in electronic microdevices has found that a combination of bottom-up syntheses such as metal oxide templating with top-down methods such as photo- or e-beam lithography can be utilized to pattern MOF thin films within devices. ${ }^{8,44,250-253}$ A recent example applied X-ray lithography and e-beam lithography to halogenated ZIF thin films (grown via chemical vapour deposition) to achieve film patterning with resolution reaching $10 \mu \mathrm{m}$ and $50 \mathrm{~nm}$, respectively. ${ }^{254}$

\section{Conclusions}

Synthetic innovations enabling the development of MOF thin films have produced a range of exciting sensing technologies, capable of sensitive and selective detection of a range of analytes, including ions, small molecules, gases, temperature, and other analytes of interest using optical, electrical, and acoustic techniques. MOF thin film technologies have the potential to significantly benefit energy, manufacturing, environmental, and medical sectors, among others. Fulfilling this potential requires (1) continued synthetic innovations to stabilize MOF thin films in harsh environments (e.g. high temperature, humidity, corrosive atmosphere, etc.), (2) developing strategies for mass production of thin films, and (3) continued innovations in the development of sensing techniques and platforms. Addressing such barriers to commercialization will be crucial for translating this transformative class of MOF sensing materials from the research lab into everyday products.

\section{Notes}

Neither the United States Government nor any agency thereof, nor any of its employees, nor the support contractor, nor any of their employees, makes any warranty, express or implied, or assumes any legal liability or responsibility for the accuracy, completeness, or usefulness of any information, apparatus, product, or process disclosed, or represents that its use would not infringe privately owned rights. Reference herein to any specific commercial product, process, or service by trade name, trademark, manufacturer, or otherwise does not necessarily constitute or imply its endorsement, recommendation, or 
favoring by the United States Government or any agency thereof. The views and opinions of authors expressed herein do not necessarily state or reflect those of the United States Government or any agency thereof.

\section{Author contributions}

The manuscript was written through contributions of all authors. All authors have given approval to the final version of the manuscript.

\section{Conflicts of interest}

There are no conflicts to declare.

\section{Acknowledgements}

James E. Ellis and Scott E. Crawford are grateful for funding through the National Energy Technology Research Participation Program, sponsored by the U.S. Department of Energy and administered by the Oak Ridge Institute for Science Education. We thank Eunchae Kim for her assistance with the scheme. This project was funded by the Department of Energy, National Energy Technology Laboratory an agency of the United States Government, through a support contract.

\section{References}

1 P. Z. Moghadam, A. Li, S. B. Wiggin, A. Tao, A. G. P. Maloney, P. A. Wood, S. C. Ward and D. Fairen-Jimenez, Chem. Mater., 2017, 29, 2618.

2 B. F. Hoskins and R. Robson, J. Am. Chem. Soc., 1990, 112, 1546.

3 S. S.-Y. Chui, S. M.-F. Lo, J. P. Charmant, A. G. Orpen and I. D. Williams, Science, 1999, 283, 1148.

4 H. Li, M. Eddaoudi, M. O'Keeffe and O. M. Yaghi, Nature, 1999, 402, 276.

5 T. Liu, P. Li, N. Yao, T. Kong, G. Cheng, S. Chen and W. Luo, Adv. Mater., 2019, 31, 1806672.

6 K. J. Erickson, F. Léonard, V. Stavila, M. E. Foster, C. D. Spataru, R. E. Jones, B. M. Foley, P. E. Hopkins, M. D. Allendorf and A. A. Talin, Adv. Mater., 2015, 27, 3453.

7 V. Stavila, A. A. Talin and M. D. Allendorf, Chem. Soc. Rev., 2014, 43, 5994.

8 I. Stassen, N. Burtch, A. Talin, P. Falcaro, M. Allendorf and R. Ameloot, Chem. Soc. Rev., 2017, 46, 3185.

9 J. Liu and C. Wöll, Chem. Soc. Rev., 2017, 46, 5730.

10 O. Shekhah, J. Liu, R. Fischer and C. Wöll, Chem. Soc. Rev., 2011, 40, 1081.

11 X. Ma, Y. Chai, P. Li and B. Wang, Acc. Chem. Res., 2019, 52, 1461.

12 A. Chidambaram and K. C. Stylianou, Inorg. Chem. Front., 2018, 5, 979.

13 Y. Zhang, S. Yuan, G. Day, X. Wang, X. Yang and H.-C. Zhou, Coord. Chem. Rev., 2018, 354, 28.
14 W.-J. Li, M. Tu, R. Cao and R. A. Fischer, J. Mater. Chem. A, 2016, 4, 12356.

15 Y. Zhang and C.-H. Chang, Processes, 2020, 8, 377.

16 Z.-G. Gu and J. Zhang, Coord. Chem. Rev., 2019, 378, 513.

17 L. J. Small and T. M. Nenoff, ACS Appl. Mater. Interfaces, 2017, 9, 44649.

18 D. Jiang, A. D. Burrows, Y. Xiong and K. J. Edler, J. Mater. Chem. A, 2013, 1.

19 L. D. Sappia, J. S. Tuninetti, M. Ceolin, W. Knoll, M. Rafti and O. Azzaroni, Glob. Chall., 2020, 4, 1900076.

20 J. Benito, S. Sorribas, I. Lucas, J. Coronas and I. Gascon, ACS Appl. Mater. Interfaces, 2016, 8, 16486.

21 P. Goel, S. Singh, H. Kaur, S. Mishra and A. Deep, Sens. Actuators, B, 2021, 329, 129157.

22 L. Fontana, I. Fratoddi, I. Venditti, D. Ksenzov, M. V. Russo and S. Grigorian, Appl. Surf. Sci., 2016, 369, 115.

23 K. Zhao, X. Yu, R. Li, A. Amassian and Y. Han, J. Mater. Chem. C, 2015, 3, 9842.

24 B. K. Kuila and M. Stamm, Macromol. Sym., 2011, 303, 85. 25 D. Zacher, O. Shekhah, C. Woll and R. A. Fischer, Chem. Soc. Rev., 2009, 38, 1418.

26 C. S. Kim, S. Lee, E. D. Gomez, J. E. Anthony and Y.-L. Loo, Appl. Phys. Lett., 2008, 93, 103302.

27 N. Patra, M. Salerno, A. Diaspro and A. Athanassiou, J. Mater. Sci., 2011, 46, 5044.

28 G. Bussetti, S. Trabattoni, S. Uttiya, A. Sassella, M. Riva, A. Picone, A. Brambilla, L. Duò, F. Ciccacci and M. Finazzi, Synth. Met., 2014, 195, 201.

29 M. S. Hosseini, S. Zeinali and M. H. Sheikhi, Sens. Actuators, $B, 2016,230,9$.

30 E. A. Gaulding, B. T. Diroll, E. D. Goodwin, Z. J. Vrtis, C. R. Kagan and C. B. Murray, Adv. Mater., 2015, 27, 2846.

31 Z. Fu and G. Xu, Chem. Rec., 2017, 17, 518.

32 H. Ohara, S. Yamamoto, D. Kuzuhara, T. Koganezawa, H. Oikawa and M. Mitsuishi, ACS Appl. Mater. Interfaces, 2020, 12, 50784 .

33 N. Nijem, K. Fürsich, S. T. Kelly, C. Swain, S. R. Leone and M. K. Gilles, Cryst. Growth Des., 2015, 15, 2948.

34 V. Chernikova, O. Shekhah and M. Eddaoudi, ACS Appl. Mater. Interfaces, 2016, 8, 20459.

35 Z. Wang and C. Wöll, Adv. Mater. Technol., 2018, 4, 1800413.

36 X. Zhang, K. Wan, P. Subramanian, M. Xu, J. Luo and J. Fransaer, J. Mater. Chem. A, 2020, 8, 7569.

37 Y. Yoo and H. K. Jeong, Chem. Commun., 2008, 2441.

38 Y. Yue, Z.-A. Qiao, X. Li, A. J. Binder, E. Formo, Z. Pan, C. Tian, Z. Bi and S. Dai, Cryst. Growth Des., 2013, 13, 1002.

39 Z.-Q. Li, M. Zhang, B. Liu, C.-Y. Guo and M. Zhou, Inorg. Chem. Commun., 2013, 36, 241.

40 Y. Yue, N. Mehio, A. J. Binder and S. Dai, CrystEngComm, 2015, 17, 1728.

41 S. E. Crawford, K.-J. Kim, Y. Yu and P. R. Ohodnicki, Cryst. Growth Des., 2018, 18, 2924.

42 P.-C. Guo, T.-Y. Chen, X.-M. Ren, Z. Chu and W. Jin, J. Mater. Chem. A, 2014, 2, 13698. 
43 A. Demessence, C. Boissière, D. Grosso, P. Horcajada, C. Serre, G. Férey, G. J. Soler-Illia and C. Sanchez, J. Mater. Chem., 2010, 20, 7676.

44 I. Stassen, M. Styles, G. Grenci, H. Van Gorp, W. Vanderlinden, S. De Feyter, P. Falcaro, D. De Vos, P. Vereecken and R. Ameloot, Nat. Mater., 2016, 15, 304.

45 T. Stassin, S. Rodríguez-Hermida, B. Schrode, A. J. Cruz,

F. Carraro, D. Kravchenko, V. Creemers, I. Stassen,

T. Hauffman and D. De Vos, Chem. Commun., 2019, $55,10056$.

46 I. Stassen, D. De Vos and R. Ameloot, Chem. - Eur. J., 2016, 22, 14452.

47 M. G. Campbell and M. Dinca, Sensors, 2017, 17, 1108.

48 H. Y. Li, S. N. Zhao, S. Q. Zang and J. Li, Chem. Soc. Rev., 2020, 49, 6364 .

49 M.-S. Yao, W.-H. Li and G. Xu, Coord. Chem. Rev., 2021, 426, 213479.

50 L. S. Xie, G. Skorupskii and M. Dinca, Chem. Rev., 2020, 120, 8536.

51 V. Rubio-Gimenez, N. Almora-Barrios, G. Escorcia-Ariza, M. Galbiati, M. Sessolo, S. Tatay and C. Marti-Gastaldo, Angew. Chem., Int. Ed., 2018, 57, 15086.

52 I. Stassen, J. H. Dou, C. Hendon and M. Dinca, ACS Cent. Sci., 2019, 5, 1425.

53 H. Yuan, J. Tao, N. Li, A. Karmakar, C. Tang, H. Cai, S. J. Pennycook, N. Singh and D. Zhao, Angew. Chem., Int. Ed., 2019, 58, 14089.

54 H. Yuan, J. Cui, N. Li, M. Li, X. Yu, W. Fan, A. Karmakar, J. Dong, S. J. Pennycook, H. Cai and D. Zhao, ACS Appl. Mater. Interfaces, 2020, 12, 36715.

55 V. Chernikova, O. Yassine, O. Shekhah, M. Eddaoudi and K. N. Salama, J. Mater. Chem. A, 2018, 6, 5550.

56 O. Yassine, O. Shekhah, A. H. Assen, Y. Belmabkhout, K. N. Salama and M. Eddaoudi, Angew. Chem., Int. Ed., 2016, 55, 15879.

57 M. R. Tchalala, Y. Belmabkhout, K. Adil, K. N. Chappanda, A. Cadiau, P. M. Bhatt, K. N. Salama and M. Eddaoudi, ACS Appl. Mater. Interfaces, 2018, 11, 1706.

58 S. Homayoonnia and S. Zeinali, Sens. Actuators, B, 2016, 237, 776.

59 C. Sapsanis, H. Omran, V. Chernikova, O. Shekhah, Y. Belmabkhout, U. Buttner, M. Eddaoudi and K. N. Salama, Sensors, 2015, 15, 18153.

60 A. H. Assen, O. Yassine, O. Shekhah, M. Eddaoudi and K. N. Salama, ACS Sens., 2017, 2, 1294.

61 A.-Q. Wu, W.-Q. Wang, H.-B. Zhan, L.-A. Cao, X.-L. Ye, J.-J. Zheng, P. N. Kumar, K. Chiranjeevulu, W.-H. Deng, G.-E. Wang, M.-S. Yao and G. Xu, Nano Res., 2020, 14, 438.

62 M. S. Yao, J. J. Zheng, A. Q. Wu, G. Xu, S. S. Nagarkar, G. Zhang, M. Tsujimoto, S. Sakaki, S. Horike, K. Otake and S. Kitagawa, Angew. Chem., Int. Ed., 2020, 59, 172.

63 Z. Meng, A. Aykanat and K. A. Mirica, J. Am. Chem. Soc., 2019, 141, 2046.

64 W. T. Koo, S. J. Kim, J. S. Jang, D. H. Kim and I. D. Kim, Adv. Sci., 2019, 6, 1900250.
65 M. S. Yao, J. W. Xiu, Q. Q. Huang, W. H. Li, W. W. Wu, A. Q. Wu, L. A. Cao, W. H. Deng, G. E. Wang and G. Xu, Angew. Chem., Int. Ed., 2019, 58, 14915.

66 M. S. Yao, X. J. Lv, Z. H. Fu, W. H. Li, W. H. Deng, G. D. Wu and G. Xu, Angew. Chem., Int. Ed., 2017, 56, 16510.

67 M. K. Smith and K. A. Mirica, J. Am. Chem. Soc., 2017, 139, 16759.

68 M. K. Smith, K. E. Jensen, P. A. Pivak and K. A. Mirica, Chem. Mater., 2016, 28, 5264.

69 M. G. Campbell, S. F. Liu, T. M. Swager and M. Dinca, J. Am. Chem. Soc., 2015, 137, 13780.

70 M. G. Campbell, D. Sheberla, S. F. Liu, T. M. Swager and M. Dinca, Angew. Chem., Int. Ed., 2015, 54, 4349.

71 S. Zeinali, S. Homayoonnia and G. Homayoonnia, Sens. Actuators, B, 2019, 278, 153.

72 S. Achmann, G. Hagen, J. Kita, I. M. Malkowsky, C. Kiener and R. Moos, Sensors, 2009, 9, 1574.

73 X. Huang, P. Sheng, Z. Tu, F. Zhang, J. Wang, H. Geng, Y. Zou, C. A. Di, Y. Yi, Y. Sun, W. Xu and D. Zhu, Nat. Commun., 2015, 6, 7408.

74 G. Wu, J. Huang, Y. Zang, J. He and G. Xu, J. Am. Chem. Soc., 2017, 139, 1360.

75 B. Wang, Y. Luo, B. Liu and G. Duan, ACS Appl. Mater. Interfaces, 2019, 11, 35935.

76 H. J. Park, M. C. So, D. Gosztola, G. P. Wiederrecht, J. D. Emery, A. B. Martinson, S. L. Er, C. E. Wilmer, N. A. Vermeulen and A. Aspuru-Guzik, ACS Appl. Mater. Interfaces, 2016, 8, 24983.

77 R. Zhang, D. Zhang, Y. Yao, Q. Zhang, Y. Xu, Y. Wu, H. Yu and G. Lu, ACS Appl. Mater. Interfaces, 2019, 11, 21010.

78 G. Lu and J. T. Hupp, J. Am. Chem. Soc., 2010, 132, 7832.

79 X. Chong, K.-J. Kim, E. Li, Y. Zhang, P. R. Ohodnicki, C.-H. Chang and A. X. Wang, Sens. Actuators, B, 2016, 232, 43.

80 R. B. Lin, S. Y. Liu, J. W. Ye, X. Y. Li and J. P. Zhang, Adv. Sci., 2016, 3, 1500434.

81 Z. Liao, T. Xia, E. Yu and Y. Cui, Crystals, 2018, 8, 338.

82 A. Karmakar, P. Samanta, S. Dutta and S. K. Ghosh, Chem. - Asian J., 2019, 14, 4506.

83 J. He, J. Xu, J. Yin, N. Li and X.-H. Bu, Sci. China Mater., 2019, 1.

84 D. Zhao, Y. Cui, Y. Yang and G. Qian, CrystEngComm, 2016, 18, 3746.

85 L. E. Kreno, K. Leong, O. K. Farha, M. Allendorf, R. P. Van Duyne and J. T. Hupp, Chem. Rev., 2011, 112, 1105.

86 Y. Liu, X.-Y. Xie, C. Cheng, Z.-S. Shao and H.-S. Wang, J. Mater. Chem. C, 2019, 7, 10743.

87 E. A. Dolgopolova, A. M. Rice, C. R. Martin and N. B. Shustova, Chem. Soc. Rev., 2018, 47, 4710.

88 B. Yan, Acc. Chem. Res., 2017, 50, 2789.

89 W. Huang, F. Pan, Y. Liu, S. Huang, Y. Li, J. Yong, Y. Li, A. M. Kirillov and D. Wu, Inorg. Chem., 2017, 56, 6362.

90 S. E. Crawford, P. R. Ohodnicki and J. P. Baltrus, J. Mater. Chem. C, 2020, 8, 7975.

91 X. Wang, W. Lu, Z.-Y. Gu, Z. Wei and H.-C. Zhou, Chem. Commun., 2016, 52, 1926. 
92 R. Chen, J. Zhang, J. Chelora, Y. Xiong, S. V. Kershaw, K. F. Li, P.-K. Lo, K. W. Cheah, A. L. Rogach and J. A. Zapien, ACS Appl. Mater. Interfaces, 2017, 9, 5699.

93 H.-R. Fu, Y. Zhao, T. Xie, M.-L. Han, L.-F. Ma and S.-Q. Zang, J. Mater. Chem. C, 2018, 6, 6440.

94 N. Zhang, D. Zhang, J. Zhao and Z. Xia, Dalton Trans., 2019, 48, 6794.

95 Y. Cui, R. Song, J. Yu, M. Liu, Z. Wang, C. Wu, Y. Yang, Z. Wang, B. Chen and G. Qian, Adv. Mater., 2015, 27, 1420.

96 J. F. Olorunyomi, M. M. Sadiq, M. Batten, K. Konstas, D. Chen, C. M. Doherty and R. A. Caruso, Adv. Opt. Mater., 2020, 8, 2000961.

97 S.-J. Qin and B. Yan, Sens. Actuators, B, 2018, 272, 510.

98 G. Lu, S. Li, Z. Guo, O. K. Farha, B. G. Hauser, X. Qi, Y. Wang, X. Wang, S. Han and X. Liu, Nat. Chem., 2012, 4, 310 .

99 C. Li, J. Hai, S. Li, B. Wang and Z. Yang, Nanoscale, 2018, 10, 8667.

100 J.-F. Feng, S.-Y. Gao, J. Shi, T.-F. Liu and R. Cao, Inorg. Chem., 2018, 57, 2447.

101 S. E. Crawford, X. Y. Gan, P. C. Lemaire, J. E. Millstone, J. P. Baltrus and P. R. Ohodnicki Jr, ACS Sens., 2019, 4, 1986.

102 L. Di, Z. Xia, J. Li, Z. Geng, C. Li, Y. Xing and Z. Yang, RSC Adv., 2019, 9, 38469.

103 P. Jia, Z. Wang, Y. Zhang, D. Zhang, W. Gao, Y. Su, Y. Li and C. Yang, Spectrochim. Acta, Part A, 2020, 230, 118084.

104 K.-J. Kim, P. Lu, J. T. Culp and P. R. Ohodnicki, ACS Sens., 2018, 3, 386.

105 F. Zhang, G. Zhang, H. Yao, Y. Wang, T. Chu and Y. Yang, Microchim. Acta, 2017, 184, 1207.

106 S. E. Crawford, J. E. Ellis, P. R. Ohodnicki and J. P. Baltrus, ACS Appl. Mater. Interfaces, 2021, 13, 7268.

107 C. Li, F. Zhang, X. Li, G. Zhang and Y. Yang, J. Lumin., 2019, 205, 23.

108 Z. Hu, C.-a. Tao, H. Liu, X. Zou, H. Zhu and J. Wang, J. Mater. Chem. A, 2014, 2, 14222.

109 W.-J. Li, S.-Y. Gao, T.-F. Liu, L.-W. Han, Z.-J. Lin and R. Cao, Langmuir, 2013, 29, 8657.

110 H.-T. Kim, W. Hwang, Y. Liu and M. Yu, Opt. Express, 2020, 28, 29937.

111 R. Cao, H. Ding, K.-J. Kim, Z. Peng, J. Wu, J. T. Culp, P. R. Ohodnicki, E. Beckman and K. P. Chen, Sens. Actuators, B, 2020, 324, 128627.

112 Y.-M. Zhu, C.-H. Zeng, T.-S. Chu, H.-M. Wang, Y.-Y. Yang, Y.-X. Tong, C.-Y. Su and W.-T. Wong, J. Mater. Chem. A, 2013, 1, 11312.

113 Q.-Q. Zhu, H. He, Y. Yan, J. Yuan, D.-Q. Lu, D.-Y. Zhang, F. Sun and G. Zhu, Inorg. Chem., 2019, 58, 7746.

114 E. Bakker, ACS Sens., 2018, 3, 1431.

115 H. Liu, H. Wang, T. Chu, M. Yu and Y. Yang, J. Mater. Chem. C, 2014, 2, 8683.

116 F. Luo, G.-M. Sun, A.-M. Zheng, S.-X. Lian, Y.-L. Liu, X. F. Feng and Y.-Y. Chu, Dalton Trans., 2012, 41, 13280.

117 D. Chen, H. Xing, Z. Su and C. Wang, Chem. Commun., 2016, 52, 2019.
118 B. Rühle, E. Virmani, H. Engelke, F. M. Hinterholzinger, T. von Zons, B. Brosent, T. Bein, A. Godt and S. Wuttke, Chem. - Eur. J., 2019, 25, 6349.

119 S. V. Eliseeva, D. N. Pleshkov, K. A. Lyssenko, L. S. Lepnev, J.-C. G. Bünzli and N. P. Kuzmina, Inorg. Chem., 2010, 49, 9300.

120 F. Doty, C. Bauer, A. Skulan, P. Grant and M. Allendorf, Adv. Mater., 2009, 21, 95.

121 A. M. Marti, S. D. Perera, L. D. McBeath and K. J. Balkus Jr, Langmuir, 2013, 29, 5927.

122 C. Zhang, Y. Che, Z. Zhang, X. Yang and L. Zang, Chem. Commun., 2011, 47, 2336.

123 Y. Gao, G. Yu, K. Liu and B. Wang, Sens. Actuators, B, 2018, 257, 931.

124 Y. Wang, G. Zhang, F. Zhang, T. Chu and Y. Yang, Sens. Actuators, B, 2017, 251, 667.

125 N. Campagnol, E. R. Souza, D. E. De Vos, K. Binnemans and J. Fransaer, Chem. Commun., 2014, 50, 12545.

126 J.-F. Feng, X. Yang, S.-Y. Gao, J. Shi and R. Cao, Langmuir, 2017, 33, 14238.

127 W. Chen, R. Fan, J. Fan, H. Liu, T. Sun, P. Wang and Y. Yang, Inorg. Chem., 2019, 58, 15118.

128 Y. Wang, T. Chu, M. Yu, H. Liu and Y. Yang, RSC Adv., 2014, 4, 58178.

129 Z. Wang, H. Liu, S. Wang, Z. Rao and Y. Yang, Sens. Actuators, B, 2015, 220, 779.

130 A. Khatun, D. K. Panda, N. Sayresmith, M. G. Walter and S. Saha, Inorg. Chem., 2019, 58, 12707.

131 G. Ji, J. Liu, X. Gao, W. Sun, J. Wang, S. Zhao and Z. Liu, J. Mater. Chem. A, 2017, 5, 10200.

132 X.-Q. Song, H.-H. Meng, Z.-G. Lin and L. Wang, ACS Appl. Polym. Mater., 2020, 2, 0644.

133 J. Min, X.-L. Qu and B. Yan, Sens. Actuators, B, 2019, 300, 126985.

134 J.-H. Wang, M. Li and D. Li, Chem. Sci., 2013, 4, 1793.

135 W.-P. Ma and B. Yan, Dalton Trans., 2020, 49, 15663.

136 X. Qin, X. Zhang, M. Wang, Y. Dong, J. Liu, Z. Zhu, M. Li, D. Yang and Y. Shao, Anal. Chem., 2018, 90, 11622.

137 J.-N. Hao and B. Yan, Nanoscale, 2016, 8, 12047.

138 S.-I. Ohira, Y. Miki, T. Matsuzaki, N. Nakamura, Y.-K. Sato, Y. Hirose and K. Toda, Anal. Chim. Acta, 2015, 886, 188.

139 F. Zhang, Y. Wang, T. Chu, Z. Wang, W. Li and Y. Yang, Analyst, 2016, 141, 4502.

140 D. Tian, Y. Li, R.-Y. Chen, Z. Chang, G.-Y. Wang and X.H. Bu, J. Mater. Chem. A, 2014, 2, 1465.

141 W.-J. Li, J. Lü, S.-Y. Gao, Q.-H. Li and R. Cao, J. Mater. Chem. A, 2014, 2, 19473.

142 C. Zhu, J. A. Perman, R. E. Gerald, S. Ma and J. Huang, ACS Appl. Mater. Interfaces, 2019, 11, 4393.

143 G. Lu, O. K. Farha, L. E. Kreno, P. M. Schoenecker, K. S. Walton, R. P. Van Duyne and J. T. Hupp, Adv. Mater., 2011, 23, 4449.

144 H. Guo, S. Zhu, D. Cai and C. Liu, Inorg. Chem. Commun., 2014, 41, 29.

145 J. Hromadka, B. Tokay, S. James, R. P. Tatam and S. Korposh, Sens. Actuators, B, 2015, 221, 891. 
146 Z. Dou, J. Yu, Y. Cui, Y. Yang, Z. Wang, D. Yang and G. Qian, J. Am. Chem. Soc., 2014, 136, 5527.

147 J.-W. Ye, H.-L. Zhou, S.-Y. Liu, X.-N. Cheng, R.-B. Lin, X.-L. Qi, J.-P. Zhang and X.-M. Chen, Chem. Mater., 2015, 27, 8255.

148 X.-L. Qu and B. Yan, Inorg. Chem., 2018, 57, 7815.

149 X. Liu, W. Fu and E. Bouwman, Chem. Commun., 2016, 52, 6926.

150 J.-f. Feng, T.-f. Liu, J. Shi, S.-y. Gao and R. Cao, ACS Appl. Mater. Interfaces, 2018, 10, 20854.

151 J. Dong, D. Zhao, Y. Lu and W.-Y. Sun, J. Mater. Chem. A, 2019, 7, 22744.

152 K. C. Park, C. Seo, G. Gupta, J. Kim and C. Y. Lee, ACS Appl. Mater. Interfaces, 2017, 9, 38670.

153 J.-C. G. Bünzli and C. Piguet, Chem. Soc. Rev., 2005, 34, 1048.

154 Y. Cui, B. Chen and G. Qian, Coord. Chem. Rev., 2014, 273, 76.

155 D. Zou, J. Zhang, Y. Cui and G. Qian, Dalton Trans., 2019, 48, 6669.

156 D.-D. Liu, Y.-L. Wang, F. Luo and Q.-Y. Liu, Inorg. Chem., 2020, 59, 2952.

157 R. G. Surbella, K. P. Carter, T. D. Lohrey, D. Reilly, M. Kalaj, B. K. McNamara, J. Schwantes and R. J. Abergel, Chem. Eur. J., 2020, 26, 13819.

158 M. D. Allendorf, C. A. Bauer, R. Bhakta and R. Houk, Chem. Soc. Rev., 2009, 38, 1330.

159 L. Xu, G. Fang, J. Liu, M. Pan, R. Wang and S. Wang, J. Mater. Chem. A, 2016, 4, 15880.

160 V. Glembockyte, M. Frenette, C. Mottillo, A. S. M. Durantini, J. Gostick, V. Štrukil, T. Friščić and G. Cosa, J. Am. Chem. Soc., 2018, 140, 16882.

161 S. Tian, S. Xu, J. Liu, C. He, Y. Xiong and P. Feng, J. Clean. Prod., 2019, 239, 117767.

162 J. An, C. M. Shade, D. A. Chengelis-Czegan, S. Petoud and N. L. Rosi, J. Am. Chem. Soc., 2011, 133, 1220.

163 S. N. Zhao, X. Z. Song, M. Zhu, X. Meng, L. L. Wu, J. Feng, S. Y. Song and H. J. Zhang, Chem. - Eur. J., 2015, 21, 9748.

164 X. Zhao, D. Liu, H. Huang and C. Zhong, Microporous Mesoporous Mater., 2016, 224, 149.

165 W. P. Lustig, S. Mukherjee, N. D. Rudd, A. V. Desai, J. Li and S. K. Ghosh, Chem. Soc. Rev., 2017, 46, 3242.

166 Z. Hu, B. J. Deibert and J. Li, Chem. Soc. Rev., 2014, 43, 5815.

167 S.-J. Qin and B. Yan, Sens. Actuators, B, 2018, 259, 125.

168 A. Coutinho and M. Prieto, J. Chem. Educ., 1993, 70, 425.

169 A. R. Holzwarth, Y. Miloslavina, M. Nilkens and P. Jahns, Chem. Phys. Lett., 2009, 483, 262.

170 K.-J. Kim, J. T. Culp, P. R. Ohodnicki, P. C. Cvetic, S. Sanguinito, A. L. Goodman and H. T. Kwon, ACS Appl. Mater. Interfaces, 2019, 11, 33489.

171 M. Meilikhov, S. Furukawa, K. Hirai, R. A. Fischer and S. Kitagawa, Angew. Chem., Int. Ed., 2013, 52, 341.

172 S. Wannapaiboon, M. Tu, K. Sumida, K. Khaletskaya, S. Furukawa, S. Kitagawa and R. A. Fischer, J. Mater. Chem. A, 2015, 3, 23385.
173 A. Sturluson, R. Sousa, Y. Zhang, M. T. Huynh, C. Laird, A. H. P. York, C. Silsby, C. H. Chang and C. M. Simon, ACS Appl. Mater. Interfaces, 2020, 12, 6546.

174 R. Sousa and C. M. Simon, ACS Sens., 2020, 5, 4035.

175 S. Okur, Z. Zhang, M. Sarheed, P. Nick, U. Lemmer and L. Heinke, Sens. Actuators, B, 2020, 306, 127502.

176 S. Okur, P. Qin, A. Chandresh, C. Li, Z. Zhang, U. Lemmer and L. Heinke, Angew. Chem., Int. Ed., 2021, 60, 3566.

177 J. Devkota, D. W. Greve, T. Hong, K.-J. Kim and P. R. Ohodnicki, IEEE Sens. J., 2020, 20, 9740.

178 V. Stavila, C. Schneider, C. Mowry, T. R. Zeitler, J. A. Greathouse, A. L. Robinson, J. M. Denning, J. Volponi, K. Leong, W. Quan, M. Tu, R. A. Fischer and M. D. Allendorf, Adv. Funct. Mater., 2016, 26, 1699.

179 B. Paschke, A. Wixforth, D. Denysenko and D. Volkmer, ACS Sens., 2017, 2, 740.

180 J. Devkota, K. J. Kim, P. R. Ohodnicki, J. T. Culp, D. W. Greve and J. W. Lekse, Nanoscale, 2018, 10, 8075.

181 F. A. Bahos, A. Sainz-Vidal, C. Sanchez-Perez, J. M. Saniger, I. Gracia, M. M. Saniger-Alba and D. Matatagui, Biosensors, 2019, 9, 4.

182 X. Fang, L. Wang, X. He, J. Xu and Z. Duan, Inorg. Chem., 2018, 57, 1689.

183 F. Xu, L. Sun, P. Huang, Y. Sun, Q. Zheng, Y. Zou, H. Chu, E. Yan, H. Zhang, J. Wang and Y. Du, Sens. Actuators, B, 2018, 254, 872.

184 M. R. Tchalala, P. M. Bhatt, K. N. Chappanda, S. R. Tavares, K. Adil, Y. Belmabkhout, A. Shkurenko, A. Cadiau, N. Heymans, G. De Weireld, G. Maurin, K. N. Salama and M. Eddaoudi, Nat. Commun., 2019, 10, 1328.

185 E. Haghighi and S. Zeinali, RSC Adv., 2019, 9, 24460.

186 M. A. Andres, M. Benzaqui, C. Serre, N. Steunou and I. Gascon, J. Colloid Interface Sci., 2018, 519, 88.

187 M. D. Allendorf, R. J. Houk, L. Andruszkiewicz, A. A. Talin, J. Pikarsky, A. Choudhury, K. A. Gall and P. J. Hesketh, J. Am. Chem. Soc., 2008, 130, 14404.

188 L. Heinke, Z. Gu and C. Woll, Nat. Commun., 2014, 5, 4562.

189 H. Yamagiwa, S. Sato, T. Fukawa, T. Ikehara, R. Maeda, T. Mihara and M. Kimura, Sci. Rep., 2014, 4, 6247.

190 C. Yim and S. Jeon, RSC Adv., 2015, 5, 67454.

191 Z. Ma, T. Yuan, Y. Fan, L. Wang, Z. Duan, W. Du, D. Zhang and J. Xu, Sens. Actuators, B, 2020, 311, 127365.

192 Z. Zhou, M.-X. Li, L. Wang, X. He, T. Chi and Z.-X. Wang, Cryst. Growth Des., 2017, 17, 6719.

193 X. Si, C. Jiao, F. Li, J. Zhang, S. Wang, S. Liu, Z. Li, L. Sun, F. Xu, Z. Gabelica and C. Schick, Energy Environ. Sci., 2011, 4, 4522 .

194 E. Haghighi and S. Zeinali, Microporous Mesoporous Mater., 2020, 300, 110065.

195 D. J. Li, Z. G. Gu, I. Vohra, Y. Kang, Y. S. Zhu and J. Zhang, Small, 2017, 13, 1604035.

196 K. J. Kim, J. E. Ellis, B. H. Howard and P. R. Ohodnicki, ACS. Appl. Mater. Interfaces, 2021, 13, 2062.

197 A. L. Robinson, V. Stavila, T. R. Zeitler, M. I. White, S. M. Thornberg, J. A. Greathouse and M. D. Allendorf, Anal. Chem., 2012, 84, 7043. 
198 L. Yang, Y. Song and L. Wang, J. Mater. Chem. B, 2020, 8, 3292.

199 Y. Shu, Q. Ye, T. Dai, Q. Xu and X. Hu, ACS Sens., 2021, 6, 641.

200 Y. Jian, W. Hu, Z. Zhao, P. Cheng, H. Haick, M. Yao and W. Wu, Nano-Micro Lett., 2020, 12, 1.

201 W. Zhang, G. Lu, S. Li, Y. Liu, H. Xu, C. Cui, W. Yan, Y. Yang and F. Huo, Chem. Commun., 2014, 50, 4296.

202 Q.-L. Zhu and Q. Xu, Chem. Soc. Rev., 2014, 43, 5468.

203 J. Lei, R. Qian, P. Ling, L. Cui and H. Ju, TrAC, Trends Anal. Chem., 2014, 58, 71.

204 P. Kumar, K.-H. Kim, K. Vellingiri, P. Samaddar, P. Kumar, A. Deep and N. Kumar, Biosens. Bioelectron., 2018, 104, 120.

205 J. H. Lee, J. Jaworski and J. H. Jung, Nanoscale, 2013, $5,8533$.

206 R. Kaur, K.-H. Kim and A. Deep, Appl. Surf. Sci., 2017, 396, 1303.

207 L. Xu, M. Pan, G. Fang and S. Wang, Sens. Actuators, B, 2019, 286, 321.

208 D. Zhang, W. Zhou, Q. Liu and Z. Xia, ACS Appl. Mater. Interfaces, 2018, 10, 27875.

209 X. Shen and B. Yan, Dalton Trans., 2015, 44, 1875.

210 Y. Mao, J. Li, W. Cao, Y. Ying, P. Hu, Y. Liu, L. Sun, H. Wang, C. Jin and X. Peng, Nat. Commun., 2014, 5, 1.

211 H. Chen, T. Yang, F. Liu and W. Li, Sens. Actuators, B, 2019, 286, 401.

212 C. M. Andolina, S. E. Crawford, A. M. Smith, K. A. Johnston, P. J. Straney, L. E. Marbella, N. L. Tolman, T. J. Hochuli and J. E. Millstone, ChemNanoMat, 2018, 4, 265.

213 S. E. Crawford, M. J. Hartmann and J. E. Millstone, Acc. Chem. Res., 2019, 52, 695.

214 J. Y. Wang, R. W. Huang, Z. Wei, X. J. Xi, X. Y. Dong and S. Q. Zang, Chem. - Eur. J., 2019, 25, 3376.

215 X.-Y. Dong, H.-L. Huang, J.-Y. Wang, H.-Y. Li and S.-Q. Zang, Chem. Mater., 2018, 30, 2160.

216 X.-Y. Dong, Y. Si, J.-S. Yang, C. Zhang, Z. Han, P. Luo, Z.-Y. Wang, S.-Q. Zang and T. C. Mak, Nat. Commun., 2020, 11, 1.

217 R.-W. Huang, Y.-S. Wei, X.-Y. Dong, X.-H. Wu, C.-X. Du, S.-Q. Zang and T. C. Mak, Nat. Chem., 2017, 9, 689.

218 M. Lu, L. Li, S. Shen, D. Chen and W. Han, New J. Chem., 2019, 43, 1032.

219 T. Zhang, B. Zou, M. Shao, X. Chen, S. Zhang, L. Li, Q. Du, H. Li, Y. Hu and J. Weng, Chem. - Eur. J., 2017, 23, 7663.

220 C. Liu, J. Wang, J. Wan and C. Yu, Coord. Chem. Rev., 2021, 432, 213743.

221 K. Ikigaki, K. Okada, Y. Tokudome, T. Toyao, P. Falcaro, C. J. Doonan and M. Takahashi, Angew. Chem., 2019, 131, 6960.

222 Z. Wang, J. Liu, B. Lukose, Z. Gu, P. G. Weidler, H. Gliemann, T. Heine and C. Wöll, Nano Lett., 2014, 14, 1526.

223 J. Liang, M. Y. Zulkifli, S. Choy, Y. Li, M. Gao, B. Kong, J. Yun and K. Liang, Environ. Sci. Technol., 2020, 54, 11356.

224 E. Virmani, J. M. Rotter, A. Mähringer, T. Von Zons, A. Godt, T. Bein, S. Wuttke and D. D. Medina, J. Am. Chem. Soc., 2018, 140, 4812.
225 K.-J. Kim, J. T. Culp, P. R. Ohodnicki, P. K. Thallapally and J. Tao, ACS Appl. Mater. Interfaces, 2021, 13, 35223.

226 C. Crivello, S. Sevim, O. Graniel, C. Franco, S. Pané, J. Puigmartí-Luis and D. Muñoz-Rojas, Mater. Horiz., 2021, 8, 168.

227 S. Han and C. B. Mullins, ChemSusChem, 2020, 13, 5433.

228 W. L. Teo, W. Zhou, C. Qian and Y. Zhao, Mater. Today, 2021, 47, 170.

229 M. J. Jellen, M. J. Ayodele, A. Cantu, M. D. Forbes and M. A. Garcia-Garibay, J. Am. Chem. Soc., 2020, 142, 18513.

230 J. M. Zadrozny, A. T. Gallagher, T. D. Harris and D. E. Freedman, J. Am. Chem. Soc., 2017, 139, 7089.

231 T. Yamabayashi, M. Atzori, L. Tesi, G. Cosquer, F. Santanni, M.-E. Boulon, E. Morra, S. Benci, R. Torre and M. Chiesa, J. Am. Chem. Soc., 2018, 140, 12090.

232 C.-J. Yu, M. D. Krzyaniak, M. S. Fataftah, M. R. Wasielewski and D. E. Freedman, Chem. Sci., 2019, 10, 1702.

233 R. A. Shugayev, S. E. Crawford, J. P. Baltrus, N. A. Diemler, J. E. Ellis, K.-J. Kim and P. C. Cvetic, Chem. Mater., 2021, 33, 6365.

234 C. L. Degen, F. Reinhard and P. Cappellaro, Rev. Mod. Phys., 2017, 89.

235 S. E. Crawford, R. A. Shugayev, H. P. Paudel, P. Lu, M. Syamlal, P. R. Ohodnicki, B. Chorpening, R. Gentry and Y. Duan, Adv. Quantum Technol., 2021, 4, 2100049.

236 X. Chong, K.-J. Kim, Y. Zhang, E. Li, P. R. Ohodnicki, C.-H. Chang and A. X. Wang, Nanotechnology, 2017, 28, 26LT01.

237 L. E. Kreno, J. T. Hupp and R. P. Van Duyne, Anal. Chem., 2010, 82, 8042.

238 K.-J. Kim, X. Chong, P. B. Kreider, G. Ma, P. R. Ohodnicki, J. P. Baltrus, A. X. Wang and C.-H. Chang, J. Mater. Chem. C, 2015, 3, 2763.

239 W. Vandezande, K. P. Janssen, F. Delport, R. Ameloot, D. E. De Vos, J. Lammertyn and M. B. Roeffaers, Anal. Chem., 2017, 89, 4480.

240 L. E. Kreno, N. G. Greeneltch, O. K. Farha, J. T. Hupp and R. P. Van Duyne, Analyst, 2014, 139, 4073.

241 P. Wang, Y. Sun, X. Li, L. Wang, Y. Xu and G. Li, Molecules, 2021, 26, 209.

242 C. Huang, A. Li, X. Chen and T. Wang, Small, 2020, 16, 2004802.

243 C. S. L. Koh, H. K. Lee, X. Han, H. Y. F. Sim and X. Y. Ling, Chem. Commun., 2018, 54, 2546.

244 D. Men, S. Feng, G. Liu, L. Hang and T. Zhang, Part. Part. Syst. Charact., 2020, 37, 1900452.

245 Y. Fu, M. Xin, J. Chong, R. Li and M. Huang, J. Mater. Sci., 2021, 56, 4151.

246 P. G. Saiz, R. F. de Luis, L. Bartolome, J. Gutiérrez, M. I. Arriortua and A. C. Lopes, J. Mater. Chem. C, 2020, 8, 13743.

247 Z. Zhang, H. T. Nguyen, S. A. Miller, A. M. Ploskonka, J. B. DeCoste and S. M. Cohen, J. Am. Chem. Soc., 2016, 138, 920.

248 T. H. Chen, I. Popov, O. Zenasni, O. Daugulis and O. S. Miljanic, Chem. Commun., 2013, 49, 6846. 
249 Y. Wang, Z. Hu, T. Kundu, Y. Cheng, J. Dong, Y. Qian, L. Zhai and D. Zhao, ACS Sustainable Chem. Eng., 2018, 6, 11904.

250 G. Lu, O. K. Farha, W. Zhang, F. Huo and J. T. Hupp, Adv. Mater., 2012, 24, 3970.

251 K. Okada, R. Ricco, Y. Tokudome, M. J. Styles, A. J. Hill, M. Takahashi and P. Falcaro, Adv. Funct. Mater., 2014, 24, 1969.

252 O. Dalstein, D. R. Ceratti, C. Boissière, D. Grosso, A. Cattoni and M. Faustini, Adv. Funct. Mater., 2016, 26, 81.
253 A. Razmjou, M. Asadnia, O. Ghaebi, H. C. Yang, M. Ebrahimi Warkiani, J. Hou and V. Chen, ACS Appl. Mater. Interfaces, 2017, 9, 38076.

254 M. Tu, B. Xia, D. E. Kravchenko, M. L. Tietze, A. J. Cruz, I. Stassen, T. Hauffman, J. Teyssandier, S. De Feyter, Z. Wang, R. A. Fischer, B. Marmiroli, H. Amenitsch, A. Torvisco, M. J. Velasquez-Hernandez, P. Falcaro and R. Ameloot, Nat. Mater., 2021, 20, 93. 